\title{
Experimental Field Test of Proposed Anti-Dart-Out Training Programs \\ Volume 2 \\ Implementation Guidelines and Program Materials
}

Richard L. Dueker

Sophie S. Berger

Applied Science Associates, Inc.

Box 158

Valencia, Pennsylvania 16059

Contract No. DOT HS-4-00955

Contract Amount $\$ 373,746$ 
This document is disseminated under the sponsorship of the Department of Transportation in the interest of information exchange. The United States Government assumes no liability for 1ts contents or use thereof. 
Technical Report Documentation Page

\begin{tabular}{|c|c|}
\hline $\begin{array}{l}\text { T. Roport No. } \\
\text { DOT HS } 806 \quad 196\end{array}$ & 3. Recipient's Catolog No. \\
\hline \multirow{2}{*}{$\begin{array}{l}\text { Tirle and Subrifle } \\
\text { Experimental Field Test of Proposed Anti-Dart- } \\
\text { Out Training Programs. Volume 2. Implementa- } \\
\text { tion Guidelines and Program Materials }\end{array}$} & $\begin{array}{l}\text { 5. Report Dote } \\
\text { December } 1981\end{array}$ \\
\hline & 6. Performing Organizotion Code \\
\hline $\begin{array}{l}\text { 7. Author's) } \\
\text { Dueker, R. L. \& Berger, S. S. }\end{array}$ & $\begin{array}{l}\text { 8. Porforming Orgonization Report No. } \\
\text { ASA } 484\end{array}$ \\
\hline \multirow{3}{*}{$\begin{array}{l}\text { 9. Performing Orogization Nomø and Addross } \\
\text { Applied Science Associates, Inc. } \\
\text { Box } 158 \\
\text { Valencla, Pennsylvania } 16059\end{array}$} & 10. Work Unit No. (TRAIS) \\
\hline & $\begin{array}{l}\text { 11. Contract or Grant No. } \\
\text { DOT-HS-4-00955 }\end{array}$ \\
\hline & \multirow{2}{*}{$\begin{array}{l}\text { 13. Type of Report and Poriod Covered } \\
\text { FINAL REPORT } \\
\text { June } 1974 \text { - December } 1980\end{array}$} \\
\hline $\begin{array}{l}\text { 12. Sponsoring Aoency Name and Address } \\
\text { Department of Transportation } \\
\text { National Highway Traffic Safety Administration }\end{array}$ & \\
\hline $\begin{array}{l}400 \text { Seventh Street, S.W. } \\
\text { Washington. DC } 20590\end{array}$ & 14. Sponsoring Agency Code \\
\hline
\end{tabular}

16. Abstrocthis report (Volume 2 of three volumes) provides detailed descriptions of all program materials employed with the recommended version of a child pedestrian safety program. Volume 1 of this report describes the conduct and results of the evaluation of two alternate child pedestrian anti-dart-out training programs and provides recommendations concerning the more effective program. The materials in Volume 2 have been revised in accordance with the recommendations for modification of this program and its materials provided in Volume 1.

This volume is designed to serve as a users guide for school systems implementing the program. It provides complete, organized information on every aspect of the program. Implementation guidelines are provided and issues of concern to users are discussed.. The full texts of the program guides which specify program content and conduct are provided. Copies of all other printed materials are included. Specifications for other program materials are provided and possible alternatives are discussed.

Several additional materials have been recommended for use in the program. These materials, training programs for the program coordinator and instructors and a script of an introductory videotape, are provided in Volume 3.

7. Koy Words Child, Pedestrian Safety

Training, Training Materials, Program Guldes, Pedestrian Safety Film, Training Curriculum

18. Distribution Stotement Available to the public through National Technical Information Service, Springfield, Virginia, 22151
19. Socurity Clessif. (of this nepert)
UNCLASS IFIED
20. Socurity Clessif. (of thi a peop)

UNCLASS IFIED

Form DOT F $1700.7(8-72)$

Reproduetion of completed poge authorizod 
METaIC CONVERSION FACTORS

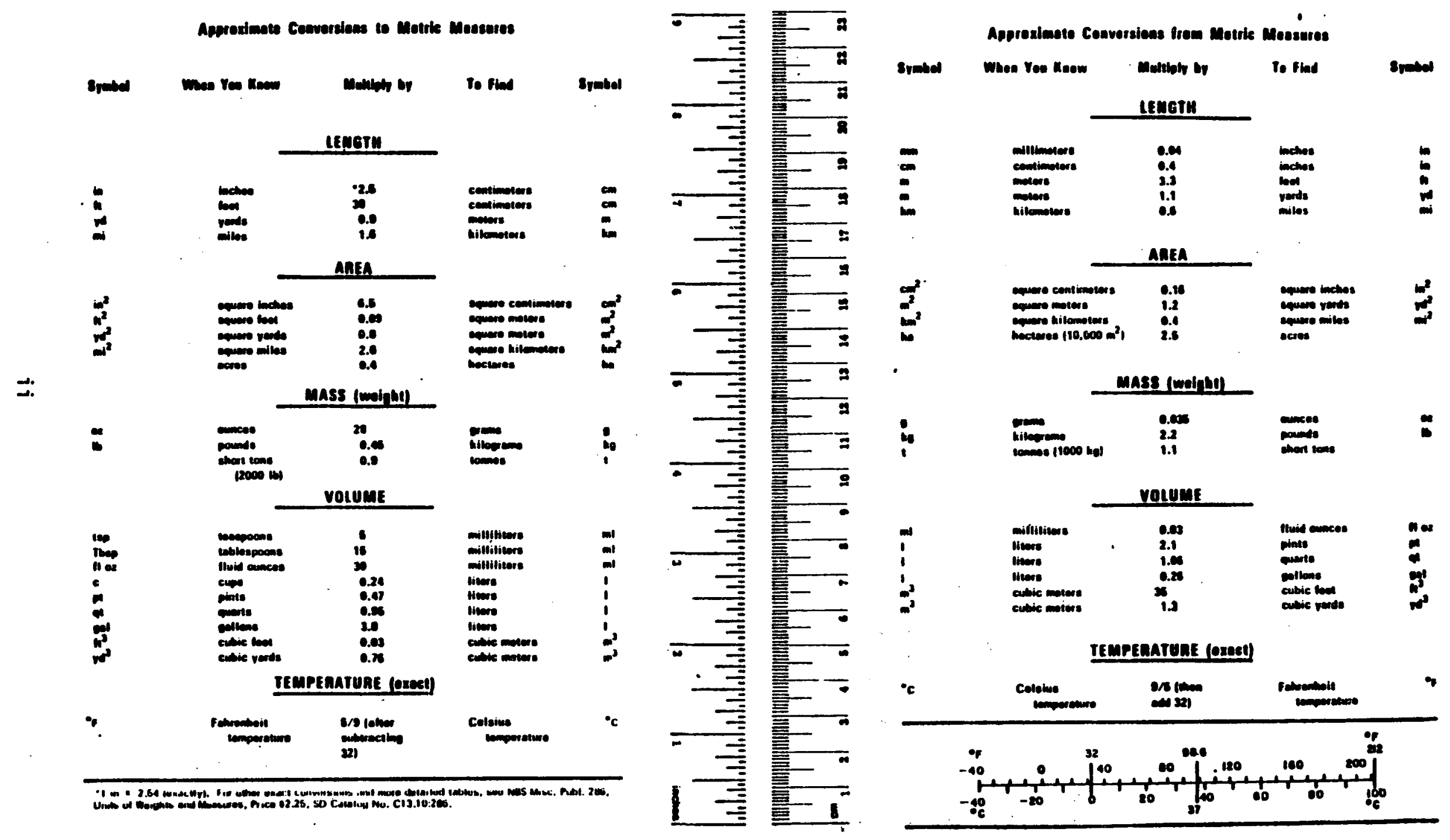


TABLE OF CONTENTS

Page

SECTION 1. INTRODUCTION ................ 1-1

Backg round ................ . . 1-1

Overview of the Anti-Dart-Out

Training Program .............. 1-2

Report Overview ............. 1-3

SECTION 2. THE PROGRAM COORDINATOR ............ 2-1

The Importance of the Coordinator . . . . . . 2-1

The Coordinator's Authority and Responsibilities . . 2-1

Selecting a Coordinator ......... 2-2

SECTION 3. PROGRAM ADMINISTRATION OPTIONS . . . . . . 3-1

Trained Specialist Option .......... 3-1

One-Instructor-Per-School option ....... 3-3

Classroom Teacher Option .......... 3-4

SECTION 4. GENERAL ISSUES .............. 4-1

Coordination With Other Traffic

Safety Messages ........... 4-1

Compliance With Jaywalking Ordinances ..... 4-2

Time and Space Requirements ........ 4-3

The Time Required to Administer the Program ... 4-3

The Space Required to Adminster the Program . . 4-3

Total School System Participation ....... 4-4

APPENDIX A. COORDINATOR'S GUIDE . . . . . . . . . . A-1

APPENDIX B. PRINCIPAL'S GUIDE . . . . . . . . . . B B-1

APPENDIX C. INSTRUCTOR'S GUIDE ..............

APPENDIX D. OTHER PRINTED MATERIAL . . . . . . . . . D D-1

Overview ............... $\mathrm{D}-2$

Parent's Pamphlet ............. D-3

Safety Certificates ........... D-5

Progress Charts ............. D-6

Reward Tokens .............. D $\mathrm{D}-7$ 


\section{TABLE OF CONTENTS (Cont'd)}

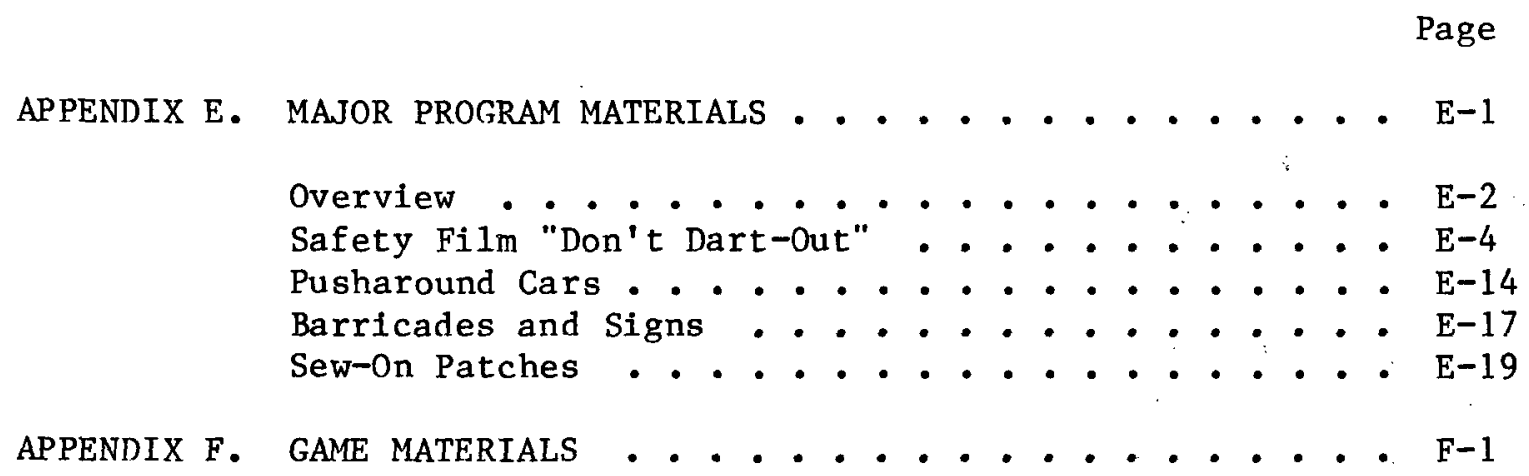


SECTION 1

INTRODUCTION

This report documents a project to field test and evaluate the Safe Street Crossing Training Program, a child pedestrian safety program designed to prevent dart-out type accidents among children in grades $\mathrm{K}-3$. The project was performed under contract to the National Highway Traffic Safety Administration (NHTSA) within the U.S. Department of Transportation.

Volume 1 of this report describes the conduct of the project and provides the results and conclusions from program testing. It also provides recommendations concerning the effectiveness of two program alternates and recommendations for modification of the recommended alternate and its materials.

This volume, Volume 2, provides detailed descriptions of all training materials employed with the recommended program, including the texts of all program guides, and is designed to present complete program implementation guidelines. The materials, as presented in this volume, have been modified in accordance with the recommendations resulting from the field testing.

Volume 3 of this report provides short courses for training the program coordinators and instructors. Lesson plans are provided, as are originals from which transparencies can be produced. The volume also contains a script for a recommended videotape which introduces the Safe Street Crossing Training Program and provides an overview of its major features.

\section{Background}

Over one-half of all child pedestrian accidents are attributed to dart-out accidents. A dart-out occurs when the child enters the street at midblock, of ten from between parked cars. Often, he fails to search for or detect approaching traffic. In the past, parents and school programs have attempted to correct the child's behavior by impressing upon him that he should never enter the street midblock. However, it is becoming widely recognized that; in spite of intense negative feedback, children will enter the street while playing (i.e., to retrieve a ball, or run to a friend). This NHTSA-sponsored program uses a different approach to changing the children's behavior. Instead of merely telling the children what not to do, the program teaches the children how to cross the street safely under all conditions through practice of the correct street-crossing procedures during play activities. 
Materials were developed for two Anti-Dart-Out Training Programs that differed on only one major point. One program used pusharound car mock-ups pushed by the children to represent traffic; the other employed a large scale traffic-flow simulator with two rear projection screens. The programs were field tested in two different cities. Data on behavioral observations, teacher and student reactions, deviations in the conduct of the program, and accident rates were collected and analyzed. Presentation of the data and their method of collection are included in volume 1 of this report. The end result of the field test effort was a set of recommendations for modifications to the program. The "pusharound car" version of the program was recommended as most effective and that program's materials were revised for inclusion in this volume.

Volume 2 serves two purposes. One is to detail all program modifications and additions. The other is to serve as a user's manual for school systems preparing to implement the program. Consequently, every effort has been made to supply complete information to facilitate use of the program.

Overview of the Anti-Dart-Out

Training Program

The main objective of this program is to teach children a simple procedure that, when learned, will prevent them from darting out into the street in front of an automobile. This procedure involves stopping at the curb, or at the boundary of parked cars, and searching left, right, then left again. If a car is detected, the child must wait until it passes, then re-initiate the left-right-left searches. The children learn to do this through guided practice in the classroom and safety games. These games provide opportunities for children to practice safety behavior in situations much like those they actually encounter when playing near the street. The games are played both in the classroom with simulated street surroundings, and on a "real-world" street where traffic is carefully controlled. The children are rewarded when they enter the street correctly to be sure that the correct behaviors is reinforced: As a reward for learning good safety habits, the children earn safety patches and receive signed certificates attesting to their achievement.

The first year of the program consists of nine 45-minute initial training sessions, in which all children in grades $\mathrm{K}-3$ are taught the safe street-crossing behavior sequence. The children view the safety film, "Don't Dart-Out," and practice the safe street-crossing sequence while playing three types of games. These games provide opportunities for the children to be involved in play situations that would cause them to enter the street. The "Ba1l-Toss Game" duplicates the situation in which a child enters the street to retrieve a ball. The "Chip Game" represents those occasions when a child is called across the street. The "Follow-the-Leader Game" involves the child in a pursuit situation. These games are played indoors, utilizing pusharound cars "driven" by the children as threatening vehicles, and outdoors on barricaded streets. The instructor reinforces each correct crossing with a safety token and verbal praise. When a child 
starts to cross incorrectly, he/she must repeat the performance until it is correct. At the end of the initial training, the children receive their safety badges and certificates.

The initial training is supplemented in the first year by follow-on. activities to keep the children familiar with the behavior sequence. The follow-on activities may take the form of additional practice, practice games, or any activity where the children are given a chance to practice the safety sequence. Kindergarten and first-grade children should have follow-on sessions every two weeks, older children at least once a month.

In all subsequent years, only Kindergarten children receive initial training. Refresher training sessions are given to the first-, second-, and third-grades at the start of the school year. There are three 45-minute refresher training sessions. The children view the safety film, "Don't Dart-Out," play the "Ball-Toss Game" indoors, and play the "Followthe-Leader Game" outside. The objective of these sessions is to reestablish, after the summer vacation, the habit of performing the safety sequence.

Follow-on sessions are again conducted monthly or bi-weekly throughout the school year following refresher training to provide continuous practice and reinforcement for the children.

The complete description of all program content and conduct is provided in Appendix C, Instructor's Guide.

\section{Report Overview}

In addition to providing documentation of program modifications and additions, this volume is designed to serve as a user's guide for school systems implementing the program. As such, it must provide complete, organized information on every aspect of the program.

Sections 2 and 3 discuss considerations in planning to implement the program. Choice of coordinator and program organization option must be made before initiating the program. In addition, certain general issues that may cause concern must be considered prior to program implementation. These issues are addressed in Section 3.

The full texts of the program guides--Coordinator's Guide, Principal's Guide, and Instructor's Guide--are provided in Appendices A, B, and C. These guides may be reproduced in their entirety to provide independent program instructional material. Therefore, the pagination is consistent within each guide rather than conforming to the report pagination. Cameraready copies of all other printed materials are provided in Appendix $D$.

Appendix E provides specifications and/or diagrams for the major program materials which were developed for the training program. In the future, these materials may be available through NHTSA but, if a school system wishes to perform the program on its own, it may use these 
specifications and/or the suggestions for substitutes provided in this appendix. The complete script of the children's safety film, "Don't DartOut," is included in this section.

Certain game materials (e.g., wastebaskets, masking tape, and balls) are required for the program but are locally available to any school system. These materials are specified in Appendix F. 
The program coordinator is the single most important factor in the success or failure of the program. His/her roles as organizer, supervisor, trouble-shooter, and spokesman for the program are integral to the smooth functioning of the program as a whole. In the final anaiysis, he/she will be responsible for making the program work. A good coordinator can make the difference between a successful program with wide acceptance and enthusiastic school support and an inefficiently administered unpopular program. Research has shown that when there is no strong coordinator, program effectiveness is greatly reduced. As with any school system-wide program involving a number of people, careful scheduling, and numerous materials, this program requires an identifiable authority to administer and coordinate it. Without central coordination, motivation and efficiency of teachers and principals in regard to the program may be reduced and program activities neglected. Also, it has been demonstrated that the presence of a strong coordinator, providing supervision and guidance, greatly enhances the degree of acceptance of the program.

\section{The Coordinator's Authority}

and Responsibilities

The coordinator's functions include:

1. Arranging for scheduling the conduct of the program in the individual schools.

2. Briefing the principals concerning the program, their roles in the conduct of the program, and the roles of their teachers.

3. Training the instructors who will administer the program.

4. Obtaining and distributing program materials.

5. Supervising instructors and spot checking the conduct of program activities in individual schools.

6. Acting as liaison between the community (e.g., parents, parent groups, the media, police, public safety organizations) and the school system in matters concerning the program. 
7. Providing instructors with ideas for new follow-on activities and acting as a focal point for the exchange of ideas among instructors.

The coordinator must be prepared to deal with the day-to-day demands of program administration. Maintaining and replacing equipment, responding to principal and parent questions, establishing a continuous flow of information about the program, and encouraging program involvement are ongoing activities. The coordinator must be continually available to handle these activities although, depending upon the program administration option, program coordination may not be a full-time job. 1

The Coordinator's Guide (Appendix A) provides complete detailed information on a11 coordinator's responsibilities.

\section{Selecting a Coordinator}

The coordinator should have the following characteristics:

1. Skill in dealing with the public and the media.

2. The ability to gain cooperation and work effectively with teachers and principals.

3. An interest in safety--a safety background is not necessary but the coordinator must have a commitment to the value of pedestrian safety programs in schools.

4. Experience in administration and supervision.

5. Experience in teaching and/or training.

6. Flexibility and adaptability.

7. Organizational skills.

8. The capacity to accept responsibility and act on his/her own Initiative.

$\bar{l}$ Program administration options are described in the next section. 


\section{SECTION 3}

\section{PROGRAM ADMINISTRATION OPTIONS}

There are three possible options for actual program administration:

1. Training by specialists.

2. Training by one instructor in each school.

3. Training by individual classroom teachers.

To avoid confusion, the program guides (Appendices $A, B$, and $C$ ) and all other program literature refer to the person administering the program as the "instructor" with the understanding that the instructor may: be either a teacher or specialist.

\section{Trained Specialist Option}

Conducting the training using program specialists is the best option and, if at all possible, should be selected. Specialists would be assigned to conduct only program activities and would be experts in program administration. They would be completely familiar with program conduct and program materials. Program administration would be the specialists only job, and they could devote full time to it, at least for part of the year. They would not be presented with the problems of scheduling conflicts, other demands on their time, or inadequate opportunities for preparation that of ten affect the classroom teacher. They would be thoroughly trained by the coordinator who would directly supervise their activities. This option permits greatest control of the program administration and ensures that all children are trained in the same competent, well-supervised manner.

The coordinator can give this small group of instructors a more intensive training program than is possible with the other options. Complete familiarity with the program, as well as the lack of competing demands, allows the specialists to feel comfortable with the program and to develop expertise in reinforcing and motivating the children. They would also be more competent to deal with minor equipment problems and would know how to quickly obtain assistance if needed. The coordinator is better able to closely supervise this small group and to observe each specialist at the beginning of the program. The coordinator could be in constant communication with the specialists and exercise direct control over the progress of the program. 
There are a number of professional and non-professional sources from which specialists may be drawn. The amount of funding available for program implementation will be an important consideration as to which sources are tapped. These sources include:

1. The administrative or central school system staff.

2. PTA members who would volunteer for the positions.

3. Aides already employed by the school system.

4. Student teachers recruited through a local college or university.

5. Substitute teachers.

6. Honors high school students as a project for extra credit, or as a volunteer project.

Whatever the source, specialists should be selected who are reliable, capable, personable, and can deal authoritatively and tactfully with both children and teachers.

For this option, the individual classroom teachers would serve as assistants to the specialists and would be trained to conduct follow-on activities. The specialists would be responsible for both initial and refresher training.

The number of specialists required depends upon the number of schools in the system and the number of $\mathrm{K}-3$ classes in each school. Each specialist would conduct training at a number of schools. The local climate is also an important consideration. In warm climates where initial training can be conducted throughout the year, a single specialist could conduct initial training in 10-15 schools, depending upon their size. Thus, a school system with 50 elementary schools would require $4-5$ specialists the first year. For subsequent years of the program, specialists would be required only for initial training of the Kindergarten and transfer students, and to conduct refresher training. Because refresher training should be conducted near the beginning of the school year, the same number of specialists will be required, but only for those initial months.

Unfortunately, not all of the country has beautiful weather all year round. In an area where there are seasonal changes, around the middle or end of November it will probably be too cold for the children to be outside. In this case, all program sessions should end before this date or begin in the spring. Therefore, more specialists would be required for a shorter period. Assuming that sessions can be scheduled for six months of the school year, seven or eight specialists would be required for initial training in a school system of 50 schools. These specialists would not work during the three month cold weather period and, consequently, some replacement specialists may have to be trained for the spring sessions.

It is possible to reduce the number of specialists required for the first year of training by initiating the program in one-half or one-third 
of the schools each year. In this case, the schools with the greatest accident frequency (e.g., areas of high traffic density) should receive training first. This is a less preferred approach because it delays realization of the full accident reduction impact of the program.

A detailed procedure for computing the minimum number of specialists required by each unique school system is provided in the Coordinator's Guide (Appendix A).

\section{One-Instructor-Per-School Option}

Option 2 involves one instructor from each school, selected by the principal and trained by the coordinator, who is responsible for initial and refresher training in his/her school (the individual classroom teachers conduct the follow-on activities). For the instructors, the principals may choose:

1. A classroom teacher.

2. A physical education teacher or some other special program teacher.

3. An experienced aide assigned to the school.

4. Volunteer personnel recruited by the school.

In the event that a classroom teacher is employed for a given school, the teacher's regular assignments must be adjusted to permit him/her to devote the required time to program activities. One problem with this option is that the principal may not be able to reapportion the teacher's regular duties to permit him/her to devote full time to the program for three to five weeks as is required for initial training. Other demands may intrude upon the teacher's time and program administration will suffer.

One possible solution to this problem would be to have these instructors administer initial training to only two or three classes at a time. The instructors would thus be involved in program activities for only an hour or two per day. With this approach, a school with $10 \mathrm{~K}-3$ classes would require approximately 15 weeks to complete initial training.

Under this option, the coordinator will be required to train and supervise a far larger number of instructors than in Option 1. It will not be possible for the coordinator to provide the same depth of preparation or the same level of guidance and support to the instructors as in Option 1. Therefore, the quality of the training given the children may be reduced and the program may be less effective.

With this option, the classroom teachers would again serve as assistants for the initial and refresher training and be responsible only for follow-on sessions. 


\section{Classroom Teacher Option}

In the classroom teacher option, each $\mathrm{K}-3$ teacher administers all program activities--initial training and refresher training as well as follow-on sessions--to his/her own class.

Although an effective program can be established using the classroom teacher option, it is somewhat more difficult to implement successfully and may take somewhat longer to accomplish than with the other options. For these reasons, it is the least preferred option. With the many demands on their time, classroom teachers may not be able to devote the required level of effort to the program. They will not have the opportunity to develop. much familiarity with the program or to become involved in it as quickly as would the specialists. With so many persons administering the program, it will be more difficult for the coordinator to provide each one with adequate guidance and support. For example, assuming all the schools administer initial training at the same time, it likely will be impossible for the coordinator to observe each teacher conducting the sessions. Consequently, errors in program administration will not be noted and corrected. Further, the teachers will have to be trained in a large group. Such an approach permits less intensive training than is possible for Options 1 and 2 , and more highly variable teacher performance can be expected.

In this option, there are no assistants built into the program. Each classroom teacher will require assistants, however, to help in the conduct of some sessions. Some schools may have aides available. Where aides are not available, the principals may obtain assistants from various sources, including:

1. Parent or community volunteers.

2. Responsible high school students.

3. Other school personnel. 
SECTION 4

GENERAL ISSUES

There are a number of issues that should be addressed prior to program implementation. These issues may cause concern both within and outside the school system and should be considered early in program planning.

\section{Coordination with Other Traffic}

Safety Messages

A major concern of many teachers and parents is the concept of teaching children to enter the street midblock. This program is in no way designed to counteract the important "cross-at-the-corner" and "cross-atthe-1ight" lessons that children typically learn in school. The Safe Street-Crossing Program is intended to be a part of a larger child safety curriculum that teaches these lessons. The instructors should emphasize to their classes that crossing at the intersection is still important. However, the goal of this program is to make sure that if a child enters the street for any reason, he does so safely. This program is aimed at those times when the child is casually playing and carelessly runs into the street to retrieve a ball or greet a friend.

Although training in proper intersection behavior is extremely important, it is becoming widely recognized that children will enter the street midblock, and it is best to teach them to do so safely. Over onehalf of all child pedestrian accidents are dart-out types. Dart-out type accidents cannot be prevented by unrealistic expectations that children will remember to cross at the corner even in the midst of playing. Dartouts can only be stopped by teaching children appropriate behavior for their inevitable midblock crossings. This program emphasizes crossing safely under all conditions especially at those times when it is, extremely impractical and unlikely that the child would go to the intersection to cross.

The children should receive a balanced safety program that teaches all aspects of traffic safety. The integration of this program into the existing safety curriculum is a necessary part of program implementation. The various safety programs must be prevented from interfering with each other while remaining maximally effective. The place of this program in relation to ongoing safety programs should be considered during early program planning. 
Occasionally, the concern will be raised that the program teaches children to jaywalk. This is seldom the case. Although the ordinances differ in each locality, in most cases, jaywalking ordinances are usually associated with busy commercial areas and prohibit crossing except under specialized conditions. These rules do not usually apply to the residential areas with which this program is concerned. This program addresses the type of accidents that occur when a child is playing by a residential street near his/her home.

The Uniform Vehicle Code $^{2}$ specifies that crossing outside a crosswalk is prohibited only between adjacent signalized intersections. Thirtyfour states and a number of municipalities have laws which conform substantially with this regulation. Another federal ordinance authorizes the state highway commissions and local authorities to prohibit pedestrians from crossing outside a crosswalk in a business district. Twenty-seven states and 20 municipalities conform to this ordinance. These rules obviously are directed at areas of high traffic volume-not quiet residential streets.

The Code also empowers local authorities to prohibit crossing outside a crosswalk on any designated highways. Again, iost municipalities limit their regulations to through streets, specifically named streets, or areas within a limited distance from a crosswalk. For example, some of the municipal ordinances are as follows:

- St. Louis and Portland prohibit crossing outside a crosswalk within 150 feet.

- Toledo prohibits crossing the roadway at any point within 300 feet of a crosswalk.

- Seattle prohibits crossing outside a crosswalk on any "arterial street."

- Tulsa specifies that in residential neighborhoods, on quiet streets, a pedestrian crossing at other than a crosswalk shall take the shortest possible route to the opposite side of the street and at a right angle to the side of the street.

Some municipalities do forbid crossing outside a crosswalk in any location. Although some cities have strict jaywalking laws, they usually are not enforced, except in busy downtown areas or selected problem

Much of the information in this subsection derives from: Pedestrian laws in the United States, Traffic Laws Commentary, 3, 3, October 1974. U.S. Department of Transportation, National Highway Traffic Safety Administration. 
districts (i.e., near a college campus). Law enforcement officials usually take the position that these strict laws are needed and enforceable only in busy, heavy traffic areas.

Familiarity with the municipal jaywalking ordinances and their enforcement is necessary before initiation of the program. Law enforcement officials should be included in early program planning discussions to clarify their positions on the issues.

\section{Time and Space Requirements}

Time and space requirements for the program should be considered when planning for program implementation.

The Time Required to

Administer the Program

Most schools require 3-5 weeks to perform the initial training. In the first year of the program, each $\mathrm{K}-3$ class participates in eight or nine 45-minute initial training sessions and monthly or biweekly follow-on sessions of not less than 45 minutes. In subsequent years, all Kindergarten classes participate in initial training while grades first through third attend three 45-minute refresher training sessions. All classes continue to participate in follow-on activities.

The time requirements of this program are not excessive and are necessary to ensure complete learning and retention. Mere exposure to safe street-crossing concepts is not enough. Typical child pedestrian safety programs are very brief, usually two to four hours per year. Such programs provide only a basic familiarity with the ideas behind safe street crossing. Although such theory is valuable, young children need practice and reinforcement to develop actual street crossing skills to apply to real life situations.

The time requirements of the program may be lessened by combining program activities with recess, physical education classes, and other school activities. Also, the continuing nature of the program must be emphasized. After the first year of the program, the time demands of the program are much reduced. For first- through third-graders, the intensive eight or nine session initial training is replaced by the three-session refresher training.

The Space Required to Administer the Program

A fairly large area, such as a gymnasium, auditorium, or lunchroom, is required for administration of the indoor sessions of the program as classrooms do not provide enough area to practice with the pusharound cars or play the games properly. Most schools do have a large area of this type 
that can easily be adapted for the program, and quickly returned to ordinary use. The pusharound cars are easily moved and stored (they are stackable), and the game equipment will fit in a small cupboard.

Obviously, a gymnasium would be the best alternative where it is possible to combine program activities with physical education periods. An auditorium or lunchroom with moveable chairs and/or tables could also be used, although time would be required to restore the furniture to its usual position. If the architecture of the school provides a large central hall, that might be an ideal place to conduct the program (scheduling around times of heavy traffic flow). Another alternative, during warm weather, would be to use the schoolyard or playground for the "indoor": sessions. However, it must not provide access to the street such that the children could enter the street during the play activity.

The available facilities of the schools must be considered when planning for program implementation.

\section{Total School System Participation}

Every effort should be made to assure that all elementary schools in the school system conduct the training. To the extent that schools elect not to conduct the training, the effect of the program on accident rates will be reduced. Obviously, with any new program, additional effort is required of school personnel to implement the program and get it running smoothly. For this reason, there is always some initial resistance which tends to disappear as the program becomes accepted.

of special concern are schools in low-income neighborhoods. Principals of schools in low-income areas, perhaps with older facilities and/or insufficient staffing, may be especially concerned about the demands of this program. Research has shown that these are precisely the schools that have the greatest need for the program. These schools are usually located in the areas of heavy traffic density and highest pedestrian accident rates.

Schools in these areas may need extra incentives and assistance. For example, to ensure that the program is properly conducted in these schools, it may be possible to have specialists conduct the program only in these schools, even though the other schools use a teacher option. If some facilities cannot meet the space requirements of the program, one solution is to conduct the indoor sessions (except for showing the $\mathrm{film}$ ) in the schoolyard. If the program is to be implemented in stages, these schools should receive it first. In general, these schools should receive all the extra attention and assistance they require, because it is in the high traffic density where the program stands to have the greatest impact on child pedestrian accidents. 
APPENDIX A

COORDINATOR'S GUIDE

A-1 


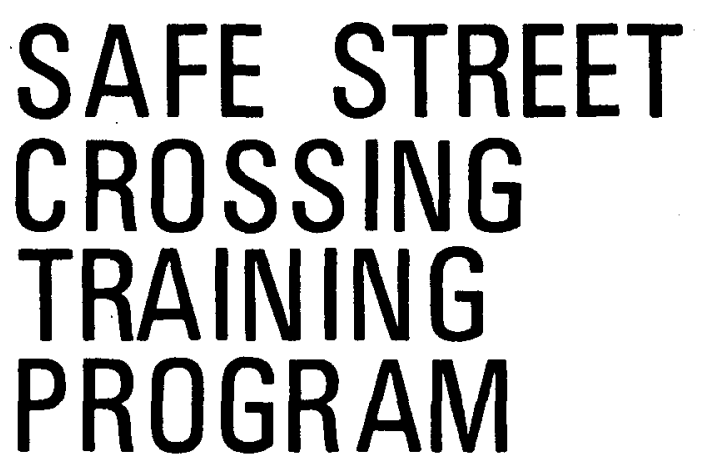

\section{COORDINATOR'S GUIDE}

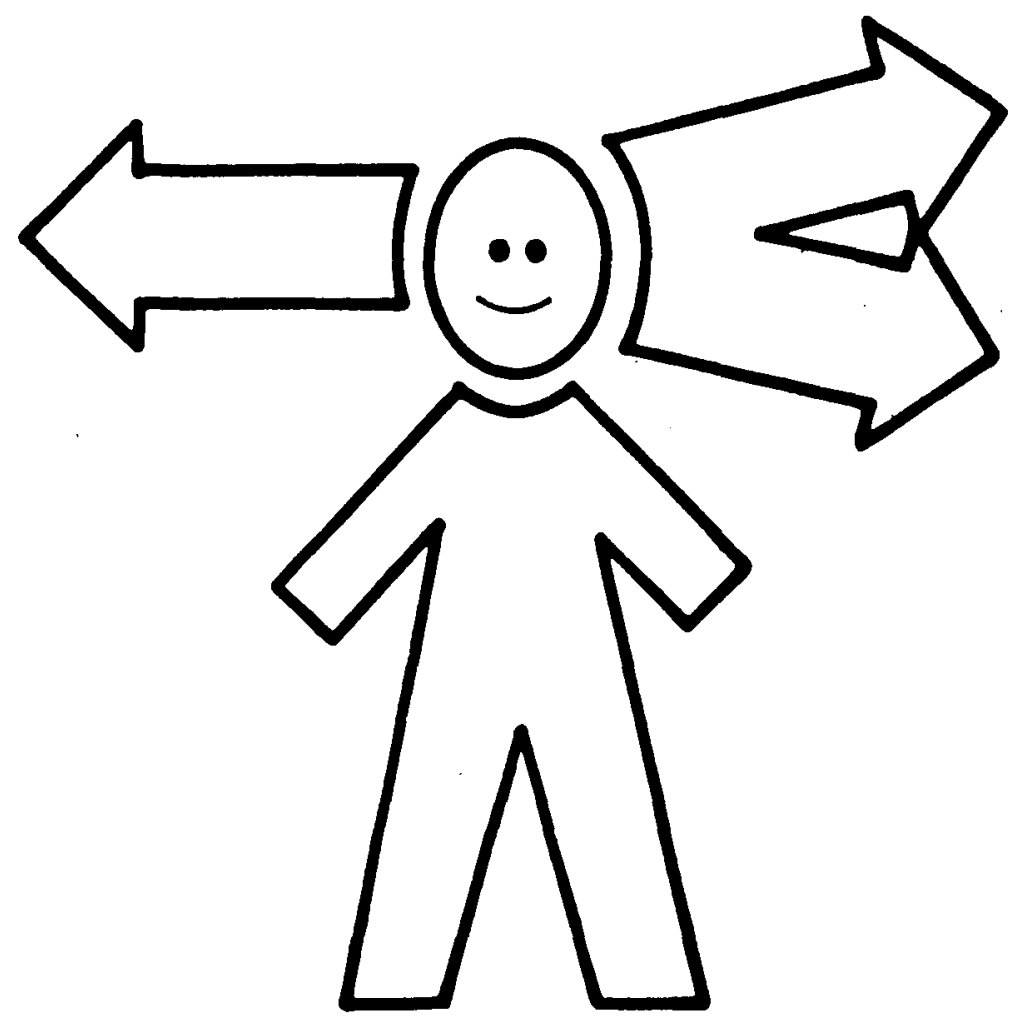

U. S. DEPARTMENT OF TRANSPORTATION

Contract No. DOT-HS-4-00955 
TABLE OF CONTENTS

Page

INTRODUCTION . . . . . . . . . . . . . . . . . 1

Why the Program Was Developed ............... 2

Program objective..................... 2

Summary of the Program ................. 4

Initia1 Training . . . . . . . . . . . . . . . 4

Follow-on Sessions.............. 6

Refresher Training .................. 7

OTHER SAFETY PROGRAMS ................. 8

OPTIONS FOR PROGRAM ADMINISTRATION . . . . . . . . . . . 9

Training by Specialists................. 9

Training by One Teacher in Each School ... . . . . . . 10

Training by Individual Classroom Teachers . . . . . . . . 10

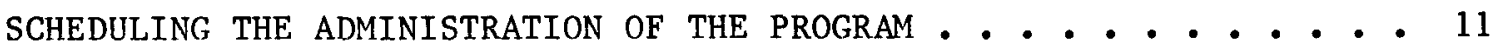

Option One: Training by Specialists .......... 11

Option Two: Training by One Teacher in Each School . . . . 13

Option Three: Training by Individual Classroom Teachers . . 13

PREPARING THE SCHOOL SYSTEM FOR THE PROGRAM . . . . . . . . . 14

Principals . . . . . . . . . . . . . . 14

Teachers .................. 15

TRAINING AND SUPERVISION OF PROGRAM INSTRUCTORS

FOR INITIAL TRAINING . . . . . . . . . . . 17

Training Program Instructors . . . . . . . . . . 17

Supervision of Program Instructors . . . . . . . . . . 18

Option One: Training by Specialists .......... 18

Option Two: Training by One Teacher in Each School . . 19

Option Three: Training by Individual Classroom Teachers . . 19

SUPERVISION OF PROGRAM INSTRUCTORS AFTER INITIAL TRAINING • • • • 20

Follow-on Activities . . . . . . . . . . . . . 20

Subsequent Years of the Program . . . . . . . . . . 21 
TABLE OF CONTENTS (Continued)

Page

OBTAINING AND DISTRIBUTING PROGRAM MATERIALS . . . . . . . 22

Class Materials . . . . . . . . . . . . . 22

School Materials .. . . . . . . . . . . . . 22

Replacement Materials ................. 23

MAKING ARRANGEMENTS FOR OUTDOOR SESSIONS . . . . . . . . . 24

Obtaining Permission to Block Streets ... . . . . . . 24

Arranging for Crossing Guards . . . . . . . . . . 24

PROGRAM ISSUES AND QUESTIONS . . . . . . . . . . . . . . 26

This Program Versus Traditional Child

Pedestrian Safety Messages . . . . . . . . . . 27

Does This Program Encourage Jaywalking? . . . . . . . . 27

The Time Required to Administer the Program . . . . . . . 27

The Space Required to Administer the Program . . . . . . 28 


\section{INTRODUCTION}

The purpose of this document is to provide guidance for the administration of the Safe Street-Crossing Program for child pedestrian safety. The program is designed to be administered to Kindergarten through thirdgrade children in each elementary school in the school system. The details of setting up and operating the program are performed by the program coordinator.

The program coordinator has the primary responsiblity for making this program work in the school system. To be successful, the program requires efficient coordination and careful administration. The coordinator will deal with teachers, principals, school executives, parents, municipal authorities, and the general public. He/she will be the authority to whom they look for guidance and explanation. For these reasons, the coordinator must become thoroughly familiar with the program and how it functions.

More specifically, the coordinator's functions include:

1. Arranging for scheduling the conduct of the program in the individual schools.

2. Briefing the principals concerning the program, their roles in the conduct of the program, and the roles of their teachers.

3. Training the instructors who will administer the program.

4. Obtaining and distributing program materials.

5. Supervising instructors and spot checking the conduct of program activities in individual schools.

6. Acting as liaison between the community (e.g., parents, parent groups, the media, police, public safety organizations) and the school system in matters concerning the program.

7. Providing instructors with ideas for new follow-on activities and acting as a focal point for the exchange of ideas among instructors.

This volume, together with the Principal's Guide and the Instructor's Guide, provides complete information on program instruction and administration. The coordinator should be thoroughly familiar with all three documents. 
Why the Program Was Developed

Statistics show that each year there are approximately 400,000 pedestrian accidents, many of them involving children. Every year, 3,000 children are killed in pedestrian accidents. While some of these accidents are undoubtedly the fault of the driver, or due to some mechanical failure in the automobile, far too many of the accidents occur because the children are unaware of the correct procedure for safely crossing the street.

Over one-half of all child pedestrian accidents are attributed to dart-out type accidents. A dart-out occurs when the child enters the street at midblock, often from between parked cars. He may be chasing a ba11, running to an ice cream vendor, or responding to a friend's or parent's call. Often, when he enters the street, he fails to search and wait for approaching traffic, and this can result in an accident.

In the past, parents and school programs have either neglected to teach safety procedures, or have attempted to correct the child's behavior by scolding or punishing the unsafe behavior. They also have tried to warn children of the potential dangers of running into the street. These methods simply do not work, largely because the children are just too young to comprehend fully the danger associated with the situation.

The Safe Street-Crossing Program uses an entirely different approach. Instead of merely telling the children what not to do, this program provides learning experiences in which the child actually practices the correct procedures to cross the street safely.

The main objective of this program is to teach children a simple procedure that, when learned, will prevent them from darting out into the street in front of an automobile. This procedure involves stopping at the curb, or at the boundary of parked cars, and searching left, right, then left again. If a car is detected, the child must wait until it passes, then re-initiate the left-right-left searches. The children learn to do this through guided practice in the classroom and safety games. These games are played both in the classroom with simulated street surroundings, and on a "real-world" street where traffic is carefully controlled. The children are rewarded when they enter the street correctly to be sure that the correct behavior is reenforced. As a reward for learning good safety habits, the children earn a safety patch and receive a signed certificate attesting to their achievement.

\section{Program Objective}

The main objective of the Safe Street-Crossing Program is to teach children a simple set of procedures that, when learned, will prevent them 
from darting out into the street in front of an automobile. A detailed description of the safe street-crossing sequence follows:

1. a. Stop at the edge of the curb, or road if there are no parked vehicles,

or

b. If parked vehicles are present, stop at the boundary between the parking lane and traffic--beyond the parked vehicles, but still close enough to touch them.

2. Turn head and eyes to the left so that the visual field includes all of the left traffic lane, and look for left-approaching traffic.

3. Turn head and eyes to the right so that the visual field includes all of the right traffic lane, and look for right-approaching traffic.

4. Turn head and eyes to the left again, so that the visual field includes all of the left traffic lane, and check to be sure that the street is still clear.

5. a. Enter the street (if no cars are detected),

or

b. If a car is detected, wait for the car and track it until it has passed. Repeat the left-right-left searches before entering the street. (Perform this step as many times as necessary until the street is clear.)

All five of these steps and only these five steps constitute the correct sequence. When visiting the classes, you should check that the teachers are rewarding the children for performing these steps correctly and in sequence. The children should NOT be rewarded for any of the following:

1. Performing only PART of the sequence (e.g., looking only left-right and failing to look left again).

2. Performing a step or steps incorrectly (e.g., not stopping).

3. Performing extra steps (e.g., looking $L-R-L-R-L)$.

4. Performing a step out of sequence (e.g., starting to search before stopping). 
Unless the teacher is consistent in determining what the correct safety procedures are (and rewards only the five properly-performed steps in the proper sequence), the children will become confused and the effectiveness of the program will suffer.

\section{Summary of the Program}

The basic program consists of nine Initial Training sessions in which the children are taught the safe street-crossing behavior sequence. At the end of the initial training, the children receive their safety badges and certificates. The initial training is supplemented in the first year by follow-on activities. In subsequent years, refresher training sessions are given to keep the children familiar with the behavior sequence, and followon sessions are again conducted.

The following is a brief description of the major activities of the Safe Street-Crossing Training Program.

\section{Initial Training}

The Safe Street-Crossing Program is administered in nine sessions. Each session is to be no longer than 45 minutes. Additional time is needed for a "preprogram activities" session and an "awards" session where the children receive their badges and safety certificates. A brief description of the activities and objectives for each initial training session follows.

Preprogram Activities. The instructor will have a safety discussion with the class to sensitize the children to the fact that pedestrian accidents have happened to people they know and could happen to them. The instructor will integrate this program into your school's existing safety curriculum. You should provide guidance concerning what material to cover in order to accomplish this.

The instructor will explain and demonstrate the safe street-crossing behavior sequence (as defined in the Program objective section of this guide).

Session 1. The children view the correct behavior sequence in the street safety film "Don't Dart-Out." They are then given a chance to practice that sequence in a "no-threat" situation. This means that the children will be allowed to rehearse their behavior without fear of punishment or loss of reward. The children practice using a "street" laid out on the floor of their classroom (or area of the school designated for this program).

Session 2. The Kindergarten and first-grade children view the safety film a second time. All children practice the behavior sequence on the simulated "street." The children will receive yellow safety tokens as a reward for correct performance. Pusharound model cars will be introduced 
as parked cars and as "threatening" vehicles. The children must walk to the edge of the parked cars to perform the sequence and cross only when no cars are coming to receive a token.

The objective of this session is to give the children additional opportunities to practice the behavior sequence in a situation where they will be rewarded.

Session 3. This session is the first of the practice game sessions. The children will play the "Ball-Toss Game" in the classroom. The object of the game is to toss a ball into a basket. When the child misses the basket, the ball will usually roll into the "street," and the child must correctly perform the behavior sequence before retrieving the ball. Some of the children will maneuver the pusharound cars up and down the "street" while the other children practice crossing. The children will receive tokens for each correct performance of the safety sequence. A simpler version of this game is provided for the younger children.

The objective of this session is to provide opportunities for the children to practice the safety sequence while entering the street to retrieve a ball during a game.

Session 4. The children play another practice game, the "Chip Game," in class. The children are divided into teams. Team members are required to cross a "street" and perform the safety sequence to obtain a chip from the instructor, and then must return to the starting circle. Those who fail to perform the sequence correctly are sent back to the starting circle and do not receive a chip or safety token until they have performed correctly. One model car will serve as a parked car. The team members must step to the street-side edge of the parked car before performing the behavior sequence. The other two cars will be "driven" up and down the street as before. A simpler version of this game is provided for the younger children.

The objective of this session is to provide opportunities for the children to practice the safety sequence, while being called across the street (in this case by the instructor).

Session 5. The children play the third practice game, the "Followthe-Leader Game," in the gymnasium or other suitably large area. During this game, the children follow a path which crosses the street. If a child fails to perform the correct safety sequence, or if the child behind catches up with him, he/she must exchange places with the child behind. There are two versions of this game: a simple version for the $\mathrm{K}-1$ grades, and a more complicated one for the older children. The pusharound cars will be "driven" as before.

The objective of this session is to provide the children with an opportunity for practicing the behavior sequence while being "chased" by another child.

Session 6. The children play the "Ball-Toss Game" outside on a nearby residential street. The game is played as described in Session 3, except that it is played near parked cars and the children must step to the edge 
of the parked cars before performing the behavior sequence. The street is blocked to traffic as described in a later section.

Session 7. The children play the "Chip Game" outside. The game will be played as described in Session 4 but with no parked cars nearby. If possible, the street site for this session should be different from the one selected for Session 6 .

Session 8. The children play the "Follow-the-Leader Game" outside as described in session 5 . The game is played near parked cars, and the children must step to the edge of the parked cars before performing the safety sequence. If possible, the site selected for this session should be different from those selected for Sessions 6 and 7 .

The objective of Sessions 6,7 , and 8 is to provide opportunities for the children to practice the safety sequence while playing the various games in a natural environment.

Make-Up Session(s). This. session or sessions should be given to those children who have missed one or more of the regular sessions. Either Sessions 6,7 , or 8 may be repeated at the instructor's (or children's) option. This session can be repeated, as required, until all of the children in the class have attended a total of at least six initial training sessions.

\section{Follow-on Sessions}

Follow-on activities are a vital part of the Safe Street-Crossing Training program. Learned behaviors must be reinforced by continuing practice and application. After completion of the initial training phase of the program, instructors must conduct frequent follow-on activities to remind the children of the safety sequence. Kindergarten and first-grade children should have follow-on sessions every two weeks, older children at least once a month.

The follow-on activities may take the form of additional practice, practice games, or any activity where the children are given a chance to practice the safety sequence. Suggestions for follow-on activities are provided in the Instructor's Guide.

Categories of follow-on activities include:

- Repeat training sessions.

- Safety walks.

- Practice during a fire drill or class trip.

- Practice during physical education activities.

- Practice emphasizing re-initiation behaviors (search again after a car has passed). 
- Races.

- Tag games.

- Invent your own games.

The objective of these sessions is to remind the children of the safety sequence and give them an opportunity for additional practice.

Refresher Training

Refresher training sessions are given in the beginning of all subsequent years to children who have already completed the initial training. There are three 45-minute sessions.

Refresher Session 1. The children view the safety film "Don't DartOut." The teacher demonstrates the safe street-crossing sequence, and the children are given a chance to practice that sequence in their classrooms.

Refresher Session 2. The children play the "Ba11-Toss Game" in the gymnasium or any other suitably large area. Tokens are not given.

Refresher Session 3. The children play the "Follow-the-Leader Game" outside. Tokens are not given.

The objective of these sessions is to reestablish, after the summer vacation, the habit of performing the safety sequence.

Follow-on sessions are again conducted monthly or bi-weekly throughout the school year following refresher training. 
OTHER SAFETY PROGRAMS

The Safe Street-Crossing Program outlined in this Guide is intended to be a part of a larger child safety curriculum. If your district has such a curriculum, you may find that these lessons may appear to contradict some others. For example, most schools use a street-safety program which teaches children that the ONLY safe place to cross the street is at the corner where there is a light, a crosswalk, or a crossing guard. Certain$1 y$, it is not the intention of this program to contradict this training. The present program is aimed at those times when the child is casually playing and carelessly runs into the street to retrieve a ball or greet a friend. The instructors have been instructed to emphasize to their classes that crossing at the intersection is still the best way.

Although training in proper intersection behavior is extremely important, it is becoming widely recognized that children will enter the street midblock, and it is best to teach them to do so safely. Dart-out type accidents cannot be prevented by unrealistic expectations that children will remember to cross at the corner even in the midst of playing. Dart-outs can only be stopped by teaching children appropriate behavior for their inevitable midblock crossings. The children should receive a balanced safety program that teaches both lessons.

You should outline some suggestions for the instructors concerning material to be covered in the initial training presession(s) which will help integrate this program into your larger safety curriculum. Give these suggestions to the principals when you give them their session schedules. This will prevent the safety programs from interfering with each other, while keeping them maximally effective. 
OPTIONS FOR PROGRAM ADMINISTRATION

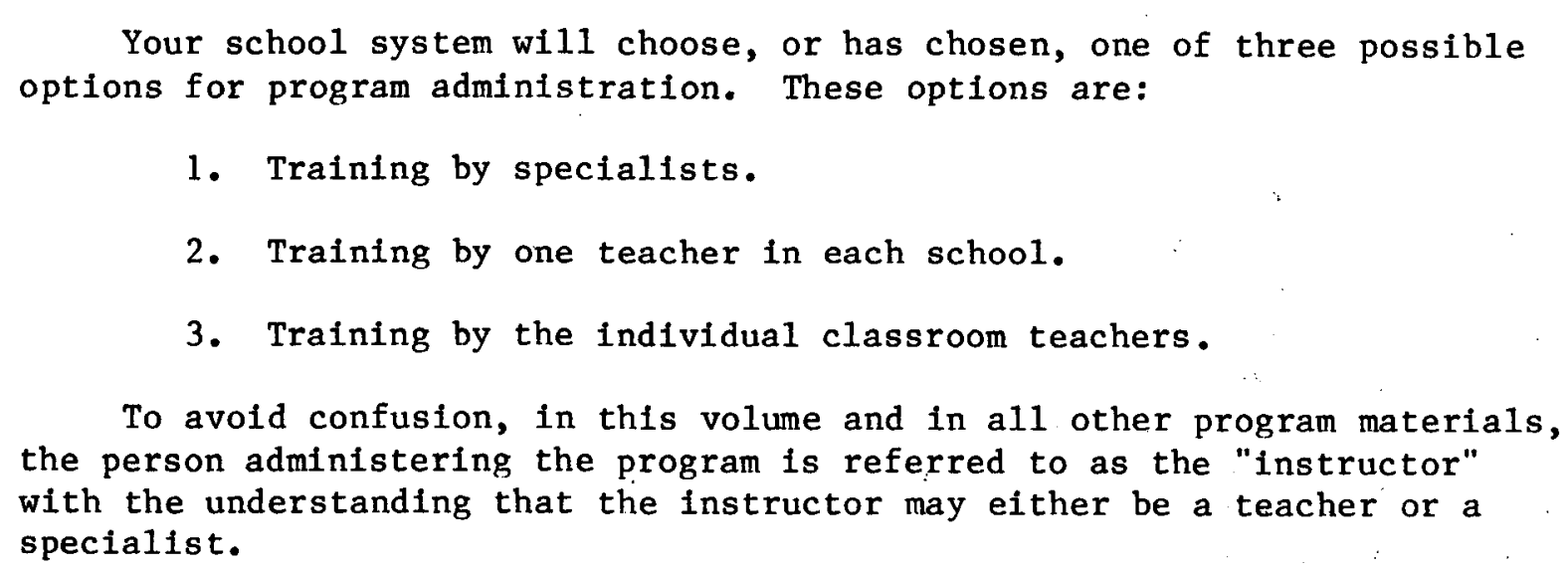

Your school system will choose, or has chosen, one of three possible options for program administration. These options are:

1. Training by specialists.

2. Training by one teacher in each schoo1.

3. Training by the individual classroom teachers.

To avold confusion, in this volume and in all other program materials, the person administering the program is referred to as the "instructor" with the understanding that the instructor may either be a teacher or a specialist.

\section{Training by Specialists}

This is the best option and permits the greatest control of program administration. Specialists would be assigned to conduct program activities exclusively and would be experts in program administration. They would be thoroughly trained by the coordinator who would directly supervise their activities.

The coordinator may be called upon to select and/or hire specialists within the constraints established by the school system. The amount of funding available will be an important consideration. Depending upon your unique constraints, you may elect to draw specialists from various professional or non-professional sources. For example:

1. The administrative or central school system staff.

2. PTA members who would volunteer for the positions.

3. Assistants already employed by the school system.

4. Student teachers recruited through a local college or university.

5. Substitute teachers.

6. Honors high school students as a project for extra credit or as a volunteer project. 
Whatever the source, you should select specialists who are reliable, capable, personable, and can deal authoritatively and tactfully with both children and teachers.

\section{Training by One Teacher in Each School}

Option 2 would involve one teacher from each school, selected by the principal and trained by the coordinator, who would be responsible for all program activities in his/her school (except for follow-on activities). This teacher's teaching assignment would be adjusted to permit him/her to devote the required time to the program. The princlpals may choose:

1. A classroom teacher.

2. A physical education teacher or some other special program teacher.

3. An experienced aide assigned to the school.

4. Volunteer personnel recruited by the school.

The classroom teachers would again serve as assistants and be trained to conduct follow-on activities.

\section{Training by Individual Classroom Teachers}

With this option, each $\mathrm{K}-3$ teacher adminsters all program activities-initial training and refresher training as well as follow-on sessions to his/her own class. The coordinator trains all the teachers and works with them to assure that they are able to effectively perform the various program activities.

Each classroom teacher will require an assistant to help in the conduct of the sessions. Some schools may have assistants available. An important function of the coordinator, if this option is chosen, is to assist the school principals in obtaining assistants when aides are not available. Assistants may be recruited/selected from various sources, including:

1. Parent or community volunteers.

2. Responsible high school students.

3. Other school personnel. 


\section{SCHEDULING THE ADMINISTRATION OF THE PROGRAM}

The degree of scheduling required is dependent upon the option your school system chooses for program administration (as defined in the previous section).

\section{Option One: Training by Specialists}

Each specialist conducts training at a number of schools and the coordinator schedules their time. When devising these session schedules, there are several constraints which you should consider:

- The number of schools in your district.

- The number of specialists avallable to you.

- The size of each school--the number of participating classes (and, in subsequent years, the number of classes which will be taught the initial training versus refresher training).

- Your local climate.

Assume that a school system with 50 schools is used as a model. The next question to consider is the number of specialists required. In warm climates where initial training can be conducted throughout the year, a single specialist could conduct initial training in 10-15 schools, depending upon their size. Thus, a school system with 50 elementary schools would require 4-5 specialists the first year. For subsequent years of the program, specialists would be required only for Initial training of the Kindergarten and transfer students, and to conduct refresher training. Under these circumstances, only two specialists would be required to maintain the program.

Unfortunately, not all of the country has beautiful weather all year round. If you live in an area where there are seasonal changes, probably around the middle or end of November it will be too cold for the children to be outside. Sessions will have to be scheduled to end before this date and/or begin in the spring. Consequently, you will require more specialists for a shorter period. Assuming you can schedule sessions for six months of the school year, seven or eight specialists woul be required for initial training in a school system of 50 schools. These specialists would not work during the three-month cold weather period and would be available for other assignments. Consequently, some new specialists may have to be trained for the spring sessions. 
Your school system may decide to reduce the number of specialists required for the first year of training by initiating the program in one-half or one-third of the schools each year. In this case, the schools with the greatest accident frequency (e.g., areas of high traffic density) should receive training first.

If Option One is selected and all schools are to be trained the first year, the procedure for scheduling is as follows:

1. Count the number of schools in your district.

2. Determine the length of time each school will need a specialist. To do this you need to know the number of classes participating in each school. You can figure that, conservatively, six classes can run sessions each day, and that there will be a total of nine sessions per school, assuming one extra session. From this information, determine how long each school would need a specialist. Always add two or three extra days to this total. This allows for time missed because of rain during the time the children are scheduled to be outdoors.

Example 1: School A has 12 classes participating in the program. If six classes a day can run sessions, each session should take two days. Since there are nine sessions to be run, School A would need eighteen days, plus two extra days. Remember that these twenty days are school days, so be sure to use a calendar when you schedule the sessions.

Example 2: School $B$ has 17 participating classes. If six classes a day can run sessions, each session will take approximately three days. Since there are nine sessions to the program, School B will need twenty-seven plus three extra school days to run the program (total thirty days).

3. Determine the number of specialists that will be required. Be sure to determine the fewest specialists possible in order to reduce costs. This is accomplished by dividing the schools into groups, based on the number of weeks they will require to perform the program (there are five days in a school week, round off uneven numbers of days to the next highest week--17 days = four weeks). For example, if there are 50 schools, 25 may require three weeks, 15 require four weeks and 10 require five weeks. Then, multiply the number of schools by the number of weeks each group requires, and add them together $[(25 \times 3)+(15 \times 4)+(10 \times 5)]$. Divide that sum by the number of total school weeks (minus Christmas vacation, etc.). If a school system in a warm weather climate has 36 weeks, you will require five or six specialists. If the school system has seasonal weather, there may be 24 weeks available for scheduling. In this 
case, eight specialists would be required instead of five.

If your schools are on an unusual system, such as yearlong schedules of a "track" system, you will have to adjust your available school time accordingly.

4. Devise a master schedule to give to the principals, showing when each school would receive training and for how long. A schedule also should be developed for each specialist, showing the schools he/she will visit and when. When devising these schedules, plot them on a calendar so that you will be sure to make allowances for all holidays. The schedules should be distributed to the principals at your meeting with them, and to the speicalists during their training course.

Option Two: Training by One Teacher in Each School

If Option Two is chosen, scheduling of schools may be unnecessary. All schools may begin training at the beginning of the school year, as each school will have its own equipment and resident instructor. Scheduling your own time will be more difficult, however, as you should visit all schools early in the program to be certain the instructors are performing correctly. This topic is discussed further in a subsequent section.

It is possible that some principals may be unable to free their instructors from all of their regular duties for four or five weeks. It may be decided that these instructors will administer initial training to only two or three classes at a time. In that case, a school with $10 \mathrm{~K}-3$ classes would require approximately 15 weeks to complete initial training. The principals will do this scheduling as they will all class scheduling within their schools, but they may request your assistance.

Option Three: Training by Individual Classroom Teachers

Scheduling schools will not be necessary with Option Three. However, scheduling your own time to visit all schools and all classes early in the program may be extremely difficult, as all schools should initiate training at the beginning of the school year. This topic is covered more fully in a subsequent section. 
PREPARING THE SCHOOL SYSTEM FOR THE PROGRAM

The success of this program is affected strongly by the degree of Interest, acceptance, and involvement demonstrated by the principals and teachers. Before dealing with any school personnel, you become throroughly familiar with all program literature and equipment. You should have a clear idea of the program's approach, rationale, and methodology so that you can competently explain the program and answer questions.

\section{Principals}

The principals will be primarily responsible for preparing the teachers in their schools, for assuring smooth program administration, and for dealing with parental questions or concerns. They must understand the program and what is required of them. If the program instructors are to be selected teachers from each school (Option Two), each principal must choose the teacher in his/her school and arrange for a replacement during the period of program administration. Other principal tasks include:

1. Informing the teachers about the program and obtaining their cooperation.

2. Assuring that program activities are properly scheduled.

3. Arranging for assistants.

- 4. Arranging for barricade guards (as required) and the blocking of streets.

5. First level liaison with parents regarding the program.

Before the beginning of the school year, arrange to conduct a meeting with all principals. This would be a half-day meeting and a suggested agenda would be as follows:

1. Introduce yourself and give a short introductory presentation on the goals of the program.

2. Show the "Introduction to the Safe Street-Crossing Training Program" film and the children's safety film, "Don't Dart-Out."

3. Ask for questions or comments. Discuss each question fully. 
4. Distribute one Principal's Guide and one Instructor's Guide to each principal. Urge them to study the guides prior to program initiation.

5. Outline their responsibilities (as described in the Principal's Guide), explain some of the problems they may face, and discuss the best way to handle them.

6. Emphasize the importance of preparing the teachers in their schools.

7. If the instructors are to be special teachers within each school (Option Two), discuss their selection and options for covering their classes during the training period. (See page 8 in the Principal's Guide.)

8. Ask for questions or comments. Encourage the principals to contact you with any scheduling, street-blocking, public relations, or other problems at any time.

9. Describe your role--visiting schools, memos, etc.

The principals may express concern over the midblock crossing issue and/or the amount of time and space required. See Program Issues and Questions section of this guide for a discussion of these concerns. Try to reassure the principals as to the legitimacy, necessity, and validity of this approach.

Principals of schools in low-income areas with older facilities and/or discipline problems may be especially concerned about the demands of this program. Research has shown that these are precisely the schools that have the greatest need for the program. These schools are usually located in the areas of highest traffic density and accident rates. Emphasize the importance of the program in their areas to these principals and offer them extra assistance. For example, to ensure that the program is properly conducted in these schools which may be understaffed and subject to extraordinary pressures, it may be possible to have specialists conduct the program only in these schools, even though the other schools use a teacher option. If some facilities cannot meet the space requirements of the program, one solution is to conduct the indoor sessions (except for the $\mathrm{film}$ ) in the schoolyard. If the program is to be implemented in stages, these areas should receive it first. Be sure to give these principals the extra attention and assistance they require.

\section{Teachers}

Motivating the teachers, if either Option one or Two are chosen, will be primarily a function of the principals. It is possible that a principal might ask you to speak at his/her school. You should respond quickly to all requests for assistance. If Option Three (classroom teachers administer the program) is chosen, you will be meeting with all teachers for a 
mass training session. (See Training and Supervision of Instructors section of this guide.) 


\section{TRAINING AND SUPERVISION OF PROGRAM \\ INSTRUCTORS FOR INITIAL TRAINING}

One of the most important functions of the coordinator is the training and supervision of the personnel who will actually administer the program. Regardless of the program admintstration option chosen, the coordinator will hold training sessions for the instructors and will be responsible for continuing supervision of program administration.

\section{Training Program Instructors}

The option which your school system chooses will determine whether you will be training specialists, a relatively small group of selected teachers, or all $\mathrm{K}-3$ teachers in the system. Of course, the option selected will influence the content and approach of the training, but the basic curriculum will remain the same.

The training course should be given before the opening of school. For Option Three, perhaps a teacher in-service day may be used. Before giving the course, be sure to:

1. Become throroughly familiar with the Instructor's Guide and the Principal's Guide.

2. Review the Instructor's Training Curriculum.

3. Study the safety film, "Don't Dart-Out," and practice using all of the equipment.

4. Assemble several sets of program materials for use in training.

Regardless of the option selected, Instructor's Guides should be distributed to the instructors in advance of the training. The course will include:

- A discussion of the goals of the program.

- Viewing the "Introduction to the Safe Street-Crossing Training Program" film and the safety film, "Don't Dart-Out."

- Demonstration of materials.

- Demonstration of the safe street-crossing sequence. 
- Emphasis on the continuing nature of the program, with particular attention to follow-on activities and refresher training.

- Opportunities for questions and comments.

\section{Supervision of Program Instructors}

Supervision of program instructors will be a vital part of the coordinator's responsibilities. The coordinator's control over the quality of program administration can be established only through thorough training, close observation, and continuing involvement with the instructors.

Option One: Training by Specialists

If Option One is selected, the coordinator will assign the specialists to the various schools. This will involve scheduling the schools and ensuring adherence to the schedule (scheduling is discussed on page 11 of this guide). Whenever possible, specialists should be assigned to schools where they would fit in best.

After the specialists have begun initial training, you may be called upon to resolve day-to-day problems. You should be prepared to deal with scheduling conflicts, questions/concerns from school personnel, mislaid equipment, among other problems that the spectalists will encounter. Each specialist should check in with you after the first day of training in each school to apprise you of the situation, even if no problems have arisen. If training in a school goes off schedule for any reason, you should be informed as soon as possible so that schedule adjustments can be made promptly.

An important coordinator's task, regardless of option, will be to observe the process of program administration. You should make a visit to each school while training is in process. This must be done at least for the first school that each specialist instructs. Observe the instructor's conduct of the session and provide him/her with corrective feedback privately after the session is over. Points to check include:

- Is the equipment set up as described in the Instructor's Guide?

- Are the games played as described in the Instructor's Guide?

- Are the children involved and interested?

- Is discipline a problem?

- Is the correct behavior sequence, and only the correct behavior sequence, reinforced consistently? 
- Is there a capable assistant present?

- Do the instructor and assistant make certain each child crosses correctly?

- Do the instructor and assistant cross correctly themselves?

Option Two: Training by one Teacher

in Each School

Although the principal in each school would naturally supervise his/her teacher, you should maintain as much control as possible over program administration. Try to visit each school at as early a point in the program as possible. Plan to visit schools in the same area each day. If no serious problems are encountered, you may be able to observe as many as four schools in one day. It is best to observe all instructors early in the program to catch and correct errors in program administration before training has proceeded too far. The points to check for are the same as those given under Option One.

Option Three: Training by Individual Classroom Teachers

Supervision of this option would be most complex. Scheduling your time to try to observe each class will be difficult. If yours is a large school system and all schools initiate training at the beginning of the year, it may be impossible for you to observe all classes. In that case, it may be best to observe only one or two classes in each school together with the principal. Show him/her what to look for and ask him/her to observe the other classes. The points to check for are the same as those given under Option One. 


\section{SUPERVISION OF PROGRAM INSTRUCTORS \\ AFTER INITIAL TRAINING}

There is a tendency on the part of teachers and principals to believe the program is over after completion of intitial training. This tendency must be counteracted. Although it is natural that there would be a reduction in interest and involvement after the first major push is over, this is a continuing program that will be a permanent part of the curriculum. The continuing nature of the program, and the need for periodic practice and reinforcement to ensure retention, should be emphasized to both principals and instructors.

\section{Follow-On Activities}

Regardless of the option selected, follow-on activities are to be performed by the individual classroom teachers. For options one and Two, this will be the only portion of the program they will conduct. They will need supervision and guidance to perform follow-on activities consistent $1 y$.

The coordinator should prepare a "Coordinator's Follow-on Memo" each month to be distributed to all $\mathrm{K}-3$ teachers. This memo should include:

- Reminders of the importance of follow-on activities.

- Suggestions for new follow-on activities.

- Descriptions of new activities performed by the teachers:

- Accident news (before/after accident rates and descriptions of accidents which have occurred).

Accident data can be obtained from the police. At your request, they will give you full information on each child pedestrian accident victim of the appropriate age $(\mathrm{K}-3)$. You can then check your enrollment to determine whether or not the child was a public school student. Only children enrolled in schools performing the program should be included in your data. "Before" period data could encompass any number of months before the program was initiated in your school system. The "after" period begins when the children begin training. You could perform "month-by-month or schoolby-school comparisons," or an overall comparison for all schools for a specified length of time for the before and after periods.

Every two months the principals should submit reports to the coordinator (on forms sent to them a week or two before they are due) on the types 
of follow-on activities performed in their schools and their frequencies. This information will be incorporated into the "Coordinator's Follow-on Memo." In this way, one teacher's new idea can be disseminated to all the teachers. Emphasize in the memo that each teacher should perform a broad range of activities--not merely repeat the same activity each month--to give the children a variety of experiences.

Make arrangements with the principals to observe as many follow-on sessions as possible. Speak with the teachers to encourage further activities.

\section{Subsequent Years of the Program}

After the first year of program administration, only Kindergartners will receive initial training. First-, second-, and third-graders will receive refresher training. Before the beginning of each school year, you should conduct a tralning course similar to that described in the previous section. If option one or Two is selected, there will be new instructors who must be trained due to attrition, and all instructors should receive a modified course that emphasizes refresher training. If option Three is selected, you should hold two courses, if possible--one for Kindergarten teachers that emphasizes initial training and one for the other teachers that emphasizes refresher training. If you are unable to conduct training with all teachers, at least provide training for new teachers.

Efforts should be made to observe as many refresher training classes as possible.

Follow-on activities and supervision should be continued in the same manner as in the first year of program administration. Reminders should be sent out at the end of refresher training and the "Coordinator's Follow-on Memo" should continue to appear each month. 
As explained earlier, one of your major concerns during the child pedestrian safety program will be obtaining and organizing the program materials for distribution. In some cases, materials are provided for each class and every student. Other materials are to be shared by all participating classes within a school. You should supervise the sorting and distribution of the materials to each class and school.

\section{Class Materials}

The first thing to do is to determine the number of classes and students for each school participating in the program. Set up a file for each school, showing how many classes will be participating and the number of children in each class.

The following is a list of materials that each class will recelve:

1. One Instructor's Guide.

2. Two packages of Yellow Safety Tokens (500 to a package).

3. One Progress Chart.

4. One roll of masking tape.

5. Parents' Pamphlets (one for each child in the class).

6. Safety Certificates (one for each child in the class).

7. Sew-on Safety Badges (one for each child in the class).

Using your class lists, divide the materials into sets, one set for each class and group all class materials together by schools. Provide two or three extra class sets for each school to allow for damage or loss.

\section{School Materials}

You will also receive a number of sets of materials which will be shared by all teachers in one school. The following is a list of materials that each school will receive:

1. One street safety film, entitled "Don't Dart-Out." 
2. One set of pusharound model cars (three cars to a set).

3. One set of street-safety barricades and signs (two barricades to a set).

4. Three sets of game materials.

Each set of games materials consists of:

1. One set of balls (one red ball and one blue ball).

2. One set of wastebaskets (one each--pink, blue, white).

3. One set of plastic chips ( 75 blue chips and 75 red chips).

4. One "Follow-the-Leader Game" rope.

Once assembled, these materials can then be distributed to the participating schools. Each school should receive the appropriate number of class sets and one set of shared materials. Distribution should be done a week or two in advance of the actual start of the sessions to give the principals and teachers a chance to acquaint themselves with the program. Your master schedule, described in an earlier section, will determine when each school receives the equipment.

Save all of the extra materials you receive and inform the schools of their availability in case anyone needs them. system.

Distribution can be done by your school system's regular distribution

\section{$\underline{\text { Replacement Materials }}$}

Before the beginning of al1 subsequent school years, the class materials must be replenished following the guidelines described above. The principals should inventory their school materials and send you a list of required replacements before the start of school so that you may supply new equi pment as needed. 
MAKING ARRANGEMENTS FOR OUTDOOR SESSIONS

Obtaining Permission to Block Streets

Sessions 6-8 of the initial training programs and all make-up sessions are scheduled to be played outdoors. In order to ensure the safety of the children, the streets must be barricaded before the games can begin. The safety program materials include barricades and signs which can be used to block the streets, but permission must be obtained from the proper authorities to set up the barricades and block the streets.

To obtain this permission, you must first locate the person in charge of traffic management in your city. Although the title may vary from city to city, he/she can usually be located at your county courthouse, in the police department, the department of transportation, or with the Department of Highways and Sewers.

When you contact this person, explain the street safety program to him/her thoroughly. Emphasize that only residential streets will be blocked, not bus lines or main throughways. Also emphasize that you are requesting permission to block the street NOT barricades. Explain that the person will be contacted by the principals to confirm streets and dates.

Be sure to obtain the authority's name, title, address, and phone number. Give these to the principals when you give them their session schedules. The Principal's Guide will instruct each principal to notify the authority of the dates, times, and locations of the streets to be blocked. You need only tell them who to call.

\section{Arranging for Crossing Guards}

As an added safety precaution, crossing guards should be stationed at the barricades during the outside games. Each city usually has a force of full- and part-time crossing guards which they will send to the schools, if at all possible. Again, as with the street-blocking, an introductory call or visit should be made to the captain of the crossing guards to explain the nature and purpose of the safety program, and to request the cooperation of the guards. The crossing guard captain can be located at the local police department. If each school maintains its own group of crossing guards, the principal can make the initial contact for his/her school. If there is a city. force, you should make the introductory call. Explain that the principals will call the guard captain with specific dates and times.

Record the captain's name, business address, and phone number. You can give these to the principals when you give them the session schedules. 
If your city is unable to provide complete or partial guard protection, it will be necessary to arrange for other help at the barricades. Work with principals to find alternate sources such as:

1. Volunteers from the PTA.

2. Parents of children participating in the program.

3. older children.

4. Members of school safety patrols. 
PROGRAM ISSUES AND QUESTIONS

The support and acceptance of teachers, principals, parents, municipal authorities and the general public is necessary for the success of this program. You may have to deal with many concerns and questions expressed by these groups.

Maintaining good public relations will be an important part of the coordinator's duties. Become acquainted with police and traffic officials, and thoroughly brief them on the program. You may be asked to speak at PTA, school board, or civic group meetings. You should have a prepared presentation and show the "Introduction to the Safe Street-Crossing Training Program" film.

It may be necessary or desirable to hold a press conference. If so, again try to show the introductory film. If asked for interviews by the media, be cooperative and respond fully to all questions.

You may also be asked to organize a press conference or interviews with school system officials and representatives of the police department. Be sure that all participants are thoroughly prepared.

When preparing the community for the program and dealing with their concerns and questions, remember that you are the primary representative of the program in your district. You provide its public image. Be informed, confident, and cooperative at all times.

The questions most often asked concerning the program are:

1. Won't this program negate traditional safety lessons that teach children to cross at the corner? Is it right to teach children to cross midblock?

2. Are we teaching the children to jaywalk?

3. Doesn't this program take more time than other child pedestrian safety programs?

4. Doesn't this program require a great deal of space to perform? 
This Program Versus Traditional Child Pedestrian Safety Messages

This program is in no way designed to counteract the important "crossat-the-corner" and "cross-at-the-light" lessons that children must learn. However, we want to be sure that if a child enters the street for any reason, he does so safely. Over one-half of all child pedestrian accidents are dart-out types. It is becoming widely recognized that in real-1ife situations, children will enter the street midblock while playing. For example, no amount of intersection crossing training will prevent a child from running into the street to retrieve a ball. This program emphasizes crossing safely under all conditions, especially at those times when it is extremely impractical and unlikely that the child would go to the intersection to cross.

Does This Program Encourage Jaywalking?

In most cities, jaywalking ordinances prohibit crossing only between adjacent signalized intersections, in business districts, within 150 feet of a crosswalk, or under other speciallzed conditions usually associated with busy commercial areas. These rules do not usually apply to the residential areas with which we are concerned. We are trying to prevent the type of accidents that occur when a child is playing by a residential street near his home.

In addition, jaywalking ordinances are often not enforced. Although some cities have strict jaywalking laws, they are not enforced except in busy downtown areas or selected problem districts (1.e., near a college campus). Law enforcement officials usually take the position that these strict laws are needed and enforceable only in busy, heavy traffic areas.

Become familiar with the jaywalking ordinances in your city and where they apply. Discuss the laws and their enforcement with municipal authorities and law enforcement officials to clarify their positions on the issue. This information will be valuable to you in dealing with questions from all sources.

The Time Required to Administer the Program

Teachers and principals may also be concerned with the amount of time that the program requires. Such an intense training program is necessary to ensure complete learning and retention. Mere exposure to safe streetcrossing concepts is not enough. Typical child pedestrian safety programs are very brief, usually two to four hours per year. Such programs provide only a basic familiarity with the ideas behind safe street crossing. Although such theory is valuable, young children need practice and reinforcement to develop actual street-crossing skills to apply to real-life 
situations. If the program is to reduce accidents, it must be properly taught and reinforced and this, of course, takes time.

The time requirements of the program may be lessened by combining program activities with recess, physical education classes, and other school activities.

In answering teacher's and principal's questions concerning the program time requirements, emphasize the continuing nature of the program and the fact that refresher training and follow-on activities are less time consuming than the initial training. There is a tendency for teachers and principals to believe the program is over after initial training. This is far from true, and the importance of the refresher training and follow-on activities should not be minimized.

\section{The Space Required to Administer the Program}

A fairly large area, such as a gymnasium, auditorium, or lunchroom, is required for administering of the indoor sessions of the program. Classrooms do not provide enough area to practice with the pusharound cars or play the games properly. Most schools do have a large area that can easily be adapted for the program and quickly returned to ordinary use. The pusharound cars are easily moved and stored (they are stackable), and the game equipment will fit in a small cupboard.

Obviously, a gymnasium would be the best alternative and, as was mentioned in the previous section, program activities can be combined with physical education periods. An auditorium or lunchroom with moveable chairs and/or tables could also be used, although time would be required to restore the furniture to its usual position. If the architecture of the school provides a large central hall, that might be an ideal place to conduct the program (scheduling around times of heavy traffic flow). Another alternative, during warm weather, would be to use the schoolyard or playground for the "indoor" sessions. However, it must be self-contained and not provide access to the street.

Work with the principals to determine the most convenient location in each school. 
APPENDIX B

PRINCIPAL 'S GUIDE

B-1 

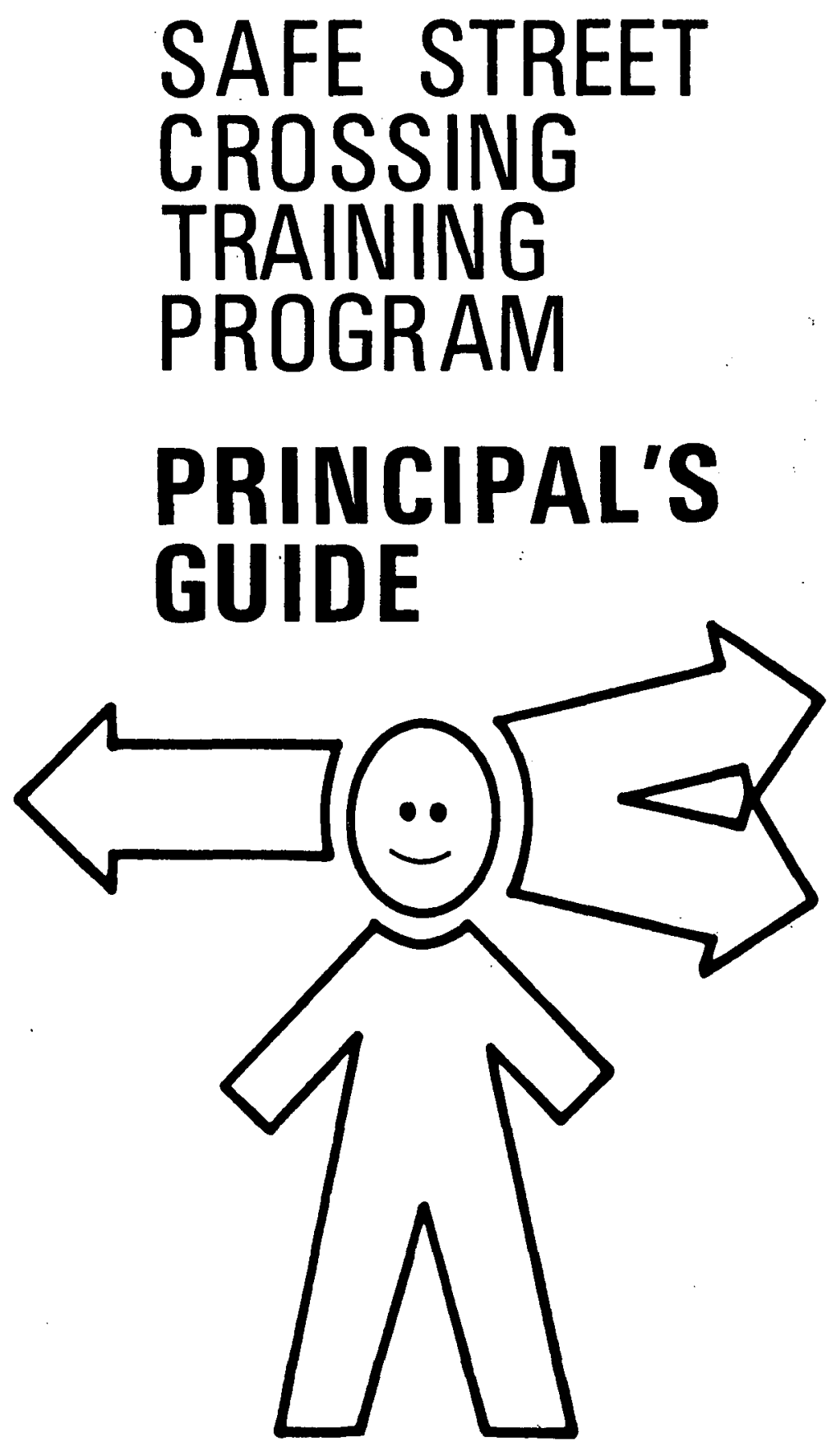

U. S. DEPARTMENT OF TRANSPORTATION

Contract No. DOT-HS-4-00955

December 1977 
TABLE OF CONTENTS

Page

INTRODUCTION . . . . . . . . . . . . . . . . 1

Why the Program Was Developed ............ 2

Program objective ..................... 3

Summary of the Program ................. 4

Initial Training . . . . . . . . . . . . 4

Follow-on Sessions ................ 6

Refresher Training ............... 7

ADMINISTERING THE PROGRAM IN YOUR SCHOOL . . . . . . . 8

Preparing the Teachers in Your School . . . . . . . . 8

Performing an Inventory of Program Materials . . . . . 9

Class Materials ................. 9

School Materials . . . . . . . . . . . . . 9

Scheduling Program Sessions . . . . . . . . . . 10

Initial Training . . . . . . . . . . . . 10

Follow-on Sessions ................ 12

Refresher Training . . . . . ......... 13

New Students . . . . . . . . . . . . 14

Arranging for Assistants . . . . . . . . . . 15

Where to Administer the Sessions . . . . . . . 15

Inside Sessions . . . . . . . . . . . . 15

Outside Sessions ................. 15

Obtaining Municipal Cooperation ......... 16

Blocking the Street ............... 17

ANSWERING PARENT'S AND TEACHER'S QUESTIONS

CONCERNING THE PROGRAM . . . . . . . . . . . . . 18

This Program Versus Traditional Child

Pedestrian Safety Messages . . . . . . . . . 18

Does This Program Encourage Jaywalking? . . . . . . . 18

The Time Required to Administer the Program . ...... 19 


\section{INTRODUCTION}

Your school is participating in a safety program whose purpose is to teach elementary school children (Grades $\mathrm{K}-3$ ) the correct procedures for safely crossing a street. Briefly, this program consists of eight or nine 45-minute intial sessions which are to be taught in a three or four week period. During the first two sessions of this program, the children will view the safety film, "Don't Dart-Out," featuring Captain Kangaroo, who will demonstrate the safe street-crossing behaviors and introduce the program. The remaining sessions consist of "safety games" which will provide opportunities for the children to practice crossing the street.

For the first year of program administration, all $\mathrm{K}-3$ classes will receive initial training. In all subsequent years, only the Kindergarten classes will receive initial training. The first-, second-, and thirdgrade classes will receive refresher training which involve three sessions similar to those of initial training. Follow-on sessions will be performed every month after both initial and refresher training. Follow-on sessions are games and activities which reinforce learning of the safe streetcrossing behaviors. They must be performed throughout the school year to ensure retention.

The success of this program is contingent upon the cooperation of everyone involved. Although the instructors are the only ones who will actually administer the sessions, there must be some overall program coordination and supervision in each school. With the aid of the training coordinator for your school system, you will supervise the administration of the program in your school. The activities under your direction will include:

1. Acquainting your teachers with the Safe Street-Crossing Training Program.

2. Obtaining, storing, and organizing program materials.

3. Coordinating and scheduling a11 class sessions.

4. Arranging for barricade guards (as required) and serving as liaison with municipal authorities to block streets for outdoor sessions.

5. Answering parents' questions regarding the program.

This booklet will give you complete guidelines, instructions, and suggestions to aid you as you coordinate and supervise the safety training program. You should also review thorough1y the Instructor's Guide. It explains and outlines the actual program sessions that are to be taught to the students. 
Although this program can stand alone, it can also function as part of a larger Child Safety Curriculum. This program may appear to contradict some of the other street-safety lessons taught as part of such a curriculum. Most children are taught to cross streets only at the corner where there is a light, crosswalk, or crossing guard. It may seem now that they are going to be taught to cross at midblock instead; or, worse yet, to play in the street. This, of course, is not the intention of the program. This program is aimed at those times when the child is casually playing and carelessly runs into the street while retrieving a ball or while being chased by a friend. The midblock crossing procedures are not substitutes for going to the intersection, and the children should still go to the intersection whenever possible.

Stress the importance of additional intersection instruction to the teachers. They should continually strive to make the distinction to the children between crossing midblock while playing and crossing at the corner when going somewhere.

\section{Why the Program Was Developed}

Statistics show that each year there are approximately 400,000 pedestrian accidents, many of them involving children. Every year 3,000 children are killed in pedestrian accidents. While some of these accidents are undoubtedly the fault of the driver, or due to some mechanical failure in the automobile, far too many of the accidents occur because the children are unaware of the correct procedures for safely crossing the street.

Over one-half of all child pedestrian fatalities are attributed to dart-out accidents. A dart-out occurs when the child enters the street at midblock, often from between parked cars. He may be chasing a ba11, running to an ice cream vendor, or responding to a friend's or parent's call. often, when he enters the street, he fails to search for and detect approaching traffic, and this can result in an accident.

In the past, parents and school programs have either neglected to teach safety procedures, or have attempted to correct the child's behavior by scolding or punishing the unsafe behavior. They have also tried to warn children of the potential dangers of running into the street. These methods simply do not work, largely because the children are just too young to fully comprehend the danger associated with the situation.

The Safe Street-Crossing Program uses an entirely different approach. Instead of merely telling the children what not to do, this program provides learning experiences in which the child actually practices the correct procedures to safely cross the street. The program's objective is to train the children to perform a simple behavior sequence which maximizes their chances of detecting and avoiding approaching vehicles when they enter the street at midblock. 
The children will learn to stop and look every time they walk into any type of street. This is accomplished by the use of guided practice in the classroom and safety games. These games provide opportunities for children to practice safety behavior in situations much like those they actually encounter when playing near the street. The games will be played both in the classroom with simulated street surroundings, and on a "real-wor1d" street where traffic is carefully controlled. As a reward for learning good safety habits, the children will earn safety patches and receive signed certificates attesting to their achievements.

\section{Program Objectives}

The main objective of the Safe Street-Crossing Program is to teach children a simple procedure that, when learned, will prevent them from darting out into the street in front of an automobile.

The following is a detailed description of the correct safety behavior sequence:

1. a. Stop at the edge of the curb or road, if there are no parked vehicles,

or

b. If parked vehicles are present, stop at the boundary between the parking lane and traffic--beyond the parked vehicles, but still close enough to touch them.

2. Turn head and eyes to the left so that the visual field includes all of the left traffic lane, and look for left-approaching traffic.

3. Turn head and eyes to the right so that the visual field includes all of the right traffic lane, and look for right-approaching traffic.

4. Turn head and eyes to the left again, so that the visual field includes all of the left traffic lane, and check to be sure that the street is still clear.

5. a. Enter the street (if no cars are detected),

or

b. If a car is detected, wait for the car and track it until it has passed. Repeat the left-right-left searches before entering the street. (Perform this step as many times as necessary until the street is clear.) 
All five of these steps and only these five steps constitute the correct sequence. When visiting the classes, you should check that the teachers are rewarding the children for performing these steps correctly and in sequence. The children should NOT be rewarded for any of the following:

1. Performing only PART of the sequence (e.g., looking only left-right and failing to look left again).

2. Performing a step or steps incorrectly (e.g., not stopping).

3. Performing extra steps (e.g., looking L-R-L-R-L).

4. Performing a step out of sequence (e.g., starting to search before stopping).

Unless the teacher is consistent in determining what the correct safety procedures are (and rewards only the five properly-performed steps in the proper sequence), the children will become confused and the effectiveness of the program will suffer.

\section{Summary of the Program}

The first year of the program consists of nine initial training sessions, in which all children in grades $\mathrm{K}-3$ are taught the safe streetcrossing behavior sequence. At the end of the initial training, the children receive their safety badges and certificates. The initial training is supplemented in the first year by follow-on activities to keep the children familiar with the behavior sequence. In all subsequent years, only Kindergarten children receive initial training. Refresher training sessions are given to the first-, second-, and third-grades at the start of the school year and are also supplemented by follow-on activities throughout the year. This will provide continuous practice and reinforcement for the children. The following is a brief description of the major activities of the safe street-crossing training program.

\section{Initial Training}

The safe-street crossing program is administered in nine sessions. Each session is to be no longer than 45 minutes. Additional time is needed for a "Preprogram Activities" session, and an "Awards" session where the children receive their badges and safety certificates. The following is a brief description of the activities and objectives for each initial training session.

Preprogram Activities. The instructor will have a safety discussion with the class to sensitize the children to the fact that pedestrian accidents have happened to people they know and could happen to them. The 
instructor will also integrate this program into your school's existing safety curriculum. The training program coordinator should provide guldance concerning what materials to cover in order to accomplish this.

The instructor will explain and demonstrate the safe street-crossing behavior sequence (as defined in the Program Objective section of this guide).

Session 1. The children view the correct behavior sequence in the street-safety film "Don't Dart-Out." They are then given a chance to practice that sequence in a "no-threat" situation. This means that the children will be allowed to rehearse their behavior without fear of punishment or loss of reward. The children practice, using a "street" laid out on the floor of the classroom (or some other area of the school which you may designate for this purpose).

Session 2. The Kindergarten and first-grade children view the safety film a second time. All children practice the behavior sequence on the simulated "street" in the gymnasium or any other suitably large area. The children will receive yellow safety tokens as a reward for correct performance. The pusharound model cars will be introduced as parked cars and as "threats" (oncoming vehicles). The children must walk to the edge of the parked cars to perform the sequence to receive a token.

The objective of this session is to give the children additional opportunities to practice the behavior sequence in a situation where they will be rewarded.

Session 3. This session is the first of the practice game sessions. The children will play the "Ba1l-Toss Game" in the gymnasium or any other suitably large area. The object of the game is to toss a ball into a basket. When the child misses the basket, the ball will usually roll into the "street," and the child must correctly perform the behavior sequence before retrieving the ball. Some of the children will maneuver the pusharound cars up and down the "street," while the other children practice crossing. The children will receive tokens for each correct performance of the safety sequence. A simpler version of this game is provided for the younger children.

The objective of this session is to provide opportunities for the children to practice the safety sequence while entering the street to retrieve a ball during a game.

Session 4. The children play another practice game, the "Chip Game," in the gymnasium or any other suitably large area. The children are divided into teams. Team members are required to cross a "street" and perform the safety sequence to obtain a chip from the instructor, and then must return to the starting circle. Those who fail to perform the sequence correctly are sent back to the starting circle and do not receive a chip or safety token until they have performed correctly. One pusharound car will serve as a parked car. The team member must step to the street-side edge of the parked car before performing the behavior sequence. The other two cars will be "driven" up and down the street as before. A simpler version of this game is provided for the younger children. 
The objective of this session is to provide opportunities for the children to practice the safety sequence while being called across the street (in this case, by the instructor).

Session 5. The children play the third practice game, the "Follow-theLeader Game," in the gymnasium or other suitably large area. During this game, the children follow a path which crosses the street. If a child fails to perform the correct safety sequence, or if the child behind catches up with him, he/she must exchange places with the child behind. There are two versions of this game: a simple version for the $\mathrm{K}-1$ grades, and a more complicated one for the older children. The pusharound cars will be "driven" as before.

The objective of this session is to provide the children with an opportunity for practicing the behavior sequence while being "chased" by another child.

Session 6. The children play the "Ball-Toss Game" outside on a nearby residential street. The game is played as described in Session 3, except that $1 \mathrm{t}$ is played near parked cars, and the children must step to the edge of the parked cars before performing the behavior sequence. The street is blocked to traffic, as described in a later section.

Session 7. The children play the "Chip Game" outside. The game will be played as described in Session 4, but with no parked cars nearby. If possible, the street site for this session should be different from the one selected for Session 6 .

Session 8. The children play "The Follow-the-Leader Game" outside, as described in Session 5. The game is played near parked cars and the children must step to the edge of the parked cars before performing the safety sequence. If possible, the site selected for this session should be different from those selected for Sessions 6 and 7 .

The objective of Sessions 6,7 , and 8 is to provide opportunities for the children to practice the safety sequence while playing the various games in a natural environment.

Make-Up Session(s). This session or sessions should be given to those children who have missed one or more of the regular sessions. Either Session 6, 7, or 8 may be repeated at the instructor's (or the children's) option. This session can be repeated, as required, until all of the children in the class have attended a total of at least six initial training sessions.

\section{Follow-on Sessions}

Follow-on activities are a vital part of the Safe Street-Crossing Training Program. It is important to reinforce learned behaviors by continuing practice after completion of the initial training phase of the program. Kindergarten and first-grade children should have follow-on sessions every two weeks, older children at least once a month. 
The follow-on activities may take the form of additional practice, practice games, or any activity where the children are given a chance to practice the safety sequence. Suggestions for follow-on activities are provided in the Instructor's Guide.

Categories of follow-on activities include:

- Repeat training sessions.

- Safety walks.

- Practice during a fire drill or class trip.

- Practice during physical education activities.

- Practice emphasising re-initiation behaviors (i.e., searching again after a car has passed).

- Races.

- Games with partners.

- Tag games.

- Instructor-invented games.

$\underline{\text { Ref resher Training }}$

Refresher training sessions are given in the beginning of all subsequent years to children who have already completed the initial training. There are three 45-minute sessions.

Refresher Session 1. The children view the safety film "Don't Dart-0ut." The teacher demonstrates the safe street crossing sequence, and the children are given a chance to practice that sequence in their classrooms.

Refresher Session 2. The children play the "Ball-Toss Game" in the gymnasium or any other suitably large area. Tokens are not given.

Refresher Session 3. The children play the "Follow-the-Leader Game" outside. Tokens are not given.

The objective of these sessions is to reestablish, after the summer vacation, the habit of performing the safety sequence.

Follow-on sessions are again conducted monthly or bi-weekly throughout the school year following refresher training. 
ADMINISTERING THE PROGRAM IN YOUR SCHOOL

Preparing the Teachers in Your School

Your school system has chosen one of three possible options for program administration. The option chosen influences the extent of involvement of the teachers in your school. These options are:

1. Training by specialists from outside your school.

2. Training by one teacher in your school.

3. Training by individual classroom teachers.

In this volume, and in all other program materials, the person administering the program is referred to as the "instructor," regardless of the option chosen.

If Option One has been selected, a trained specialist will be assigned to your school for a specified length of time to conduct the initial and refresher training. Your coordinator will work with you to determine the most convenient schedule. In Option Two, you will select one person to act as program administrator in your school. He/she will attend training sessions given by the coordinator and will administer the initial and refresher training to all classes. You may select a classroom teacher, a physical education teacher, an experienced aide, or even a parent volunteer but, in all cases, you should make certain that this person will be free to administer the program to all $\mathrm{K}-3$ classes. This may involve arranging for a replacement to cover that person's regular class responsibilities while he/she is administering the program or temporarily suspending some other activities for the duration of the initial and refresher training. of course, if a parent volunteer is obtainable, these staffing and scheduling changes will not be necessary.

If either Option One or Option Two have been chosen, the individual classroom teachers should serve as assistants to the instructor in administering the program to their classes. The classroom teachers will administer follow-on sessions themselves, so experience gained in acting as assistants will be important to them. In this regard, note that preprogram activities and Session 1 of the initial training are also designed to be administered in the individual classrooms by the classroom teacher, with some input from the instructor.

For either Option One or Two, it will be necessary to prepare the teachers in your school before the onset of initial training. It is important that all teachers in your school have a basic understanding of the goals and motives of the program, and are familiar with the Instructor's Guide. Therefore, distribute a copy of the Instructor's Guide to each of 
your $\mathrm{k}-3$ teachers well in advance of the planned start of the program in your school. Then, hold a brief meeting to explain the purpose of the program, review program activities, and discuss what will be expected of the teachers. Emphasize the importance of closely following the Instructor's Guide in all activities and tell them when they will receive the class materials.

If Option Three has been selected, all your $\mathrm{k}-3$ teachers will attend a day of training in program administration before the start of school. If possible, you should also attend the training course.

\section{Performing an Inventory of Program Materials}

The training program coordinator will send you a complete package of all program materials that will be used exclusively by your school. Some of these materials will be divided into sets--one set for each class participating in the program. The remainder of the materials are to be shared among all participating classes in your school.

\section{Class Materials}

Each class set will contain:

1. One Instructor's Guide.

2. Two packages of yellow safety tokens (500 to a package).

3. One Progress Chart.

4. One roll of masking tape.

5. Parents' Pamphlets (one for each child in the class).

6. Safety Certificates (one for each child in the class).

7. Sew-on Safety Badges (one for each child in the class).

Distribute one set of these materials to each teacher and instruct them to inventory their materials. You will be given several extra sets to allow for loss or damage. If you find that any of these materials are missing, notify your training coordinator.

\section{School Materials}

Some of the materials which are needed to administer the program will be shared by all $\mathrm{k}-3$ classes in your school. These materials include:

1. One street safety film, entitled "Don't Dart-Out." 
2. One set of pusharound model cars (three cars to a set).

3. One set of street safety barricades and signs (two barricades to a set).

4. Three sets of game materials.

Each set of game materials consists of:

1. One set of balls (one red ball and one blue ball).

2. One set of wastebaskets (one each--pink, blue, white).

3. One set of plastic chips ( 75 blue chips and 75 red chips).

4. One "Follow-the-Leader Game" rope.

These materials should be stored in a central location that will be easily accessible to the teachers but will not be disturbed by the children. If any of this equipment is missing or damaged upon receipt, notify your training coordinator immediately.

\section{Scheduling Program Sessions}

\section{Initial Training}

Initial training sessions must be closely spaced in order to provide effective initial learning. To ensure efficient use of school materials, smooth coordination of all program activities and prompt completion of initial training, you should devise a session schedule for each of your $\mathrm{K}-3$ classes.

If your school system has elected to have specialists from outside your school conduct the training, the coordinator will work with you in scheduling when training will be conducted in your school. If training is being performed by a teacher or teachers within your school, you have somewhat more freedom concerning when the program will be conducted.

In any case, it is generally best to complete the program as early in the school year as possible. The onset of cold weather is an important reason for early completion. The later in the year the program is begun, the greater chance of bad weather interfering with the outdoor sessions. If you live in a cold weather climate, be sure to schedule the conduct of the program so that all sessions are completed before cold weather is likely to be a problem. Alternatively, the initial training may be scheduled for the spring. However, refresher training should always be performed in the fall when school re-opens after summer vacation.

Depending upon the number of $\mathrm{K}-3$ classes in your school, administration of initial training may require from two to five weeks to train all classes at the same time. An average school can usually complete the 
Initial training sessions, including a make-up session in three to four weeks. Since each session is to take about 45 minutes, you can probably schedule one class session for each period and six classes per day.

Session 1 should be administered to all $\mathrm{K}-3$ classes at the same time. The safety film should be shown to all classes in the gymnasium, auditorium, or other central location. Then each class should have streetcrossing demonstration and practice in their individual classrooms. All future classes should take place in a large area such as the gymnasium, auditorium, or lunchroom. Classrooms are not suitable for the other sessions, as a large uncrowded area is necessary for the proper use of the pusharound cars. The program materials are not difficult to set up or store and will not interfere with the use of the area for other activities when program sessions are not in progress. It will, of course, be necessary to carefully schedule the use of this area as well as the use of the equipment.

If possible, Kindergarten classes should be scheduled every day or every other day; older grades two or three times a week. When you schedule the training for first-, second-, and third-grades, skip a day or two between each session.

Outdoor sessions must sometimes be delayed due to rain. In that case, the teacher should repeat an indoor session during the time scheduled for outdoor sessions (to maintain continuity), and perform the outdoor session at the earliest possible opportunity. Therefore, there may be some deviations from your schedule due to bad weather. However, the deviations should only involve substituting an indoor for an outdoor sessions and extending the length of the program, not missing any scheduled sessions. The outdoor sessions are extremely important as they provide opportunities for the children to practice the safe street-crossing sequence under reallife conditions: Do not skip any of the outdoor sessions.

When you have finished your master schedule, showing the day and time for each class to participate in each session ${ }^{1}$, make an individual class schedule for each teacher. The individual schedules should cover the entire initial training (including make-up sessions), and should tell the teacher the day and time he/she is scheduled for each session. A sample chart for scheduling sessions among 10 classes is given below.

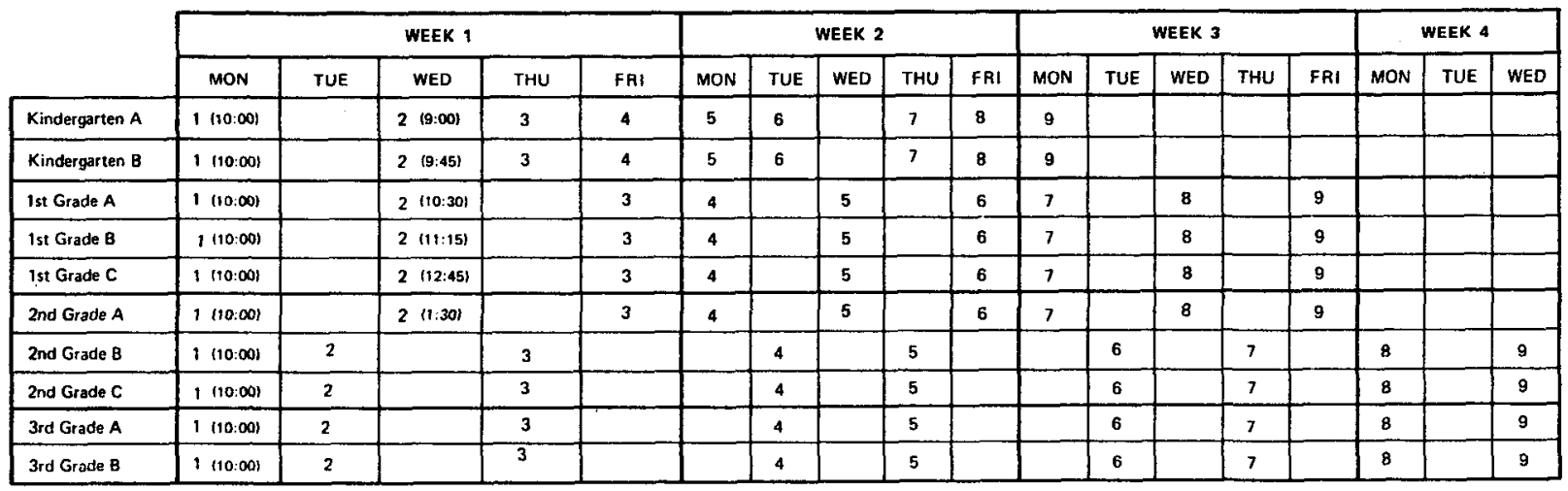

loutside sessions may take longer for each individual class if you include walking time to and from the street location where the session is conducted. 
The following is a sample of a schedule for an individual class:

$\begin{array}{lll}\text { Session } 1 \text { - Monday, September } 8 & (10: 00) \\ \text { Session } 2 \text { - Tuesday, September } 9 & (9: 00) \\ \text { Session } 3 \text { - Thursday, September 11 } & (9: 00) \\ \text { Session } 4 \text { - Friday, September 12 } & (9: 00) \\ \text { Session } 5 \text { - Monday, September 15 } & (9: 00) \\ \text { Session } 6 \text { - Tuesday, September 16 } & (9: 00) \\ \text { Session } 7 \text { - Thursday, September 18 } & (9: 00) \\ \text { Session } 8 \text { - Friday, September 19 } & (9: 00) \\ \text { Session } 9 \text { - Monday, September 22 } & (9: 00)\end{array}$

\section{Follow-on Sessions}

The importance of follow-on sessions cannot be overestimated. You should make every effort to ensure that follow-on activities are performed by the teachers in your school on a continuing basis.

Make certain that teachers are aware that they must perform follow-on sessions shortly after completion of both initial and refresher training, as we11 as throughout the school year. Kindergarten and first-grade classes should perform follow-on activities every two weeks, second-and third-grade classes at least once per month. Draw up and distribute a schedule for each month.

If Option One or Two is chosen, follow-on sessions will be the first program activities which the teachers are called upon to perform themselves, without the aid of a specialist or specially-trained teacher. Therefore, they may need assistance and guidance. When you distribute the monthly follow-on schedule, you should also give each teacher a copy of the "Coordinator's Follow-on Memo." Your coordinator will send you copies of this memo which will include reminders of the importance of follow-on activities, accident news, and suggestions for new follow-on activities. Every two months, each principal should submit a report to the coordinator on the type of follow-on activities performed in his/her school, and their frequencies. If any of your teachers devises a new activity that is successful, include that information in your memo. It may become part of the next "Coordinator's Follow-on Memo."

If teachers wish to perform outside sessions that will involve blocking off the street, they should inform you so that you can make appropriate arrangements. Encourage your teachers to choose a broad range of activities.

Any time a teacher wishes to perform an extra follow-on session or incorporate follow-on activities into other activities, he or she should feel free to do so. A sample follow-on schedule is given below. 


\section{Week 1}

Kindergarten $A$ Kindergarten $B$ First-Grade A First-Grade B First-Grade $C$ Second-Grade A Second-Grade B Second-Grade C Third-Grade A Third-Grade B
Mon. 10:00

Tues 10:00

Wed. 10:00

Thurs. 10:00

Fri. 10:00
Week 2

Mon. 10:00

Tues. 10:00

Wed. 10:00

Thurs. 10:00

Fri. 10:00
Week 3

Week 4

Mon. 10:00

Tues. 10:00

Wed. 10:00

Thurs. 10:00

Fri. 10:00

\section{Refresher Training}

Refresher training is an abbreviated form of the program designed to reestablish the behavior sequence after the summer vacation. In the second and subsequent years of the program, only the Kindergarten classes will be involved in initial training. Grades $1-3$ will receive a three session refresher training course. Session 1 will involve reshowing the safety. film, "Don't Dart-Out," and may be done concurrently with Session 1 of the Kindergarten initial training. Session 2 is an indoor session, Session 3 an outdoor session. Refresher training should be scheduled for the same period as initial training for the Kindergartners.

The interval between refresher training sessions can be one, two, or three days. As refresher training consists of only three sessions, scheduling should not be difficult. A sample schedule, showing initial training for the Kindergarten classes, and refresher training for grades $1-3$, is provided below. If you know of an upcoming trip to the library, nature walk, etc., that would provide natural opportunities for practicing the behavior sequence, discuss this with the teachers.

\begin{tabular}{|c|c|c|c|c|c|c|c|c|c|c|c|}
\hline & \multicolumn{5}{|c|}{ WEEK 1} & \multicolumn{5}{|c|}{ WEEK 2} & \multirow{2}{*}{$\frac{\text { WEEK } 3}{\text { MON }}$} \\
\hline & MON & TUE & WED & THU & FRI & MON & TUE & WED & THU & FRI & \\
\hline Kindergarten $\mathrm{A}$ & $1(10: 00)$ & $2(9: 00)$ & & $3(9: 00)$ & $4(9: 00)$ & $5(9: 00)$ & 6 & & 7 & 8 & 9 \\
\hline Kindergarten $\mathrm{B}$ & 1 (10:00) & $2(9: 45)$ & & $3(9: 45)$ & $4(9: 45)$ & $5(9: 45)$ & 6 & & 7 & 8 & 9 \\
\hline 1st Grade A & $1 R(10: 00)$ & & $2 R(9: 00)$ & & $3 \mathrm{~A}(10: 30)$ & & & & & & \\
\hline 1st Grade B & IR $\{10: 00\}$ & & $2 \mathrm{R}(9: 45)$ & & $3 R \quad(11: 15)$ & & & & & & \\
\hline Ist Grade C & $1 \mathrm{R}(10: 00)$ & & $2 R(10: 30)$ & & 3R (12:45) & & & & & & \\
\hline 2nd Grade A & 1月 $(10: 00)$ & & $2 R(11: 15)$ & & $3 R(1: 30)$ & & & & & & \\
\hline 2nd Grade B & TR $(10 ; \infty)$ & & & $2 R(10: 30)$ & & $3 R(10: 30)$ & & & & & \\
\hline 2nd Grade C & IR (10:00) & & & 2R (11:15) & & $3 R$ (11:15) & & & & & \\
\hline 3rd Grade A & 1P (10:00) & & & $2 R(12: 45)$ & & $3 R$ (12:45) & & & & & \\
\hline 3rd Grade B & IR $(10: 00)$ & & & $2 A(1: 30)$ & & $3 R(1: 30)$ & & & & & \\
\hline
\end{tabular}

An individual class schedule might look like this:

First-Grade B - Mrs. Jones

Refresher Session 1 Refresher Session 2 Refresher Session 3
Monday, September 10 10:00

Wednesday, September $129: 45$

Friday, September $14 \quad 11: 15$ 
New Students

In the first year of your school's participation in this safety training program, every Kindergarten through third-grade class will be receiving the initial training. In all subsequent years, all but the Kindergarten classes will be receiving only refresher training. This may create a problem for first-, second- and third-grade students who are new to your school and have not previously been exposed to the initial training. Refresher training will not be sufficient to bring the new students to the same skill level as the other children. The new children must be given additional training.

Your teachers will inform you of the number of new students in their classes. There are several ways of handling these students.

1. They may take refresher training with their classes, then get a minimum of three extra sessions in a special class of all the new students. They would receive badges and certificates at the end of the three extra sessions.

2. You may arrange for the special class to receive the entire initial training program.

3. The new students may attend the initial training sessions being given in the Kindergarten classes.

Whichever method you choose, each student will be able to participate fully in the training program. Your training program coordinator can supply you with extra badges and certificates for those new students who weren't originaly scheduled for initial training.

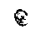

Arranging for Assistants

All the training sessions except Session 1 are designed to be performed with the assistance of another adult. One person cannot supervise and reinforce the program adequately. If a specialist has been assigned to your school, or one teacher is serving as instructor to all the classes, the individual classroom teachers should act as assistants. This will provide them with the valuable experience they need for conducting follow-on activities.

If the classroom teachers are in charge of administering the program to their classes, it will be necessary to find and schedule assistants. Your usual school aides, parent or community volunteers, or older (i.e., high-school aged) students may be employed. Be sure to provide each assistant with a copy of the Instructor's Guide. The assistants should be thoroughly familiar with the Guide before starting to help with the sessions. 
Where to Administer the Sessions

\section{Inside Sessions}

Al1 the inside sessions, except Session 1, should be administered in the gymnasium, auditorium or other suitably large area. The equipment can easily be stored away when the room is needed for other purposes. The program requires a large open space for proper use of the pusharound cars and effective game activities.

\section{Outside Sessions}

The last three sessions in the program [plus the make-up session(s)] are games which are to be played outside using a real street. These sessions are extremely important to provide the children with practice under real-life conditions. To ensure the children's safety, the street must be blocked at both ends, and the site must meet some general requirements. It will be your responsibility to choose the sites for the games. Each location must meet the following requirements:

1. Midblock location. The site for the game must be at least 20 feet from the nearest intersection.

2. Narrow residential street. Try to find a two-lane street in a residential area. Not only will the traffic be more moderate, but commercial establishments would resent any road-blocking.

3. Two-way traffic flow.

4. Normal/1ight traffic flow.

5. Traffic speed of $30 \mathrm{mph}$ or less.

6. Close to school. Remember that some of the children are only five years old and a long walk might tire them. Also, time spent walking is time not spent practicing.

7. Not a bus route. This applies to both school bus routes and any local mass-transit. The police probably will not allow any road to be blocked that is part of a commercial public bus route. The same would apply for school buses. Even if permitted, removing the road blocks for every bus would cause too much interruption and trouble for the teacher.

8. Convenient alternate (detour) routes. Try to choose a site where the road can be blocked at the intersection, and where it will be convenient for oncoming traffic to select an alternate route. The signs on the barricades have moveable arrows to direct traffic to an alternate route. 
9. Enough space for playing games. Each game requires approximately 40 feet of free space on one side of the street.

10. Presence of parked cars at the site. One of the games requires that two parked cars be present at the game site. Most residential streets allow parallel curb parking, so this shouldn't be a problem.

Ideally, it would be best to choose three different streets, so that each game could be played in a different environment. If not, the same location or street could be used twice by having the children play on a different side of the street each time; or, if the street is long, a different segment on the same side could be chosen.

\section{Obtaining Municipal Cooperation}

After you have chosen probable street locations for playing the outside games, your next step will be to secure permission from the appropriate municipal authorities to block the streets. Your training program coordinator can assist you with this task.

Make a complete list showing dates, times, and complete locations for each day you need to block a street. For example: May 28 - 10:00 a.m. 3:00 p.m. - Oak Street between E1m and Maple.

Your training program coordinator will provide you with the name, title, address, and phone number of the appropriate person to contact to obtain permission to block the streets. Call this person at least three weeks in advance of the first date you need to block the street. Briefly explain the purpose of the street safety program and emphasize that you want only permission to block the streets; your school will supply the necessary roadblocks and detour signs. You probably will be asked to send a complete list of dates, times, and locations to his/her department. It is a good idea to do this anyway so that there will be no confusion about when and which streets are to be blocked. Try to obtain written permission from this person, in case you might be questioned later by officers on patrol. If you have any problems, contact your training program coordinator for assistance.

A second call should be made to the appropriate department if school crossing guards are to be stationed at the barricades during the outside games. Again, your training program coordinator will provide you with the name, title, address, and phone number of the correct person to contact. The guards are to be stationed at the barricades to ensure that no motorists enter the "game area." Most cities have full-time and part-time guards, and will assign you guards whenever possible to help with the games. Follow the same procedure as you did to obtain permission to block the street. Explain the importance of the street safety program and follow this up with a letter giving dates, times, and exact locations where you would like to have the guards. You will need two guards for each day. 
If your city is unable to provide complete or partial guard protection, arrange to have others help at the barricades. You might try to get volunteers from the PTA, or ask parents of children participating in the program to help. If parents are unavailable, older children or members of your school safety patrol could guard the barricades and streets during their study hall periods.

\section{Blocking the Street}

On days that the streets are to be blocked, set up the barricades about 20 minutes in advance of the first session. Place the barricades and signs in the middle of the street to block the street as completely as possible. This will minimize the chances of anyone "running" the barricades. Station one crossing guard at each barricade. The crossing guards should be instructed to:

- Set the moveable arrows on the barricade signs to show the proper direction(s) for motorists: to detour.

- Flag down motorists who don't detour.

- Instruct those motorists who must use the street to proceed at $20 \mathrm{mph}$ or slower, and explain to the motorists that children are in the street.

- Warn the the teacher and class when a car does come down the street without stopping for the barricade.

When all the sessions for any day have been completed, and all of the children are inside, have the barricades taken down and brought back into the school. 


\title{
ANSWERING PARENT'S AND TEACHER'S QUESTIONS \\ CONCERNING THE PROGRAM
}

\author{
The questions asked most often by parents and teachers are: \\ 1. Won't this program negate traditional safety lessons \\ that teach children to cross at the corner? Is it right \\ to teach children to cross midblock? \\ 2. Are we teaching the children to jaywalk? \\ 3. Doesn't this program take more time than other child \\ pedestrian safety programs?
}

This Program Versus Traditional Child Pedestrian Safety Messages

This program is in no way designed to counteract the important "crossat-the-corner" and cross-at-the-1ight" lessons that children must learn. However, we want to be sure that if a child enters the street for any reason, he does so safely. Over one-half of all child pedestrian accidents are dart-out types. It is becoming widely recognized that in real-life situations, children will enter the street midblock while playing. For example, no amount of intersection crossing training will prevent a child from running into the street to retrieve a ball. This program emphasizes crossing safely under all conditions, especially at those times when it is extremely impractical and unlikely that the child would go to the intersection to cross.

\section{Does This Program Encourage Jaywalking?}

In most cities, jaywalking ordinances prohibit midblock crossing only between adjacent signalized intersections, in business districts, within 150 feet of a crosswalk, or under other specialized conditions usually associated with busy commercial areas. These rules do not usually apply to the residential areas with which we are concerned. We are trying to prevent the accident that occurs when a child is playing by a residential street near his home.

In addition, jaywalking ordinances are of ten not enforced. Al though some cities have strict jaywalking laws, they are not enforced except in busy downtown areas or selected problem districts (i.e., near a college 
campus). Law enforcement officials usually take the position that these strict laws are needed and enforceable only in busy, heavy traffic areas.

If you are in any doubt about the applicability or enforcement of jaywalking ordinances in your area, consult your coordinator. He/she is in contact with local law enforcement officials and will be able to answer your questions.

The Time Required to

Administer the Program

Teachers may also be concerned with the amount of time that the program requires. Such an intense training program is necessary to ensure complete learning and retention. Mere exposure to safe street crossing concepts is not enough. Typical child pedestrian safety programs are very brief, usually two to four hours per year. Such programs provide only a basic familiarity with the ideas behind safe street crossing. Although such theory is valuable, young children need practice and reinforcement to develop actual street crossing skills to apply to real-life situations. If the program is to reduce accidents, it must be properly taught and reinforced and this, of course, takes time.

The time requirements of the program may be lessened by combining program activities with recess, physical education classes, and other school activities.

In answering teacher's questions concerning the program time requirements, emphasize the continuing nature of the program and the fact that refresher training and follow-on activities are less time consuming than the initial training. There is a tendency for teachers to believe the program is over after initial training. This is far from true and the importance of the refresher training and follow-on activities should not be minimized. 
APPENDIX C

INSTRUCTOR'S GUIDE

C-1 

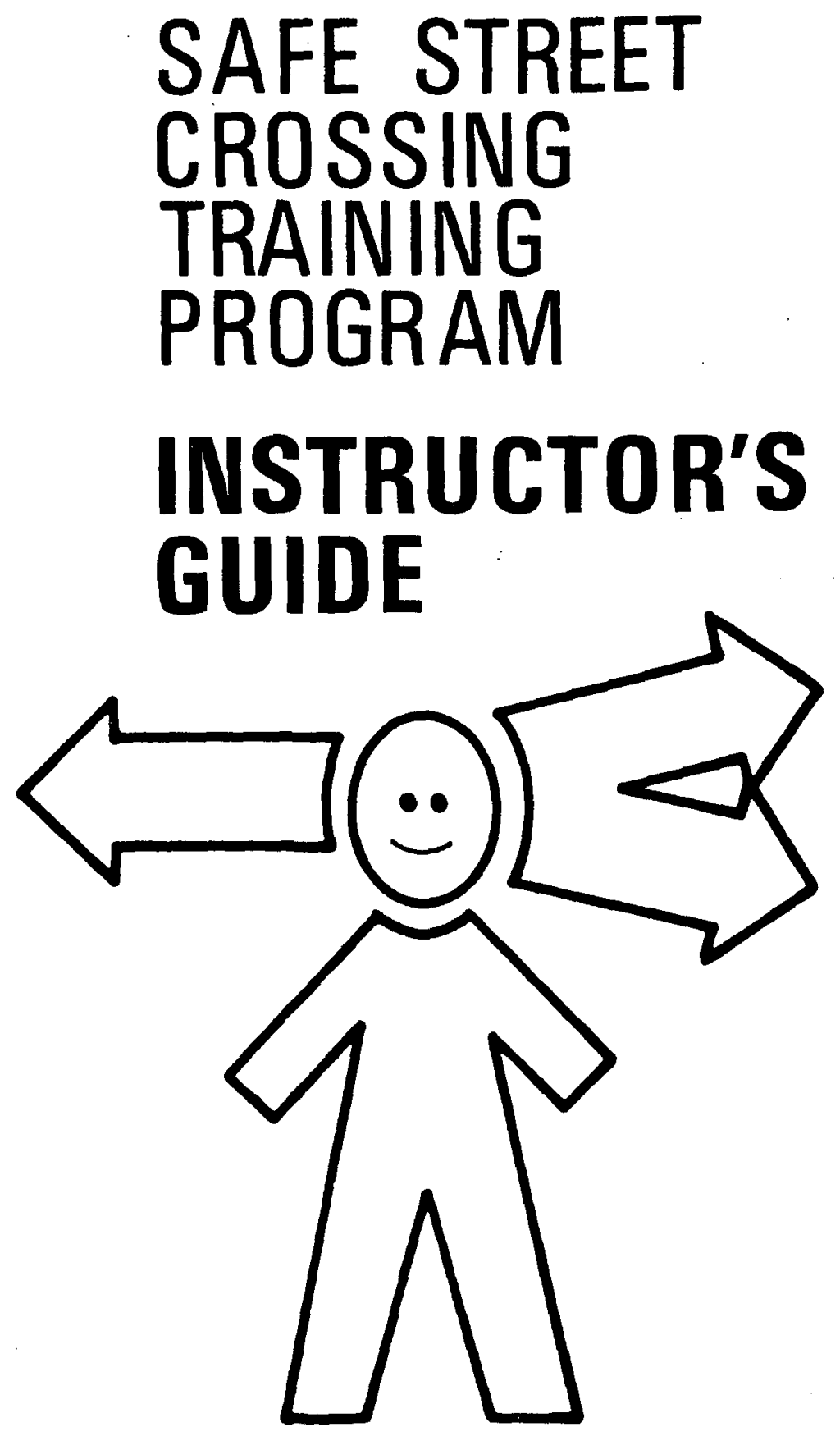

U. S. DEPARTMENT OF TRANSPORTATION Contract No. DOT-HS-4-00955 
TABLE OF CONTENTS

Page

HOW TO USE THIS GUIDE . . . . . . . . . . . . . . . . iii

INTRODUCTION ............................. 1

Why the Program Was Developed ............. 1

Program objective ................. 2

Summary of the Program ............... 3

Initial Training ................. 3

Follow-on Sessions .............. 4

Refresher Training ............. 4

PREPARING AND ADMINISTERING THE PROGRAM . . . . . . . . . 5

Filling Out Progress Charts . . . . . . . . . 5

Collecting Required Materials .............. 5

Class Materials................ 5

School Materials .................. 6

Sending Home the Parents' Pamphlets . . . . . . . . 6

Scheduling Sessions ................ 6

Arranging for an Assistant ............ 7

Other Safety Programs ............... 7

PREPROGRAM ACTIVITIES . . . . . . . . . . . . . . 9

Safety Discussion . . . . . . . . . . . . . 9

Other Activities (Optional) ............ 10

SESSION 1: INTRODUCTION AND PRACTICE . . . . . . . . . 12

SESSION 2: PRACTICE AND REWARDS . . . . . . . . . . . 14

SESSION 3: INSIDE PRACTICE, "BALLTOSS GAME" . . . . . . . 17

SESSION 4: INSIDE PRACTICE, "CHIP GAME" . . . . . . . . . 22

SESSION 5: INSIDE PRACTICE, "FOLLOW-THE-LEADER GAME" • • • • • 26

SESSION 6: OUTSIDE PRACTICE, "BALL-TOSS GAME"

SESSION 7: OUTSIDE PRACTICE, "CHIP GAME" . . . . . . . . . 32

SESSION 8: OUTSIDE PRACTICE, "FOLLOW-THE-LEADER GAME" • • • • • 34

SESSION 9: MAKE-UP SESSIONS . . . . . . . . . . . . 36 
TABLE OF CONTENTS (Continued)

Page

AWARDING THE SAFETY BADGES AND CERTIFICATES . . . . . . . 37

FOLLOW-ON ACTIVITIES . . . . . . . . . . . . 38

REFRESHER TRAINING ................... 43

REFRESHER SESSION 1: RE-INTRODUCTION AND PRACTICE . . . . . . 44

REFRESHER SESSION 2: INSIDE PRACTICE, "BALL-TOSS GAME" . • • . . 46

REFRESHER SESSION 3: OUTSIDE PRACTICE, "FOLLOW-THE-LEADER

GAME" ............... 49

REFRESHER FOLLOW-ON ACTIVITIES . . . . . . . . . . . 51

LIST OF FIGURES

Figure $\quad$ Page

1 Safety Badge, Suitable for Coloring . . . . . . . . 11

2 Diagram of Playing Area--"Bal1-Toss Game" . . . . . . 18

3 Children Playing "Ba11-Toss Game" . . . . . . . . . 20

4 Diagram of Playing Area--"Chip Game" . . . . . . . 23

5 Diagram of Playing Area--"Follow-The-Leader Game" . . . . 27 
HOW TO USE THIS GUIDE

This program is designed for children between the ages of five and nine, i.e., grades Kindergarten through three. If the children in your class have not had the program in previous years, you should administer the full program, i.e., the preprogram activities, the eight (or nine) program sessions, and follow-on sessions. If most of your children have been previously exposed to the full program, refresher training and subsequent follow-on activities will be required as described in the last section of the guide.

If you unfamiliar with the Safe Street Crossing Training Program, you should first read this guide from front to back, paying particular attention to the Introduction. Thereafter, before you perform any program activity, study the section relating to that activity. In preparing for a program session, be sure to allow yourself enough time to become thoroughly familiar with the session instructions and to gather any materials you may need. 
INTRODUCTION

Why the Program Was Developed

Statistics show that each year there are approximately 400,000 pedestrian accidents, many of them involving children. Every year, 3,000 children are killed in pedestrian accidents. While some of these accidents are undoubtedly the fault of the driver, or due to some mechanical failure in the automobile, far too many of the accidents occur because the children were unaware of the correct procedures for safely crossing the street.

Over one-half of all child pedestrian fatalities are attributed to dart-out accidents. A dart-out occurs when the child enters the street at midblock, often from between parked cars. He may be chasing a ball, running to an ice cream vendor, or responding to a friend's or parent's ca11. Often, when he enters the street, he fails to search and wait for approaching traffic, and this can result in an accident.

In the past, parents and school programs have either neglected to teach safety procedures, or have attempted to correct the child's behavior by scolding or punishing the unsafe behavior. They have also tried to warn children of the potential dangers of running into the street. These methods simply do not work, largely because the children are just too young to fully comprehend the danger associated with the situation.

The Safe Street Crossing program uses an entirely different approach. Instead of merely telling the children what not to do, the program provides learning experience in which the child actualiy practices the correct procedures to safely cross the street. The program's objective is to train the children to perform simple behaviors which maximize their chances of detecting and avoiding approaching vehicles when they enter the street at midblock locations.

The children will learn to stop and look every time they walk into any type of street. This is accomplished by the use of guided practice in the classroom and safety games. These games provide opportunities for children to practice safety behavior in situations much like those they actually encounter when playing near the street. The games will be played both in the classroom with simulated street surroundings, and on a "real-world" street where traffic is carefully controlled. As a reward for learning good safety habits, the children will earn a safety patch, and receive a signed certificate attesting to their achievements. 


\section{Program Objectives}

The main objective of the Street Safe Crossing Program is to teach children a simple set of procedures that, when learned, will prevent them from darting out into the street in front of an automobile. A detailed description of the safe street crossing sequence that the children will be taught follows:

1. a. Stop at the edge of the curb or road, if there are no parked vehicles,

or

b. If parked vehicles are present, stop at the boundary between the parking lane and traffic--beyond the parked vehicles, but still close enough to touch them.

2. Turn head and eyes to the left so that the visual field includes all of the left traffic lane, and look for left-approaching traffic.

3. Turn head and eyes to the right so that the visual field includes all of the right traffic lane, and look for right-approaching traffic.

4. Turn head and eyes to the left again, so that the visual field includes all of the left traffic lane, and check to be sure that the street is still clear.

5. a. Enter the street (if no cars are detected),

or

b. If a car is detected, wait for the car and track it until it has passed. Repeat the left-right-left searches before entering the street. (Perform this step as many times as necessary until the street is clear.)

All five of these steps and only these five steps constitute the correct sequence. In conducting the program, you should reward the children for performing these steps correctly and in sequence. DO NOT reward the children for any of the following:

1. Performing only PART of the sequence (e.g., looking only left-right and failing to look left again).

2. Performing a step or steps incorrectly (e.g., not stopping).

3. Performing extra steps (e.g., looking L-R-L-R-L). 
4. Performing a step out of sequence (e.g., starting to search before stopping).

Unless you are consistent in determining what the correct safety procedures are (and reward only the five properly performed steps in the proper sequence), the children will become confused, you will get confused, and the effectiveness of the program will suffer.

The children practice the sequence in each of the program sessions. It is recommended that each child attend at least six program sessions in order to earn his patch and certificate.

\section{Summary of the Problem}

The Safe Street-Crossing Training Program involves the following major elements :

\section{Initial Training}

A set of 10 activities given to all $\mathrm{K}-3$ students during the first year of the program and, in subsequent years, only to the Kindergartners. These activities are:

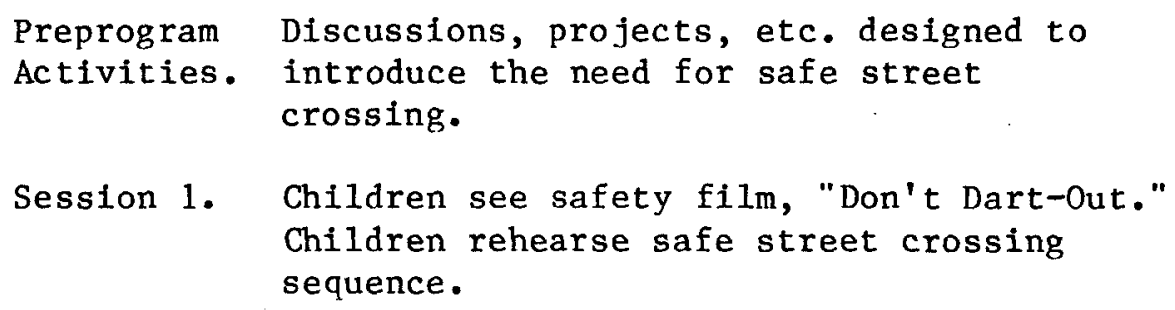

Session 1. Children see safety film, "Don't Dart-Out." Children rehearse safe street crossing sequence.

Session 2. Kindergarten and first-grade children see film again. All children practice behavior sequence. Tokens are given for correct performance.

Session 3. Children play the "Ball Toss Game" in the gymnasium, or any other suitably large area.

Session 4. Children play the "Chip Game" in the gymnasium, or any other suitably large area.

Session 5. Children play the "Follow-the-Leader Game" in the gymnasium or any other suitably large area.

Session 6. Children play the "Ball Toss Game" outside at the street. 


\author{
Session 7. Children play the "Chip Game" at the \\ street. \\ Session 8. Children play the "Follow-the-Leader Game" \\ at the street. \\ Session 9. Optional session repeating Sessions 6, 7, \\ or 8 , where additional practice is \\ desired.
}

\title{
Follow-on Sessions
}

Periodic training sessions, similar to the initial training sessions which are conducted throughout the school year (monthly for second and third graders, biweekly for Kindergartners and first graders).

\section{$\underline{\text { Refresher Training }}$}

A set of three training sessions given in subsequent school years to children who have completed the initial training to re-emphasize the safe street-crossing behaviors. These sessions are:

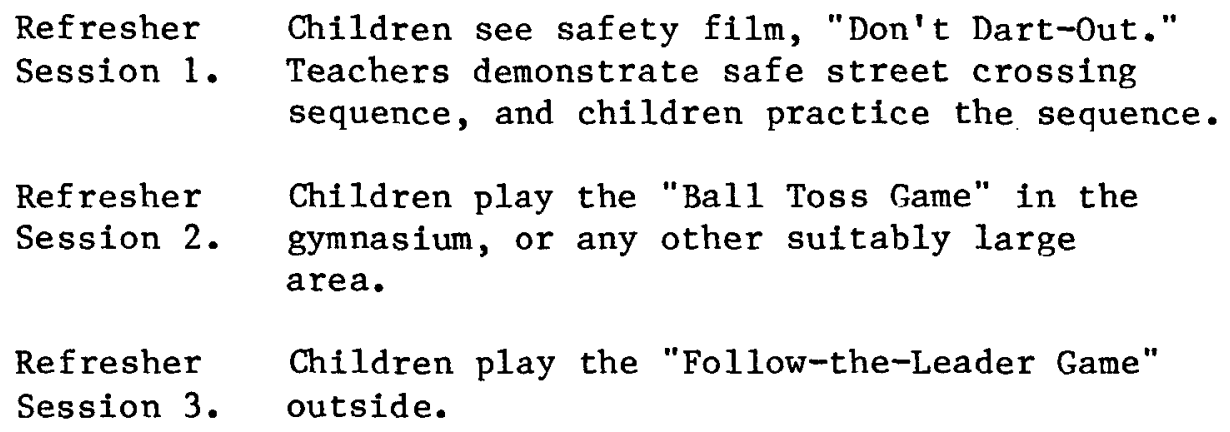

Monthly or bi-weekly follow-on sessions continue throughout the school year following refresher training. 
PREPARING AND ADMINISTERING THE PROGRAM

There are several things you should do before beginning the program. These activities include: (1) filling out a progress chart, (2) collecting all required materials, (3) sending home Parents' Pamphlets, (4) scheduling program activities, and (5) arranging for an assistant.

\section{Filling Out Progress Charts}

A progress chart is provided with your program materials. Before beginning the scheduled sessions, you should fill out the chart for the class. Fill in the names of each child in the class in the spaces under the left-hand column marked "Name." Your name and classroom number go in the appropriate blanks. There are nine columns remaining, one for each of the regular and makeup practice sessions. Following each session, every child should receive a check for that session opposite his name. Hang the chart in a conspicuous place in the classroom. You might have the children mark checks after their names following each session so that they are aware they must receive these checks to receive their safety badges. Between sessions, leave the chart where the children can see it. At the end of the program, when the chart is filled (or almost filled), each child receives the safety patch and certificate.

\section{Collecting Required Materials}

Each class should receive a set of program class materials. You will need these materials to teach the sessions. In addition, other required materials will be shared by all the participating classes in the school. The principal will have them stored in a central location. The materials you need for each session are listed in the description of each session later in this guide. Below is a complete listing of all the materials required for the safety training program. Check to be sure that the class has all the class materials and that the school materials are available.

\section{Class Materials}

Two packages of yellow Safety Tokens (500 to a package)

One Progress Chart

One roll of masking tape (two-inch)

Parents' Pamphlets (one for each child in your class)

Safety Certificates (one for each child in your class)

Sew-on Safety Badges (one for each child in your class) 
School Materials

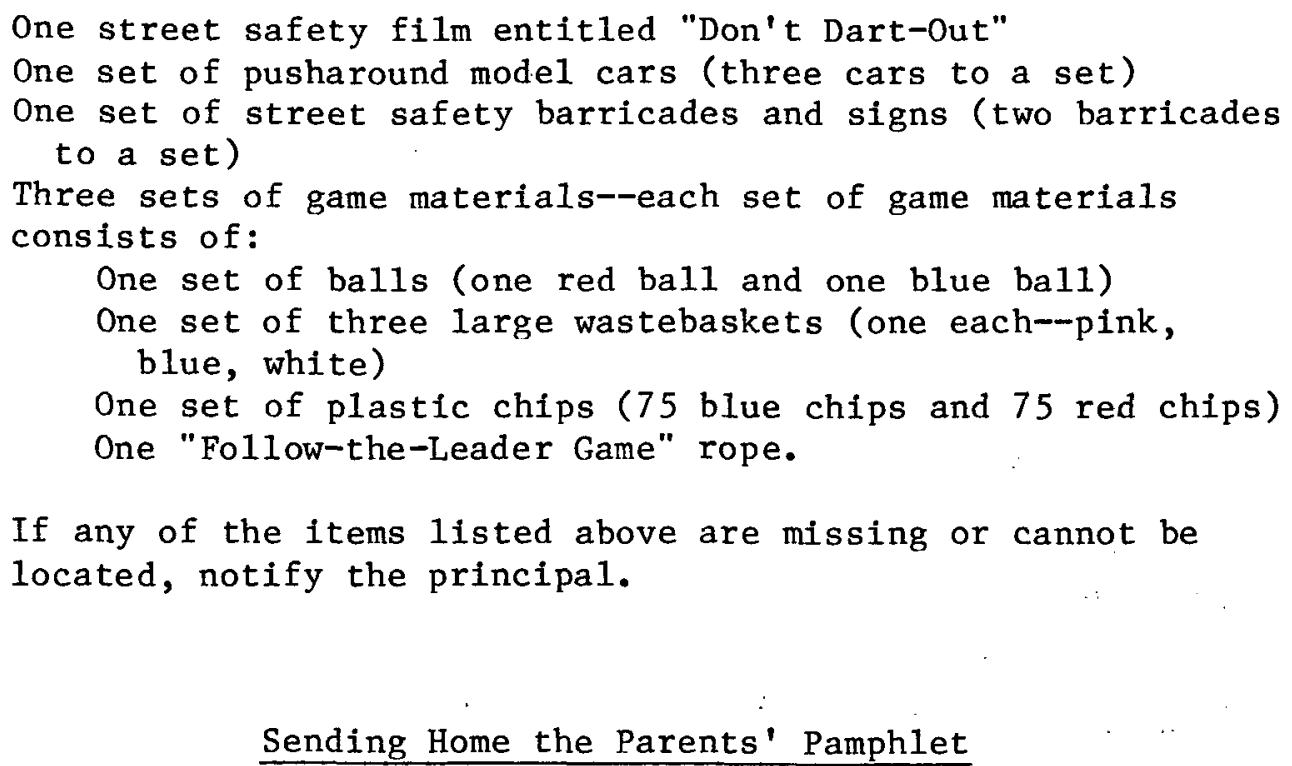

You have been provided with pamphlets which are to be distributed to the parents of all children participating in the program. These pamphlets briefly describe the program, and offer explanations of how the parents can help. You should send these pamphlets home with the children about three days before you administer the first session.

\section{Scheduling Sessions}

For a number of reasons, all scheduling of program activities should be coordinated through the principal or the person appointed to coordinate the program in the school:

1. Some of the program materials must be shared by all the classes in the school.

2. Except for Session 1, all program sessions should be, performed in a large central area such as the gymnasium or auditorium which must be shared by all classes and will probably be needed for other activities.

3. Since the outside sessions require blocking the street, sessions must be scheduled so that the street is blocked for as short a time (on as few occasions) as possible.

The principal will help you and the other teachers coordinate your schedules so that everyone has access to the materials and locations he or she needs. 
In genera1, Kinkdergarten classes should conduct sessions every day or every other day. The first- through third-grade classes should conduct sessions two or three times per week. About one hour should be allowed for outside sessions, including the walk to and from the street location where the session is conducted. Inside sessions should require about 45 minutes.

\section{Arranging for an Assistant}

It is important that you have someone to assist you in administering the sessions. Sessions 3 through 8 , in particular, are difficult to perform correctly without help. The principal will coordinate the scheduling of assistants.

If the classroom teacher is not administering the sessions, he/she should act as the assistant. In addition to: being the person best able to control the class, by assisting he/she will gain important experience in the conduct of the program which will be useful when he/she administers the follow-on training.

Assistants should be familiar with the sections of this guide pertaining to the sessions they are to help administer. If at all possible, you should have the same assistant for Sessions 3 through 8 .

\section{Other Safety Programs}

Either now or at some time in the past, the children in the class have probably been exposed to other safety programs. Typically, these programs will have taught children never to cross at midblock, but to always walk to the corner where there is a light or a crosswalk. Some parents may complain, and you might be wondering, "Won't this program teach children that it is 0.K. to cross at midblock?" The answer is definitely, "No!" This program is aimed at those times when the child is casually playing and carelessly runs into the street to greet a friend or chase a ball and not when he is planning to cross a street. When you're teaching this safety program, remind the children that the midblock safety behaviors are not substitutes for crossing at the intersections. Emphasize that this program is for those times when they don't go to the intersection because they are in the middle of playing. They should always cross at the corner when they are going somewhere (i.e., to school, to the store).

Although the primary purpose of this course is to teach safe midblock crossing behavior, you do not want to negate the "cross at the corner" concept that the children may have already learned. To prevent this, you 
may decide to include intersection practice as part of the training sessions. Such practice would, basically, involve:

1. For indoor sessions, setting up a simulated intersection and having the children cross with and without a signal light before and after the session.

2. For outdoor sessions, the teacher could have the class cross at an intersection going to and from the midblock practice area.

3. The child would be taught to cross with the 1ight after searching all directions and to search before crossing even though the crossing guard is present. 
Before you actually begin the program sessions, preprogram activities should be conducted to get the children interested in the safety theme. As a minimum, the safety discussion described below should be held, and the other optional activities are recommended.

\section{Safety Discussion}

Objectives of the Discussion.

1. To remind the children that streets are dangerous and must be crossed with caution.

2. To sensitize the children to the fact that pedestrian accidents have happened to people they know and could happen to them.

3. To review the pedestrian safety rules which are taught as a part of your school system's safety curriculum.*

Materials Required

None

Personnel Required

Instructor

Preparation Activities

None

Conduct of the Discussion

1. Explain how many children are hurt by cars.

2. Ask children to tell about experiences involving pedestrian accidents to themselves or friends.

*Your training program coordinator can provide you with guidance concerning what material should be covered. 
3. Explain dangers of running into the street, especially from between parked cars.

4. Review pedestrian safety rules. Explain that, although they should always try to cross at the intersections, there will be times when they may need to enter the street in the middle of the block and this program will teach them how to do this safely.

5. Ask children if they know how to cross streets safely, i.e., what they must do as they cross the street.

6. Explain and demonstrate the safe street-crossing sequence (as defined on page 2 ).

\section{Other Activities (Optiona1)}

Other suggestions for preprogram activities are as follows:

1. Have the children color the safety badge. A drawing is enclosed at the end of this section which you can trace and ditto. (Grades $\mathrm{K}-1$ ) (See Figure 1)

2. Have the children make their own street-crossing safety posters. You could turn this into a contest and award a prize or ribbon to the best ones. (Grades 2-3)

3. The children may have trouble discriminating their left from their right. If your class does not know left and right, you might spend a few days teaching the concepts of left and right, so that when you introduce the behavior sequence, there will be less confusion. One way of helping the children discriminate is to tie colored yarn around their left wrist. They can remember to look in the direction of the yarn first. 


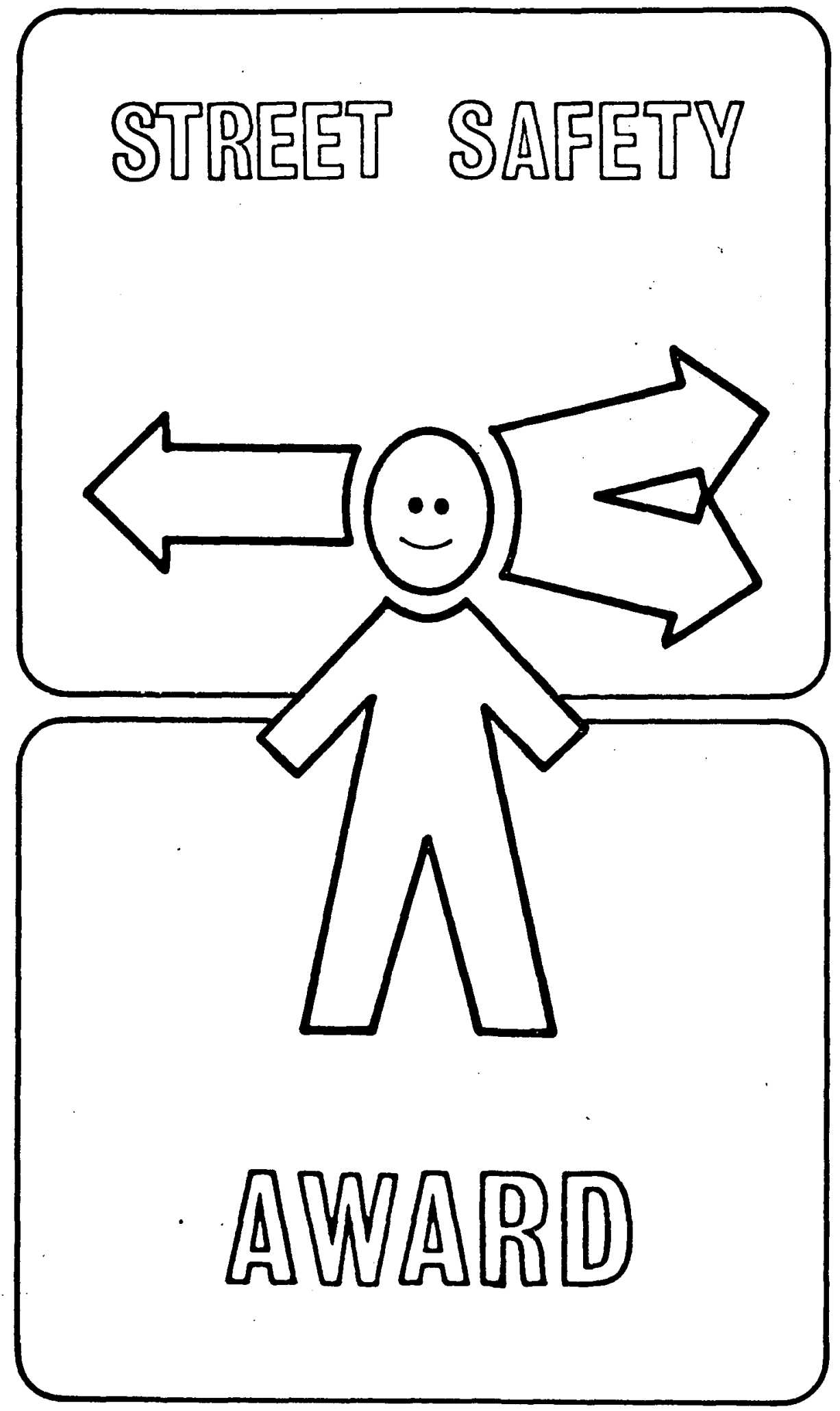

Figure 1. Safety Badge, Suitable for Coloring 
SESSION 1. INTRODUCTION AND PRACTICE

\section{Introduction}

The children are introduced to the safe street crossing sequence, and given a chance to practice that sequence.

Objectives of the Session

1. To introduce the safety training program.

2. To give the children guided practice in performing the behavior sequence.

\section{Materials Required}

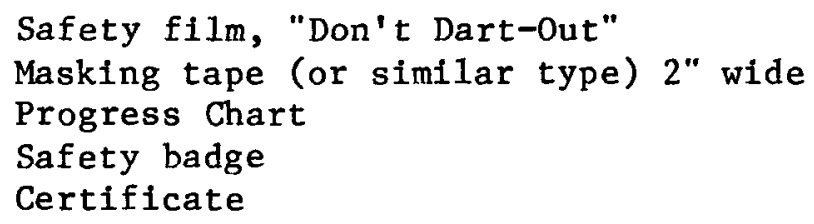

Personne1 Required

Instructor

\section{Preparation Activities}

1. Be sure you have filled out a Progress Chart for your class.

2. Put about ten feet of masking tape in a straight line, parallel and about three feet away from the doorway of the class. Put another 10 feet of masking tape in a parallel line about seven feet from the first line. The taped lines serve as curbs; the area in between is the "street."

\section{Conduct of the Session}

1. The film will be shown to all $\mathrm{K}-3$ classes at the same time in a central location. 
2. When you return to your classroom, show the class the Progress Chart and explain that they will earn a check each time the class practices, if they cross the street correctly. Then, show the safety badge and certificate and explain that if they can fill their chart with checks, they can each earn a badge and certificate.

3. With your back to the children, model the safe street crossing sequence, using the tape to serve as curb and street. Explain that, since no cars are in view, you can cross the street. Cross again, facing the children, and repeat the sequence. Mention that the reason you look to the left a second time is because the cars approach from that side. Emphasize that when you perform the sequence, you are looking for cars.

4. Guide each child through the safe street crossing sequence. As the child is performing, instruct him/her to say "left-right1eft." Do not let the child sit down until he/she is able to correctly perform the sequence.

5. Have the children choose partners. Instruct each pair to perform the sequence, saying "left-right-left." Make sure each member of each pair performs the sequence correctly before sitting down. Remind the children that even when they are with other children or adults they must always look.

6. Give each child a check opposite his name under Session 1 on the Progress Chart.

DOs and DON'Ts

1. DON'T let a child (or pair of children) finish their turn on an incorrect performance. Always have them do it correctly before they sit down.

2. Do physically and verbally guide each child through the sequence during his/her first performance.

3. Do have the children say aloud "left-right-left" every time they perform the sequence.

4. Do ask the children several times during the session what they are looking for.

5. Do impress on the children that they are learning to cross the street safely because "it is a good thing," not just to earn a badge.

6. Do be enthusiastic about the badge. The children must want to earn one. 
SESSION 2: PRACTICE AND REWARDS

\section{Introduction}

Session 2 provides further opportunities for the children to practice the behavior sequence. During this session, the children will receive safety tokens as a reward for correct performance. Two car mockups will serve as parked cars. The children must walk to the edge of the parked cars to perform the sequence and receive their tokens. This session and al1 future sessions should be performed in a large room such as the gymnasium, auditorium, or lunchroom.

Objective of the Session

To give children additional practice of the behavior sequence in a situation where they will be rewarded.

\section{Materials Required}

Three car mockups

Two-inch masking tape

Yellow safety tokens

Safety film, "Don't Dart-Out" (for $\mathrm{K}-1$ classes only)

\section{Personnel Required}

Instructor

\section{Preparation Activities}

1. The street area should be marked with tape as described in Session 1.

2. Be sure the film is ready for showing ( $K-1$ classes only).

3. Set up two car mockups in the "street," parallel to one curb to serve as parked cars.

\section{Conduct of the Session}

1. Show the safety film again ( $\mathrm{K}-1$ classes only). 
2. With your back to the children, model the correct behavior sequence, using the tape to serve as curb and street. Emphasize that when parked cars are present, you must walk to the boundary of the cars so you can see the street. Explain that, since no cars are in view, you can cross the street. Cross again, facing the children, and repeat the sequence. Mention that the reason you look to the left a second time is because the cars approach from that side. Emphasize that when you perform the sequence, you are looking for cars.

3. Show the children the yellow safety tokens. Explain that everyone who performs the sequence correctly will get a safety token which he/she can keep.

4. Ask each child to perform the behavior sequence. As the child is. performing, instruct him/her to say "left-right-left." Do not let the child sit down until he/she is able to correctly perform the sequence. When the child performs correctly without prompting, give him/her a token. Make sure he/she walks to the boundary of the parked cars.

5. Have the children choose partners. Instruct each pair to perform the sequence, saying "1eft-right-left." Make sure each pair performs the sequence correctly before sitting down. When the children perform correctly, give them safety tokens. Do not introduce the cars to the children until AFTER this point.

6. Introduce the cars into the situation in a low-key, serious manner. Explain that cars are a threat to children on the street, because children are much smaller than cars, and liable to get hurt.

7. Allow a11 the children to take turns "riding" in the cars today. Try to desensitize the children to the cars as much as possible. Explain to them that the cars will be in the street when they are trying to cross. Emphasize that the cars are not toys--they represent the threat of real cars.

8. Choose two children to serve as "cars" during practice. Give these children the car mockups and instruct them to move at a slow, even pace up and down the "street." Have them circle the room in opposite directions so that "cars" are not always on the "street" and gaps occur when it is safe to enter. (2-3 grade classes only)

9. Have each child perform the behavior sequence in the presence of moving cars. Make sure each child performs the sequence correctly before sitting down. When the child performs correctly, give him/her a safety token. Expect the children to be distracted by the cars, and reiterate that they are not toys. Change car drivers several times during the practice. (2-3 grade classes only)

10. Give each child a check opposite his name under Session 2 on the Progress Chart. 
1. DON'T present the cars as toys. Emphasize to the children that real cars are dangerous, and that children should ALWAYS be very careful in the presence of a moving car.

2. Do praise the children often as they perform the correct procedure.

3. DON'T ignore a child when he performs the correct sequence. When a child is ignored, he may stop performing correctly.

4. Do try to desensitize the children to the cars. The children are sure to be curious and excited when the cars are shown. Until the children become used to the cars, they will be distracted and will not concentrate on performing the sequence.

5. Do emphasize that the children are to listen to be sure the parked cars don't have their. engines running and look to be sure the parked cars aren't about to back up or puli out. 


\section{SESSION 3: INSIDE PRACTICE, "BALL-TOSS GAME"}

\section{Introduction}

This session is the first of the practice games sessions. The "Ba11Toss Game" is played by the children. The object of the game is to toss a ball into a basket. When the child misses the basket, the ball will usually roll out into the "street" area. The children must then perform the safe street-crossing sequence correctly before retrieving the ball.

The children will alternate the roles of oncoming cars and pedestrians. The pedestrian must stop at the curb (and at the boundary when parked cars are present), search adequately, and then cross the street. The children will gain tokens for appropriate behavior in the role of pedestrians. In a later session, the children will play the same game under controlled conditions in a "real life" street.

\section{Objective of the Session}

To provide opportunities for the children to practice the behavior sequence while entering the street to retrieve a ball.

\section{Materials Required}

Two-inch masking tape (or similar type)

Three mockup cars

One red bal1--three-inch diameter

One blue ball--three-inch diameter

One pink plastic wastebasket

One blue plastic wastebasket

Yellow safety tokens

\section{Personnel Required}

Instructor and Assistant

\section{Preparation Activities (See diagram of playing area, Figure 2)}

1. If not already done, follow the diagram in Figure 2. Place about 40 feet of tape in a straight line near the center of the room. This is to serve as a curb. Place another 40 feet of tape about 10 feet away from the first line, parallel to it. This is the other curb. The area in the middle will serve as a street. 


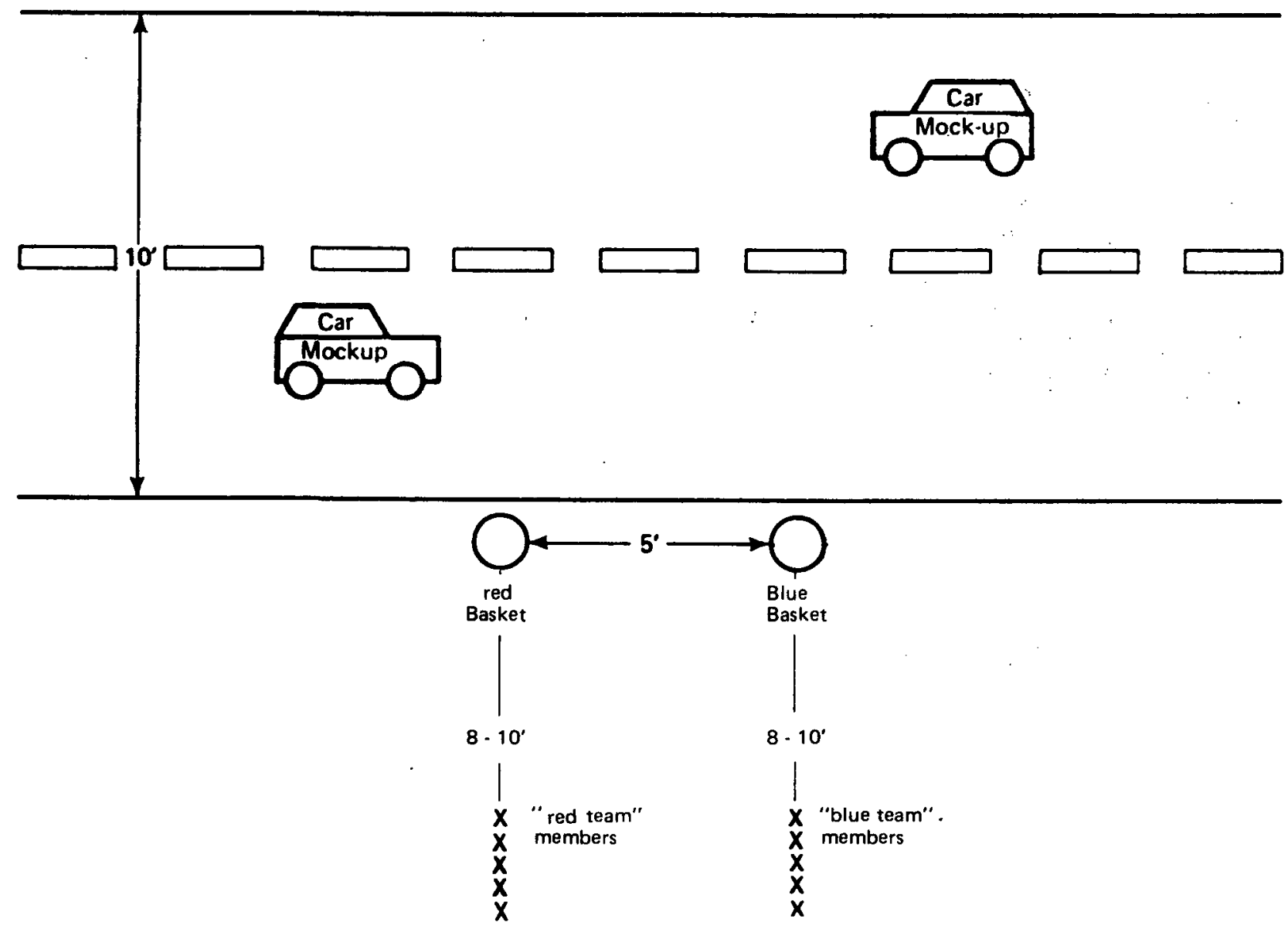

Figure 2. Diagram of Playing Area--Ball-Toss Game 
2. Place the two wastebaskets near the curb on the playing area. Set them about five feet apart.

3. Arrange to have an assistant help you with this session. Thorough 1y explain the session and the behavior sequence to him/her.

\section{Conduct of the Session}

1. Evenly divide the class into two teams. Designate one team as the "red team," the other as the "blue team."

2. Choose three children to serve as "cars." Give these children the car mockups and instruct them to move at a slow, even pace up and down the "street." (Have them circle the room in opposite directions so that "cars" are not always on the "street," and it is safe to enter.)

3. Have the teams form a line at a right angle to the curb. Have the blue team in front of the blue basket, with the first person in the line eight feet away from the basket. (You may have to move back further for the older children.) Have the red team likewise face the red basket. Place a piece of tape on the floor for the children on each team to stand behind.

4. The first child on each team throws the ball and tries to get it into the basket (it must go in on the fly, not bounce in). If the ball goes into the basket, the thrower runs to the basket, gets the ball, and runs back to the 1ine. He/she then takes another turn, and keeps tossing until he/she misses.

5. If he/she misses the basket, he/she retrieves the ball, gives it to the next person in line, and goes to the end of the line. If the ball goes into the street area, he/she must perform the safe street-crossing sequence before stepping into the street to get the ba11. (See Figure 3) If the sequence is done correctly, he/she is given a yellow safety token. If not, he/she must repeat the sequence until it is done right.

6. Halfway through the game, call "stop." Assign two different children (who have already had their turns) to ride the cars.

7. Have an assistant watch one team while you watch the other. Both of you must check to make sure everyone performs the behavior sequence correctly and receives a safety token. You will also keep score for your team. The team with the most baskets wins the game.

Simplified Session (Optional)

Kindergarten children are often not as motivated by competitive team games as are the older children and may be confused by it. The game may be modified for their use. One possible modification of the game is for you 


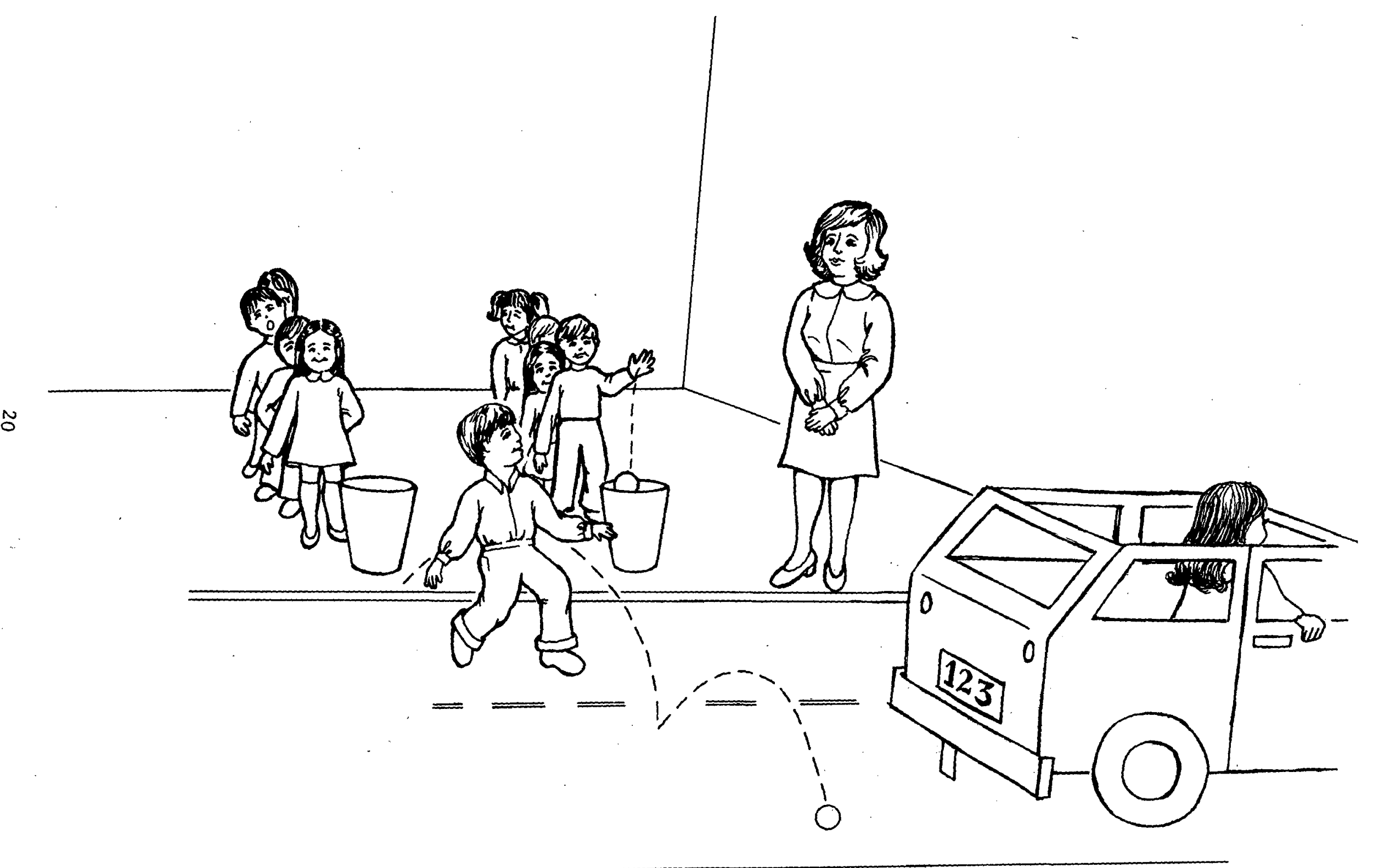


to throw the ball into the street--the children take turns retrieving it while the other children practice throwing balls into baskets. This will prevent the children not actually crossing from becoming bored. The same system of reinforcement used for the older children would be employed for the Kindergarten children as well.

\section{DOs and DON'Ts}

1. Do watch each team separately (you can watch one team, the assistant can watch the other), to make sure that you are able to see each child perform the behavior sequence.

2. Do collect and keep the game materials. They are needed for other games. The children should each have at least one yellow safety token which they keep.

3. DON'T present the cars as toys. Before beginning the game, emphasize that, when crossing the street, the children MUST look for and stop for the cars.

4. Do treat the simulated street as real. When you cross the street, remember to perform the sequence.

5. Do give each child a check opposite his name under Session 3 on the Progress Chart. 
SESSION 4: INSIDE PRACTICE, "CHIP GAME"

\section{Introduction}

This session includes a practice game, the "Chip Game" which is a type of relay race. Teams are required to get a colored chip from you and return to the starting circle as quickly as possible. In order to receive the chips, the team members must cross a "street," and exhibit the proper behavior sequence before crossing. Those who fail to look "left-rightleft" are sent back to begin again, thus taking up time and delaying the entire team's progress. The team with the most chips at the end of the game wins. One car mockup will serve as a parked car. The other two will be "driven" up and down the street as before. The children must step to the street-side edge of the parked car before performing the behavior. sequence.

\section{Objective of the Session}

To provide opportunities for practice of the behavior sequence, by having the child cross the street to receive a chip. This duplicates the situation of a child being called across a street by a friend or an adult.

\section{Materials Required}

Two-inch masking tape

Three mockup cars

Yellow safety tokens

One pink plastic wastebasket

One blue plastic wastebasket

Seventy-five red plastic chips

Seventy-five blue plastic chips

\section{Preparation Activities}

1. If not previously arranged, place about 40 feet of tape in a straight line near the center of the room (see the diagram of the playing area, Figure 4). This is to serve as a curb. Place another 40 feet of tape about 10 feet away from the first line, parallel to it. This is the other curb. The area in the middle will serve as a street.

2. Put one of the car mockups parallel to the curb in the street area. It is to serve as a parked car. 

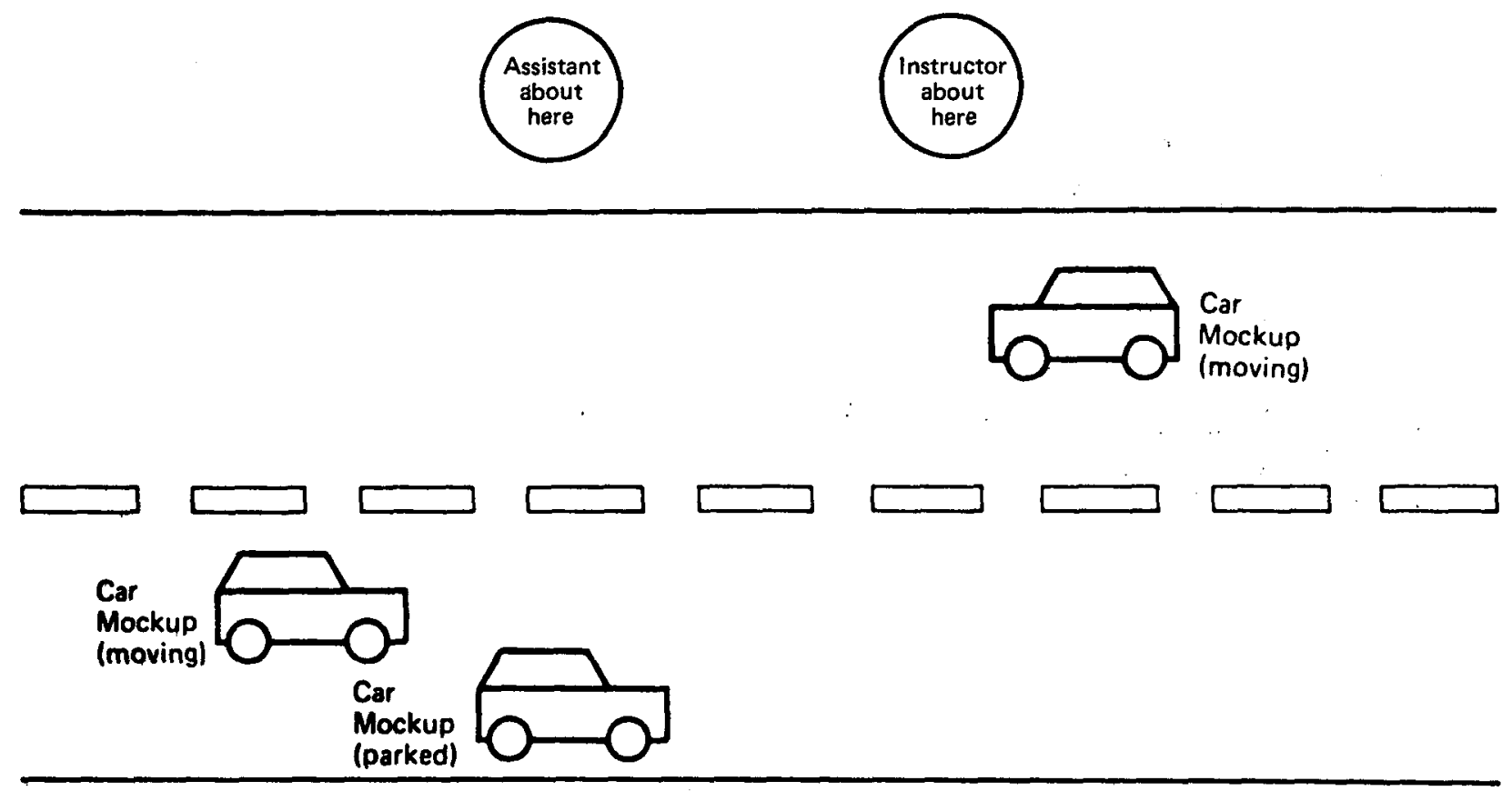

\begin{tabular}{|c|c|}
\hline $\begin{array}{l}x \times x \\
x \times y\end{array}$ & $x \times x$ \\
\hline & \\
\hline $\begin{array}{l}x \times x \\
x \times x\end{array}$ & \\
\hline$\times \times \times$ & $x \times x$ \\
\hline $\begin{array}{l}\text { "A" } \\
\text { Team } \\
\text { Members }\end{array}$ & $\begin{array}{l}\text { "B" } \\
\text { Team } \\
\text { Members }\end{array}$ \\
\hline
\end{tabular}

Figure 4. Diagram of Playing Area--Chip Game 
3. Arrange to have an assistant help you with this session. Try to get the same person who helped you before. Thoroughly explain the session and the behavior sequence to him/her.

Conduct of the Game

1. Divide the class evenly into two teams.

2. Assign two children, one from each team, to act as "cars." Have them walk at a slow, even pace in the street area. (Have them circle the room, in opposite directions, so the "cars" aren't always in the street.)

3. Have the teams line up as shown in the diagram.

4. You and your assistant should stand on the side of the street across from the children. You will watch one team and the assistant the other. Each of you should have a set of colored chips in a wastebasket. One has the "red" team, the other the "blue team."

5. To begin the game, you and your assistant at the same time call the first person in line on your respective teams. For example, "David, red."

6. When you call to the child to come over to where you are standing, the child must cross the street from the edge of the parked cars. Before crossing, he/she must perform the behavior sequence. If he/she tries to cross without performing the behavior sequence or crosses too close to approaching cars, he/she must go back to the end of the line. When the sequence is performed correctly, the child is given a safety token when he/she reaches you. The child can then take a game piece from the basket and return to the end of his/her line. Watch the child as he/she recrosses the street to assure that the recrossing is also correct.

7. As soon as the player on your team returns to the line, call to the next child on your team. Your assistant, of course, will do likewise.

8. Halfway through the game, assign two different children to act as cars, so everyone gets to play.

9. Play the game for a specified time (e.g., 20 minutes). Collect and count the game pieces. The team with the most pieces is the winner. Younger children will enjoy individual praise of the number of pieces each has collected. 


\section{Simplified Session (Optional)}

Kindergarten children may not be prepared for a game which involves so much competition. In their case, you and your assistant may simply call the children over without dividing them into spectfic teams. The children will be pleased to amass their own chips without concern for a team score. In all other respects, the game would be identical to the version for the older children.

\section{DOs and DON'Ts}

1. Do collect and keep the game pieces. They are needed for other games. The children should have one to three yellow safety tokens each, which they keep.

2. Do keep the game moving quickly and with excitement.

3. Do emphasize that the children should always perform the sequence even when someone is calling to them or they are being crossed by an adult.

4. Do emphasize that the children are to listen to be sure the parked cars don't have their engine running, and look to be sure the parked cars aren't about to back up or puli out.

5. Do give each child a check opposite his name under Session 4 on the Progress Chart. 
SESSION 5: INSIDE PRACTICE, "FOLLOW-THE-LEADER GAME"

\section{Introduction}

In this session, the children will play a game in which they must follow a path which crosses the street. They must perform the correct behavior sequence to cross. If a child fails to perform the sequence, he/she must exchange places with the child behind. This game provides the children with opportunities to practice the behavior sequence when they are in the situation of being pursued.

\section{Objective of the Game}

To provide an opportunity for practicing the behavior sequence in a pursuit situation.

\section{Materials Required}

Three car mockups

Two-inch masking tape (plain)

Three large wastebaskets

Yellow safety tokens

"Follow-the-Leader Game" rope

\section{Personnel Required}

Instructor and Assistant

\section{Preparation Activities}

1. If not already prepared, put 40 feet of masking tape in a straight line. Put another 40 feet of tape in a parallel line about eight feet from the first line (see diagram of playing area, Figure 5).

2. Arrange the wastebaskets as shown in Figure 5.

3. Make a $3^{\prime} \times 6^{\prime}$ start zone and end zone with the masking tape as shown in Figure 5.

4. Place the rope along the path outlined in the figure to direct the children through the course. Uncolored sections of the rope should extend across the "street." 


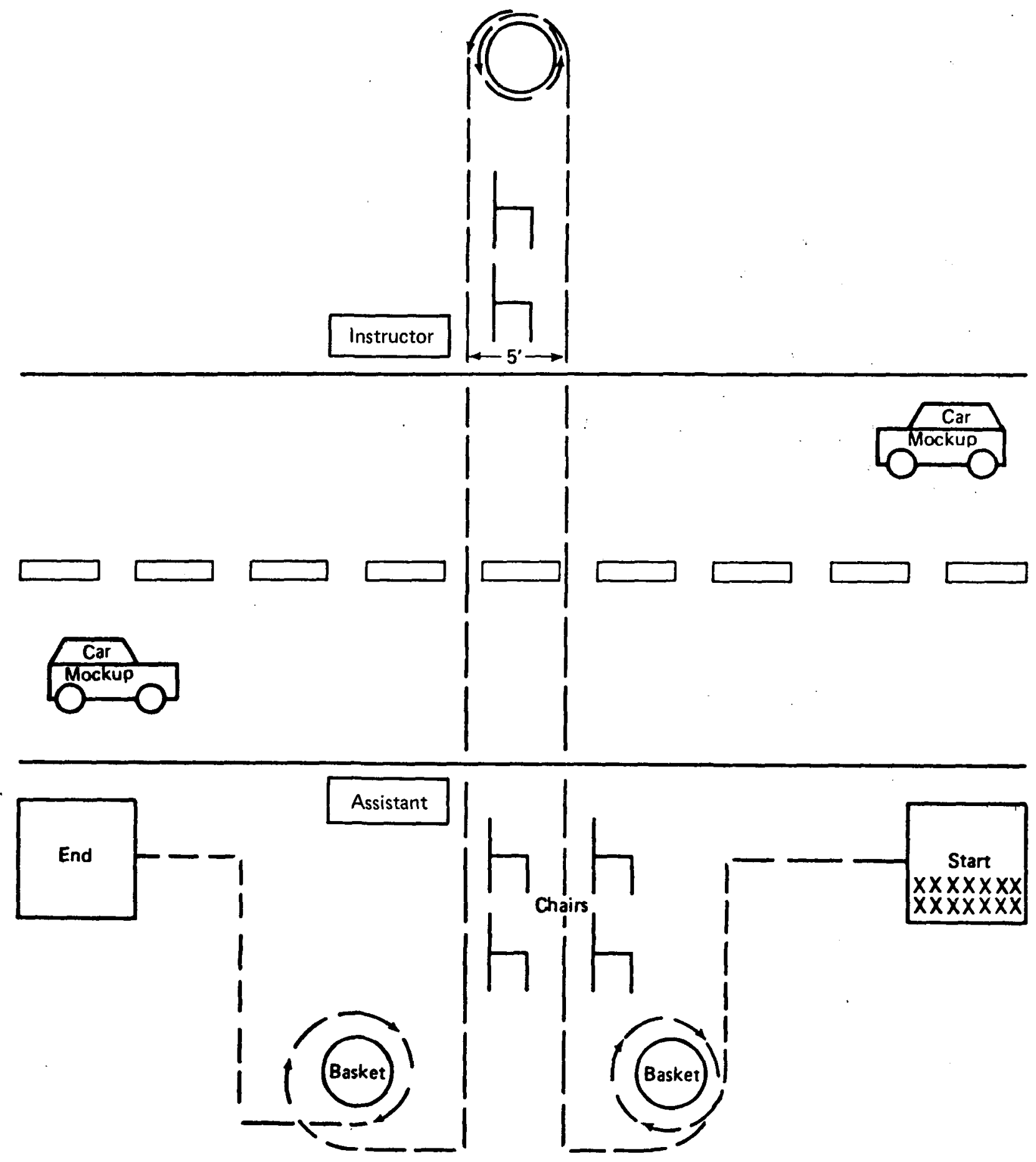

Figure 5. Diagram of Playing Area--Follow-the-Leader Game 
5. Arrange to have an assistant help you with this session. Try to get someone who has helped you before. Thoroughly explain the session and the behavior sequence to him/her.

Conduct of the Session

1. Assign three children to be "cars." Instruct them to walk at a slow, even pace in the street. (Have them circle part of the room in opposite directions so the street will be clear at times.)

2. Ask the class to line up in a row in the start zone, beginning with the smallest child.

3. Explain that the object of the game is to complete the course and reach the end zone as quickly as possible without making any mistakes in following the path, and without letting anyone catch up and pass them. Children can only be passed in the game area, NOT in the street. A child who is waiting. to cross the street can't be passed by another child.

4. The first child in line (the smallest in the class) is told to begin walking the path as quickly as he/she can, but to make sure the path is followed. The child must hop around the wastebaskets on one foot. The child must jump for the red segments of the rope, skip for the blue, and run for the yellow. The plain section of the rope, extending across the street area, indicates "walk." The next person begins when the first child crosses the street for the first time and each successive player begins when the child before him/her reaches that point.

5. The instructor and assistant check the children's performance of the correct street-crossing behavior. If the player makes a mistake in performing the sequence, he/she loses one place in line.

6. As the players reach the end zone, the instructor gives them a yellow safety token as a reward.

7. Halfway through the game, call "stop" and assign three children who have finished to be cars.

8. The game is over when all children have had a turn. Play the game a second time by having the children follow the course in reverse, i.e., from the end zone to the start zone.

\section{Simplified Sessions (Optional)}

The Kindergarten children may be required to follow the rope, not perform varying types of movements. They also need not be penalized by changing places with the child behind if this rule causes them to become confused. 
DOs and DON'Ts

1. Do have an assistant watch one crossing area. Watch the other yourself. When a child forgets to perform the behavior sequence, or performs incorrectly, be sure he/she changes places with the child behind.

2. Do play the game again if time permits.

3. Do give each child a check opposite his/her name under Session 5 of the Progress Chart. 
SESSION 6: OUTSIDE PRACTICE, "BALL-TOSS GAME"

\section{$\underline{\text { Introduction }}$}

The "Ba11-Toss Game" is played outside under more realistic conditions than the indoor version. The game is played near arranged parked cars and the children must step to the edge of the parked cars before performing the behavior sequence.

\section{Objective of the Session}

To provide opportunities for the children to practice the behavior sequence while playing the "Ball-Toss Game" in a natural environment.

Materials Required

Same as required for Session 3, except that you will NOT need the car mockups or the masking tape.

Two street safety barricades and signs.

\section{Personne1 Required}

Instructor and Assistant

Prpearation Activities

1. Set up the game area in the selected site as per Figure 3.

NOTE: Check with the principal to determine the site

for Session 6 . Be sure that all arrangements have been made for blocking traffic on the street during the period in which you will be conducting the session.

2. Arrange to have an assistant help you with this session. Try to get someone who has helped you before.

Conduct of the Session

Have the children play the "Ba11-Toss Game" as described in Session 3. 
DOs and DON'Ts

1. Do read the instructions for Session 3 .

2. Do make sure the children walk to the edge of the parked cars before performing the behavior sequence.

3. Do check to be sure that the street-blocking barricades are manned and in place before beginning the session.

4. Do remind the children that, although they may see the barricades, cars may still be coming down the street; so they must be sure to watch for them.

5. Do be alert to signals from the crossing guards. They will warn you if someone "runs" the barricades.

6. Do emphasize that the children are to listen to be sure the parked cars don't have their engines running, and look to be sure the parked cars aren't about to back up or pull out.

7. Do ask the children often what they are looking for, or ask a child who has just completed searching and is about to cross "Are there any cars coming?" 


\section{SESSION 7: OUTSIDE PRACTICE, "CHIP GAME"}

\section{Introduction}

The "Chip Game" is played outside under more realistic conditions than the indoor version. If possible, the site for this session will be different from that used in Session 6 .

Objective of the Session

To provide opportunities for the children to practice the behavior sequence while playing the "Chip Game" in a: normal environment.

\section{Materials Required}

Same as required for Session 4, except that you will NOT need the car mockups or the masking tape.

Two street safety barricades and signs.

$\underline{\text { Personnel Required }}$

Instructor and Assistant

\section{Preparation Activities}

1. Set up the game area in the selected site as per Figure 4.

NOTE: Check with the principal to determine the site for Session 7. Be sure that all arrangements have been made for blocking traffic on the street during the period in which you will be conducting the session.

2. Arrange to have an assistant help you with this session. Try to get someone who has helped you before.

\section{Conduct of the Session}

Have the children play the "Chip Game" as described in Session 4. 
DOs and DON'Ts

1. Do read the instructions for Session 4.

2. Do emphasize that the children should always perform the sequence, even when someone is calling them or they are being crossed by an adult. 


\section{SESSION 8: OUTSIDE PRACTICE, "FOLLOW-THE-LEADER GAME"}

\section{Introduction}

The "Follow-the-Leader Game" is played outside under more realistic conditions than the indoor version. The game is played near parked cars and the children must step to the edge of the parked cars before performing the behavior sequence. If possible, the site for this session will be different from those used in Sessions 6 and 7 .

\section{Objective of the Session}

To provide opportunities for the children to practice the behavior sequence while playing the "Follow-the-Leader Game" in a normal environment.

\section{Materials Required}

Same as required for Session 5, except that you will NOT need the car mockups or the masking tape.

Two street safety barricades and signs.

Personne1 Required

Instructor and Assistant

\section{Preparation Activities}

1. Set up the game area in the selected site as per Figure 5 .

NOTE: Check with the principal to determine the site for Session 8. Be sure that all arrangements have been made for blocking traffic on the street during the period in which you will be conducting the session.

2. Arrange to have an assistant help you with this session. If possible, try to get someone who has helped you before.

\section{Conduct of the Session}

Have the children play the "Follow-the-Leader Game" as described in Session 5. 
DOs and DON'Ts

1. Do read the instructions for Session 5 . 
SESSION 9: MAKE-UP SESSIONS

\section{Introduction}

This last session is an additional practice game session. This practice should take place outside at one of the game sites, if at a11 possible. If not, play inside. Repeat the game that was the class favorite.

\section{Objective of the Session}

To give those children who missed any of the first eight sessions a chance for additional practice.

\section{Conduct of the Session}

For whichever game session you choose, have the children play exactly as before. Refer to the instructions for that session.

\section{DOs and DON'Ts}

1. Do reread the instructions for the game you are going to play.

2. Do repeat this session, if necessary, to ensure that all of the children in your class participate in at least six sessions.

3. Do repeat this session until you feel that all children in your class can:

- Stop both at the curb and/or at the boundary of the parked cars.

- Search adequately in both directions and track all cars they see.

- Explain what they are looking for and why they look left a second time. 


\section{AWARDING THE SAFETY BADGES}

AND CERTIFICATES

After all the sessions have been completed [including the make-up session(s)], the children can receive their safety badges and certificates. To make sure that each child understands the significance of the badges, you should have them perform the "left-right-left" sequence on the simulated street before giving them their awards. All of the children in your class should be able to correctly perform the entire safety sequence, both in the presence and absence of parked cars. 
FOLLOW-ON ACTIVITIES

This program should not end with the completion of the initial training. For this program to have any permanent effect, the children should continue to practice what they have learned, not only throughout this school year, but in years to come. Children easily forget what they have learned. They need constant reminders and reinforcement. If the teacher does not conduct follow-on activities which permit the children to practice the safe street crossing sequence, the initial training will be lost. In. addition, research has shown that children who have received initial training most often have problems with their re-initiation behavior, that is, re-initiating their searches after a car has passed. Follow-on activities w11l help practice this concept.

Follow-on sessions should be performed at least once a month for second- and third-graders, and every two weeks for Kindergartners and firstgraders. Follow-on activities may be incorporated into the regular physical education program or maintained as separate sessions. The behaviors learned during the initial training must be constantly re-emphasized to ensure retention. The need to stop and search for cars while in the midst of activities should be consistently reiterated and reinforced by repeating initial training sessions, creating new activities, and incorporating the safe street crossing behaviors into ongoing activities. It is best to perform as many different types of activities as possible to ensure greater generalization of the behavior. Some suggestions for follow-on activities are given below.

\section{Repeat Training Sessions}

1. Have the children play one of the initial training games. Play them outside, or inside if the car mockups are available. (Guidelines for choosing street settings are given in Sessions 6, 7, and 8. Be sure to coordinate your requirements with the principal.) You could even award special privileges for winning, or have permanent teams and running contests. Do not distribute safety tokens in these sessions.

2. Periodically, reconstruct the simulated street in the classroom, gymnasium, or playground. (Instructions for this are found in Session 1.) Have all children perform the behavior sequence.

\section{Go for a Safety Walk}

Take the children for a walk. Practice crossing at several points with individuals and/or small groups. The teacher should always cross with the children and be prepared to restrain any child, if necessary. Crossing 
both midblock and at intersections should be practiced. Re-initiation (searching again after a car has passed) should be stressed. Praise children who perform correctly.

Practice During a Fire Drill or Class Trip

Whenever the class is on the street for any reason (e.g., fire drill, going to or from the 1ibrary), you could have the children perform the sequence when they cross the street. Praise children who correctly perform the sequence. Re-initiation should be stressed.

\section{Practice During Physical Education Activities}

During regular physical education activities, an out-of-bounds area may be delineated as a simulated street. Any time a child must retrieve a ball from that area or passes through that area, he must cross correctly before he can rejoin the game. If the children are playing in the schoolyard and the ball enters the street, a child may be sent to retrieve it (if it is safe to do so). After his/her return, the other children should be asked whether the street entry was done safely. If the entry was proper, praise the child; if not, have him/her repeat it as you and the children watch.

\section{Practice Emphasizing Re-initiation Behaviors}

Since the most common error made by children who have had initial training is re-initiating the searches after a car has passed, special exercises emphasizing reinitiating in real-life situations should be performed. Three activities for doing this are as follows:

1. Practice with the Pusharound Cars. Set up the simulated street as you did for the initial training sessions and have some of the children drive the pusharound cars up and down the street. Have each child step up to the curb as a "car" is approaching, search, wait for the car to pass, then search again (i.e., re-inttiate the search). If another "car" is coming when the reinitiated search occurs, the child should wait for that "car" and search again. Repeatedly demonstrate the correct procedure. Correct the children's mistakes and have the children practice until they can re-initiate correctly.

2. Practice with Staged Traffic. Have an assistant drive a car up and down a street blocked from other traffic. The driver will, of course, be aware of the children and will drive cautiously. The instructor should stand beside each crossing child, prepared to restrain him/ her. Each child should search as the car approaches at a close enough distance to present a threat, wait, and re-initiate the search when the car passes. This exercise should be carried out on a street with parked cars present so the child must cross between the cars. 
3. Practice with Real Traffic. This exercise is similar to 2 , above, except it should be performed on an unblocked street with light traffic. In this exercise, the children need not cross the street. Instead, each child should search, wait, and re-initiate search as before, and tell you when he/she thinks it would be safe to cross.

\section{Races}

Any race between two teams which involves crossing either a simulated or real (blocked) street and penalizes the child who crosses incorrectly. would be appropriate. For example, an egg and spoon race where the relay includes a street crossing would provide the excitement of a race and opportunities for performing the sequence. The child who starts to cross incorrectly must go back to his/her starting point, approach the street again, and correctly perform the sequence.

\section{Games with Partners}

These games would involve an equal number of children lined up on either side of either a real (blocked) or simulated street. Each child has a partner across the street. The child must cross the street to reach his partner, perform some task, and return. His partner then repeats the activity.

Some sample games of this type include:

1. The Balloon Game. The children are divided into two teams. Half of each team stands across the street holding balloons for their partners who are lined up opposite them. Each child must run across the street (one at a time), pop the balloon held by his partner, and run back. When the team members have all returned, they are given balloons and their partners must pop them in the same manner. The first team to pop all their balloons on both sides, and have all their team members back in their original positions, wins. A child who starts to cross incorrectly must repeat the sequence and loses time.

2. The Lap Game. The game begins with two groups of five children. The other children line up to be prepared to replace those who will be eliminated. There should be 10 children actively playing at all times. The groups of five are placed opposite to each other across the street. When the instructor says go, the children on one side all run across the street and sit (or lean) on their partner's laps (the partners should crouch or knee1). The last child across is eliminated. The children then return as a group to their own side, and their partners must cross the same way. As each child 
is eliminated, he/she is replaced so that all the children have an opportunity to play. All but two children are eventually eliminated, and they are the winners. The children must perform the sequence correctly to cross. If they fail to do so, they are automatically eliminated.

Tag Games

1. Animal Tag. Some of the children pretend that they are various animals and must make the appropriate noise as they cross. A zookeeper or dog catcher (another child) is pursuing each child, and he can escape if he reaches a certain spot on the other side of the street and freezes into a typical pose for that animal before the zookeeper can tag him. The animal has a few steps head start on the zookeeper, and they must cross from different spots so that the animal cannot be tagged while searching. After each pair of children has crossed, the roles are reversed so each child may be an animal. This game is only suitable for the older children.

2. Automobile Tag. Four or five children are chosen to act as cars. They must march up and down the street at a fast walk. If they exceed the "speed limit" (begin to run), they are eliminated from the game. One child serves as a policeman to regulate the "cars." The other children line up to cross and, if a child fails to search or re-initiate the search correctly, he/she must go to the back of the line. The children must cross only when no cars are close enough to tag them fairly or they are eliminated. A child who crosses correctly in both directions may exchange places with one of the "cars." This game is only suitable for the older children.

\section{Invent Your Own Games} istics :

To be effective, the practice game must have the following character-

1. It must provide opportunity for everyone to practice the sequence, not just passively hear about it.

2. The game activities should recreate the activities that children engage in that most often lead to dart-out accidents :
a. Chasing a toy or ball into the street
b. Chasing or being chased. 


\section{c. Intent on some goal across the street (e.g., a friend).}

3. It should be exciting so that the street-crossing becomes an incidental part of the play of the game. Fast-moving competitive games are good in this respect for second- and third-graders. Simpler games must be provided for younger children.

4. It should be simple enough that you can run the game and closely observe the street crossings with available help (i.e., an assistant, older children). 
Even children who have had the full Safe Street-Crossing Training, including follow-on activities, can be expected to forget some of what they have learned over the summer vacation. For this reason, children who were exposed to the program in the previous school year should be, given refresher training early in subsequent school years, up to and including third-grade. The refresher training is basically an abbreviated version of the children's original training, involving three sessions. Follow-on activities should then be continued throughout the school year.

No awards (i.e., badges or certificates) are given following the refresher training, and safety tokens are not distributed.

\section{New Students}

Prior to administering the refresher training, check to see if there are any students who haven't had the initial training. Your principal may arrange for these children to receive the initial training sessions. Alternatively, you may decide to perform extra sessions with these children beyond the refresher training to provide them with additional practice. 
REFRESHER SESSION 1: RE-INTRODUCTION AND PRACTICE

\section{Introduction}

The children are re-introduced to the safe street crossing sequence and given a chance to practice that sequence.

Objectives of the Session

1. To remind the children of the safety training program.

2. To give the children. guided practice in performing the safe street crossing sequence.

\section{Materials Required}

Safety film "Don't Dart-Out"

Masking tape (or similar type) two-inches wide

Personnel Required

Instructor

\section{Preparation Activities}

Put about 10 feet of masking tape in a straight line parallel and about three feet away from the doorway of the classroom. Put another 10 feet of masking tape in a parallel line about seven feet from the first line. The taped lines serve as curbs; the area between is the "street."

Conduct of the Session

1. The film will be shown to all $\mathrm{K}-3$ classes at the same time in a central location.

2. When you return to your classroom, ask the children if they remember the safe street crossing sequence. Ask for volunteers to demonstrate. Ask the children what they are looking for.

3. With your back to the children, model the safe street crossing sequence, using the tape to serve as curb and street. Explain 
that, since no cars are in view, you can cross the street. Cross again, facing the children, and repeat the sequence. Mention that the reason you look to the left a second time is because the cars approach from that side. Emphasize that, when you perform the sequence, you are looking for cars.

4. Guide each child through the safe street crossing sequence. As the child is performing, instruct him/her to say "Left-rightleft." Do not let the child sit down until he/she is able to correctly perform the sequence.

5. Have the children choose partners. Instruct each pair to perform the sequence, saying "Left-right-left." Make sure each member of each pair performs the sequence correctly before sitting down. Remind the children that, even when they are with other children or adults, they must always look.

DOs and DON'Ts

1. DON'T let a child (or pair of children) finish their turn on an incorrect performance. Always have them perform correctly before they sit down.

2. Do physically and verbally guide each chlld through the sequence during his/her first performance.

3. Do have the children say aloud "Left-right-Left" every time they perform the sequence.

4. Do ask the children several times during the session what they are looking for.

5. Do remind the children of the past year's safe street crossing activities. 
REFRESHER SESSION 2: INSIDE PRACTICE, "BALL-TOSS GAME"

\section{Introduction}

The "Ba11-Toss Game" is played by the children. The object of the game is to toss a ball into a basket. When the child misses the basket, the ball will usually roll out into the "street" area. The children must then perform the safe street-crossing sequence correctly before retrieving the ball.

The children will alternate the roles of oncoming cars and pedestrians. The pedestrians must stop at the curb (and at the boundary when parked cars are present), search adequately, and then cross the street.

Objective of the Session

To provide opportunities for the children to practice the behavior sequence while entering the street to retrieve a ball.

\section{Materials Required}

Two-inch masking tape (or similar type)

Three mockup cars

One red bal1--three-inch diameter

One blue ball--three-inch diameter

One pink plastic wastebasket

one blue plastic wastebasket

\section{Personnel Required}

Instructor and Assistant

Preparation Activities (See diagram of playing area, Figure 2, page 18)

1. If not already done, follow the diagram in Figure 2 to place about 40 feet of tape in a straight line near the center of the gymnasium or other large area. This is to serve as the curb. One side of the area divided by the tape will be the "street." The other side is the playing area.

2. Place the two wastebaskets near the curb on the playing area. Set them about five feet apart. 
3. Arrange to have an assistant help you with this session. Thoroughly explain the session and the behavior sequence to $\mathrm{him} / \mathrm{her}$.

\section{Conduct of the Session}

1. Evenly divide the class into two teams. Designate one team as the "red team," the other as the "blue team."

2. Choose three children to serve as "cars." Give these children the car mockups and instruct them to move at a slow, even pace up and down the "street." (Have them circle the room in opposite directions so that "cars" are not always on the "street" and it is safe to enter.)

3. Have the team form a line at a right angle to the curb. Have the blue team in front of the blue basket, with the first person in the line eight feet away from the basket. (You may have to move back further for the older children.) Have the red team likewise face the red basket. Place a piece of tape on the floor for the children on each team to stand behind.

4. The first child on each team throws the ball and tries to get it into the basket (it must go in on the $f 1 y$, not bounce in). If the ball goes into the basket, the thrower runs to the basket, gets the bal1, and runs back to the line. He/she then takes another turn, and keeps tossing until he/she misses.

5. If he/she misses the basket, he/she retrieves the ball, gives it to the next person in line, and goes to the end of the line. If the ball goes into the street area, he/she must perform the safe street crossing sequence before stepping into the street to get the ball. If not, he/she must repeat the sequence until it is done right.

6. Halfway through the game, call "stop." Assign three different children (who have already had their turns) to ride the cars.

7. Have an assistant watch one team while you watch the other. Both of you must check to make sure everyone performs the behavior sequence correctly. You will also keep score for your team. The team with the most baskets wins the game.

\section{Simplified Sessions (Optional)}

Kindergarten children are of ten not as motivated by competitive team games as are the older children and may be confused by it. The game may be modified for their use. One possible modification of the game is for you to throw the ball into the street--the children take turns retrieving it, while the other children practice throwing balls into baskets. This will prevent the children not actually crossing from becoming bored. 
1. Do, whenever possible, verba1ly praise the children for correct performance of the behavior sequence.

2. Do watch each team separately (you can watch one team, the assistant can watch the other), to make sure that you are able to see each child perform the behavior sequence.

3. Do collect and keep the game materials. They are needed for other games.

4. DON'T present the cars as toys. Before beginning the game, emphasize that, when crossin; the street, the children MUST look for and stop for the cars.

5. Do treat the simulated street as real. When you cross the street, remember to perform the sequence. 
REFRESHER SESSION 3: OUTSIDE PRACTICE, "FOLLOW-THE-LEADER GAME"

\section{Introduction}

In this session, the children will play a game in which they must follow a path which crosses the street. They must perform the correct behavior sequence to cross. If a child fails to perform the sequence, he/she must exchange places with the child behind. This game provides the children with opportunities to practice the behavior sequence when they are in the situation of being pursued. The "Follow-the-Leader Game" is played outside under more realistic conditions than the indoor games. The game is played near parked cars and the children must step to the edge of the parked cars before performing the behavior sequence.

\section{Objective of the Game}

To provide an opportunity for practicing the behavior sequence in a pursuit situation and in a normal environment.

\section{Materials Required}

Three large wastebaskets

"Follow-the-Leader Game" rope

\section{Personnel Required}

Instructor and Assistant

\section{Preparation Activities}

1. Set up the game area in the selected site as per Figure 5, page 27. Arrange the wastebaskets as shown in Figure 5 . Make a $3^{\prime} \times 6^{\prime}$ start zone and end zone with the masking tape as shown in the figure. Place the rope along the path outlined in the figure to direct the children through the course. The uncolored section of the rope should extend across the "street."

NOTE: Check with the principal to determine the site for Refresher Session 3. Be sure that al1 arrangements have been made for blocking traffic on the street during the period in which you will be conducting the session. 
2. Arrange to have an assistant help you with this session. If possible, try to get someone who has helped you before.

\section{Conduct of the Session}

1. Ask the class to line up in a row in the start zone, beginning with the smallest child.

2. Explain that the object of the game is to complete the course and reach the end zone as quickly as possible without making any mistakes in following the path, and without letting anyone catch up and pass them. Children can only be passed in the game area, NOT in the street. A child who is waiting to cross the street can't be passed by another child.

3. The first child in line (the smallest in the class) is told to begin walking the path as quickly as he/she can, but to make sure the path is followed. The child must hop around the wastebaskets on one foot. The child must jump for the red segments of the rope, skip for the blue, and run for the yellow. The plain section of the rope extending across the street area indicates "walk."

4. The instructor and assistant check the children's performance of the correct street-crossing behavior. If the player makes a mistake in performing the sequence, he/she loses one place in line.

5. The game is over when all children have had a turn. Play the game a second time by having the children follow the course in reverse, i.e., from the end zone to the start zone.

DOs and DON'Ts

1. Do make sure the children walk to the edge of the parked cars before performing the behavior sequence.

2. Do check to be sure that the street-blocking barricades are manned and in place before beginning the session.

3. Do remind the children that, although they may see the barricades, cars may still be coming down the street; so they must be sure to watch for them.

4. Do be alert to signals from the crossing guards. They will warn you if someone "runs" the barricades.

5. Do emphasize that the children are to listen to be sure the parked cars don't have their engines running, and look to be sure the parked cars aren't about to back up or pul1 out.

6. Do play the game again if time permits. 
REFRESHER FOLLOW-ON ACTIVITIES

After the refresher training sessions are conducted, initiate follow-on activities as described in the previous section. The first follow-on session should be scheduled to occur soon (i.e., one to two. weeks) following the third refresher session. 


\section{APPENDIX D}

OTHER PRINTED MATERIAL

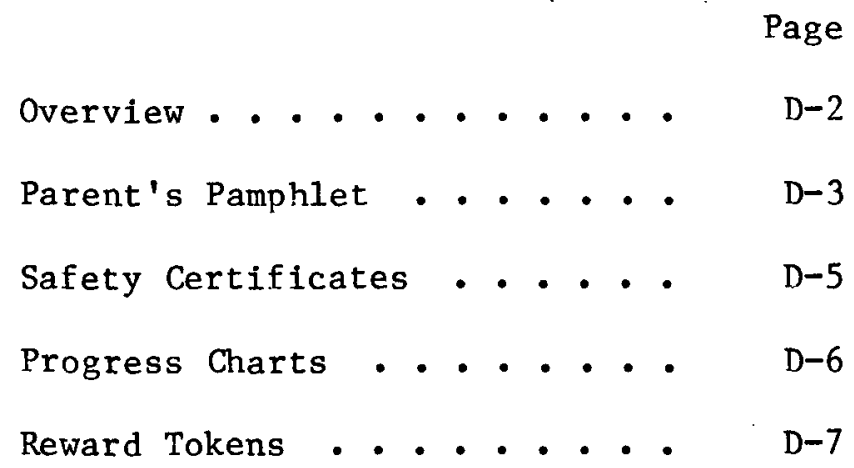


OTHER PRINTED MATERIALS

\section{Overview}

In addition to the three program manuals, there are four other types of program materials that must be printed. They are as follows:

1. Parents' Pamphlets.

2. Safety Certificates.

3. Progress Charts.

4. Reward Tokens.

These materials may be produced from the camera-ready copies included in this section. A method for computing the number of materials required is given in the Coordinator's Guide (Appendix A).

The Parents' Pamphlets should be a three-fold flyer printed on 8-1/2 $\times 11$ inch, 60 pound offset paper, preferably of a bright, eyecatching color. The safety certificates should be printed on $8-1 / 2 \times 5-1 / 2$ inch cover stock. For the Progress Charts, 30 x 20 5-ply white blank paper, coated on one side, is recommended.

The reward tokens should be printed on paper stock of a bright color (preferably yellow or gold) and be approximately $1-1 / 2$ inch square. A page of tokens are provided with guidelines for the paper cutter indicated. 


\section{AWARDS FOR CHILDREN}

In a few weeks, your child will re ceive a certificate showing that he/she has completed the first part of the program. In addition, your child will be awarded a safety patch designed to serve as a reminder of which way to look when entering the street. Praise your child for earning the awards and sew the patch onto his/her clothing. Frequently remind him/her of its meaning. you do. If you always look carefully before crossing, your child will too.

2. By reminding children to cross at the corner whenever possible.

3. By asking your child to demonstrate the safe streetcrossing sequence for you.

4. By pointing out when others are crossing incorrectly and asking your child to identify what they are doing wrong.

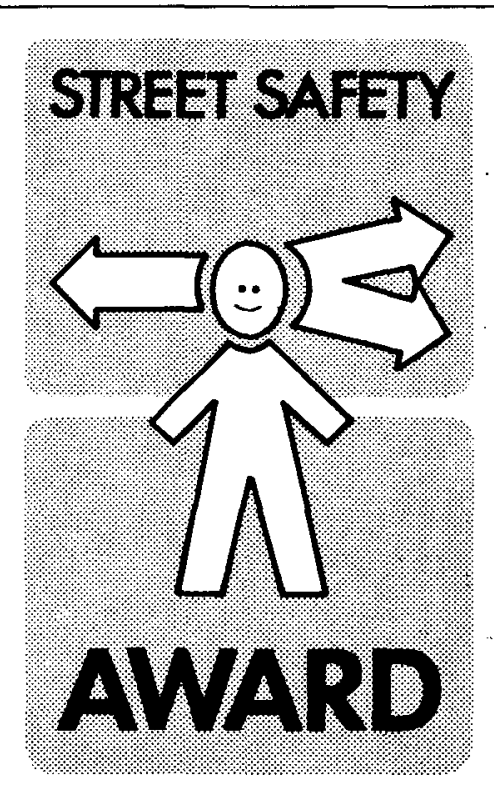

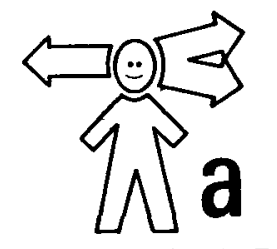

message to parents about the

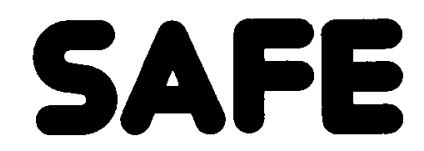
STREET CROSSING program 


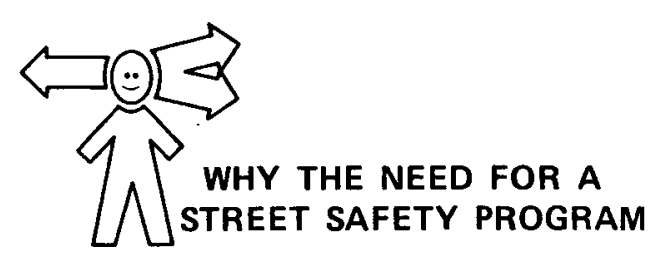

Motor vehicle accidents are the leading cause of deaths for children 5 to 14 years of age. Four out of every ten pedestrians injured in traffic are in this age bracket.

Figures compiled by the U. S. De partment of Transportation (DOT) show that, among children, one type of accident occurs most frequently.
The program is uniquely different from many safety programs which merely tell a child how to cross the street. It requires your child to practice, under controlled conditions, what he/she should actually do when crossing.

The program uses a variety of techniques. It includes:

- Demonstration of how to stop and look both ways when crossing.

- Practice stopping and looking, both in class and on the street (the street, of course, will be blocked).

- Games especially designed to be like the running and chasing activities that often result in children entering the street.

These techniques were chosen after careful study as the most effective way to teach young children how to enter streets safely. Playing the games, in particular, will teach the children that they must stop and look no matter what they're doing when they enter the street.

\section{HOW YOU CAN HELP}

As a parent, the most helpful thing you can do is to watch to be sure your child does the following things when he crosses the street with you:

1. Stops on the curb when no parked cars are present, or at the street side of any parked cars.

2. Looks left-right-left to check for oncoming cars.

3. If a car is coming, watches it until it passes and then looks left-right-left again.

4. Crosses only when the way is clear of traffic from either direction.

If you find that your child is doing this correctly, praise and encourage him. If the child fails to stop and look, gently remind him of what he should have done.

child will receive several hours of training on how to safely enter the street. Then, extra training will be given periodically through the rest of this school year and in later years until your child completes third grade. 


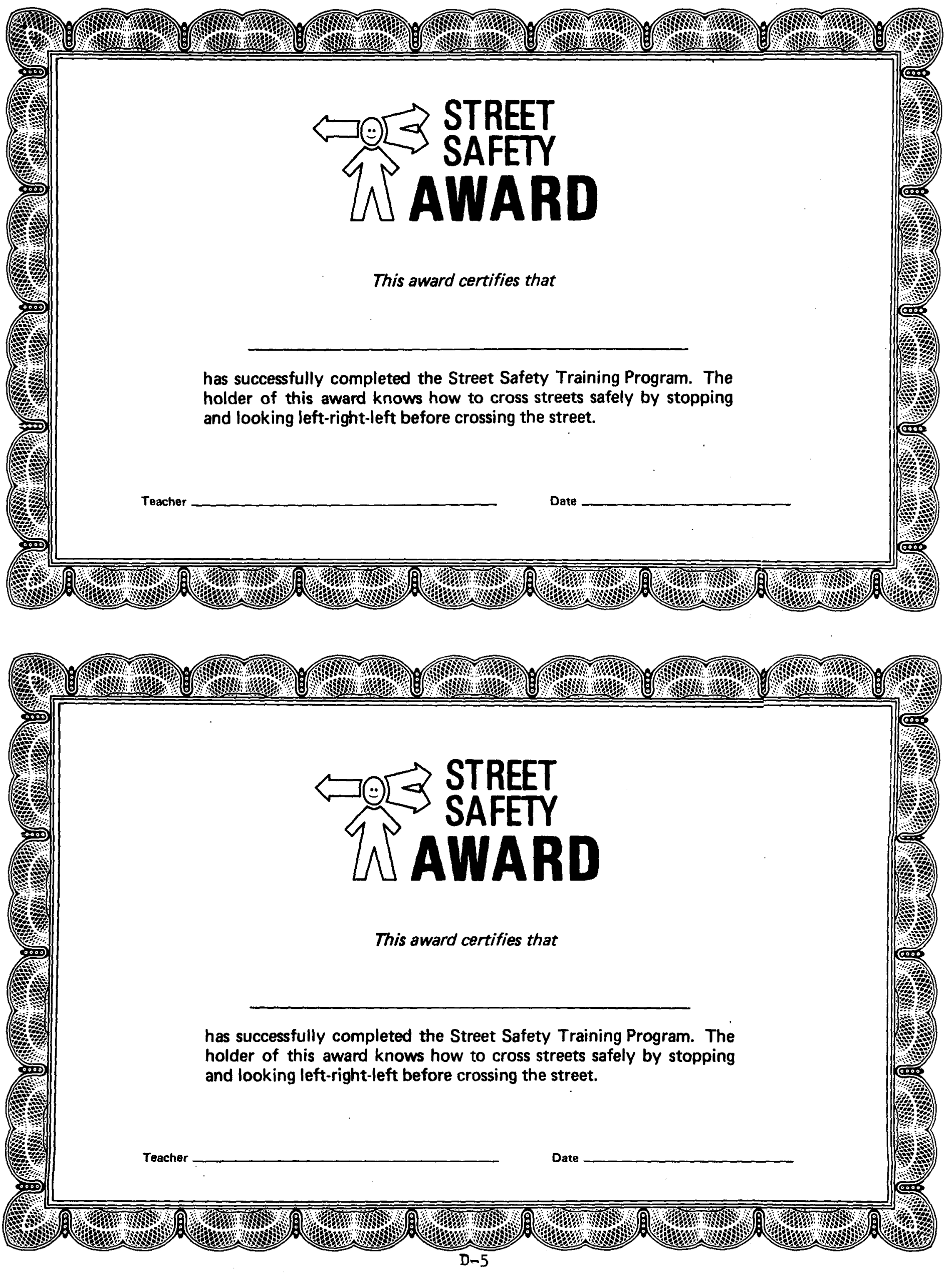



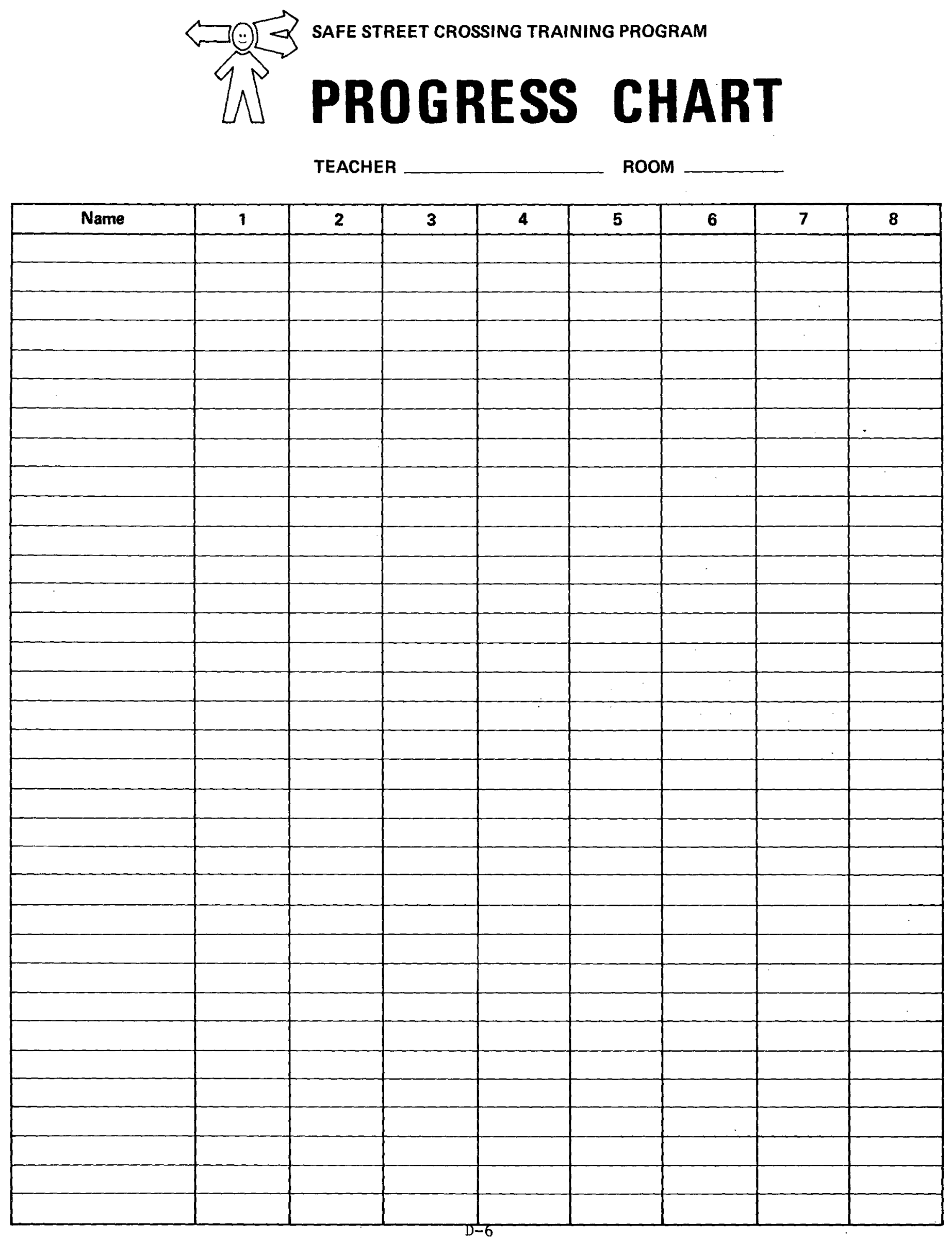


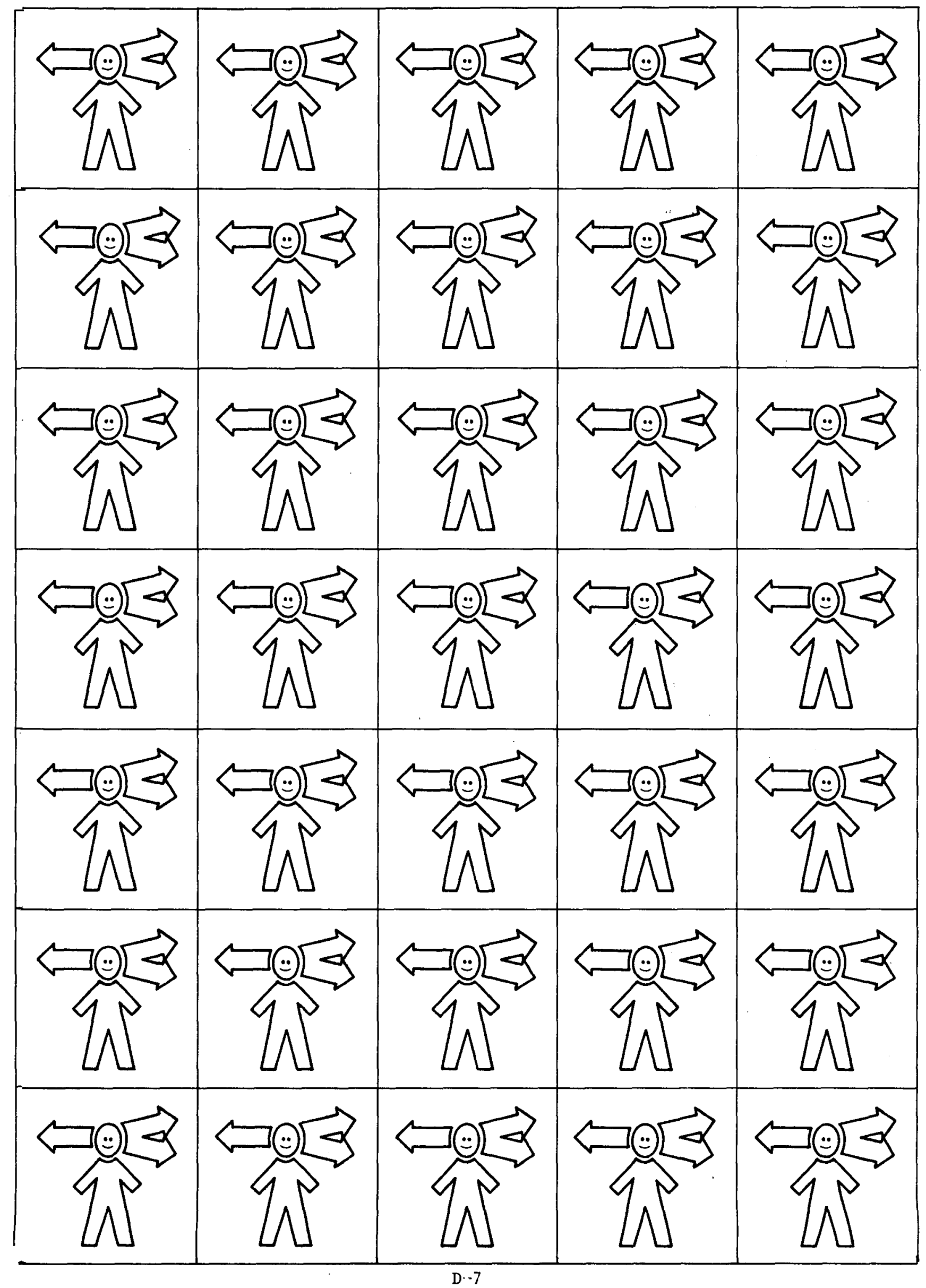


APPENDIX E

MAJOR PROGRAM MATERIALS

$\begin{array}{ll} & \text { Page } \\ \text { Overview . . . . . . } & \text { E-2 } \\ \text { Safety Film "Don't Dart-Out" . } & \text { E-4 } \\ \text { Pusharound Cars . . . . } & \text { E-14 } \\ \text { Barricades and Signs . . . } & \text { E-17 } \\ \text { Sew-on Patches . . . . . } & \text { E-19 }\end{array}$


MAJOR PROGRAM MATERIALS

\section{Overview}

The major program materials cannot be easily purchased or reproduced as is the case with the game and printed materials. However, in the event that they are unavailable from the National Highway Traffic Safety Administration (NHTSA), there are some possible substitutes. The major program materials include:

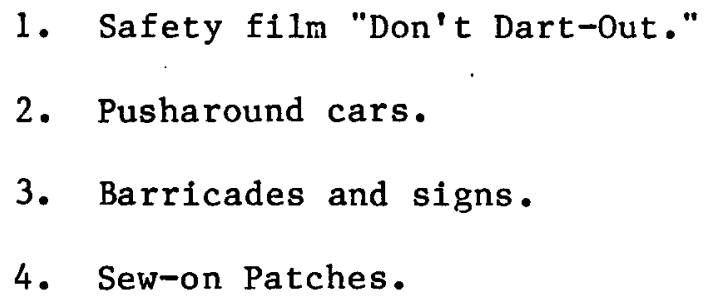

There is, of course, no substitute for the film which features "Captain Kangaroo." However, the script/storyboard for this film is included in this section and teachers and/or students may wish to act out the story.

The pusharound cars are wood reinforced fiberboard and are in sets of three colors. Headlights, tail lights, license plates, and front, back and side windows are decal materials. The wheels are eight-inch diameter, three-quarter inch wide molded plastic with a rubber tread mounted on a one-half inch axle with removable acorn nuts. The axles and wheels are removeable, and the cars are constructed to nest easily for storage and shipment. As an alternative to the pusharound cars, tricycles or other ride-in toy vehtcles may be used. The school system, or the students themselves, may provide these toy vehicles.

The barricades are eight-feet long and two and one-half feet high. The wooden bar is made up of two units, each four-feet long with a hinge riveted through the bottom 1ip of both pieces. This allows the barricades to fold for easy storage and shipment. Each four-foot long unit is composed of a four-inch high three-eighth inch plywood board topped by a twoinch wide strip of one-quarter inch masonite. Another two-inch wide strip of three-eighth inch plywood is attached to the bottom of the plywood board. The outside end of each unit is reinforced by a block of three four-inch by four-inch pieces of three-eighth inch plywood which has two slits in the bottom for the metal supports. The supports are constructed of black mild steel. An arrow is attached to the "Detour" sign by wing nuts that allow the arrow to be pointed in efther direction. The whole bar is painted black with two segments of yellow stripes. There are large staples attached to the underside of the bar from which the signs can be suspended, using binder clips. 
The $30^{\prime \prime} \times 20^{\prime \prime}$ signs are 36 -point white outdoor board and are silkscreened in black ink.

Sawhorses and boards with homemade signs attached may be substituted for the barricades. If barricade guards are present, the type of barricade used is not crucial, as long as there is some type of structure to partially block the street.

There are no substitutes for the patches, but they may be produced locally if a suitable manufacturer can be found. If they are produced locally, iron-on patches rather than sew-on patches may be obtained. They should conform in all other respects to the specifications given. The patches are 2-1/4" $\times 3-1 / 2$ " rectangular cloth badges with three-color embroidery (black, white and red) on Apple Green twill with a white ravelproof border. 


\section{Title}

Scene 1. Urban street, cars parked on both sides.

Three children playing ball on sidewalk. Mark, the first child (black male) throws the ball against a wall or pair of steps and the two standing in the rear reach up for it. Shannon (white male) is furthest into the street. He stands between two parked cars and catches the ball.

Mark hits the ball against the step (or wal1) and it flies over the children's heads into the street. Shannon turns and runs into the first lane, into the 1 path of a car. Marta (white female) is shown cringing. Mark calls out "Shannon, watch out!" The car stops suddenly, brakes screeching, and Shannon is shown frozen, with the ball in his hand. He is pale, but not too upset. He walks to the curb. The driver is also shaken and pale. He wipes his brow and starts to move the car forward very slowly. The other two children meet Shannon and talk to him animatedly.

Children quiet down and start playing an entirely different game on the sidewalk. It involves throwing the ball from one to the other with one child in between trying to block each throw. This continues as Voiceover begins and camera pulls away so that the scene gets smaller. (Dissolve)

\section{Music}

Street sounds, muted.

Sound effects as needed.

Mark: Shannon, watch out!

C.K.*: Every day many, many children are hurt by cars on city streets. Shannon was very lucky. He could have been badly hurt.

\footnotetext{
*C.K. - Captaị Kangaroo
} 
C.K. on same street, fairly close shot. He wears TV costume, stands on sidewalk. Children can be seen some distance away, two sitting on steps, one standing.

View of the children who get up and start playing the same in-the-street game they were playing when we first saw them, then view of street traffic going by. Should include trucks and cars.

\section{(Dissolve)}

New scene. C.K. Is walking toward Shannon and the other two children. He waves to Shannon, who waves back. C.K. continues to walk toward group, then stops when they run towards him.

When C.K. is introduced, he nods to each of the children. Then he leads them to steps and a11 sit down.
C.K. :

Hello, I'm Captain Kangaroo. I'd like to talk to talk to you about playing safely near the street.

Playing outdoors is always fun and young children need lots of fresh air and outside activity to keep them healthy.

As we just saw, though, the big problem with playing outside is that cars are often passing by while you're playing, and you really have to be careful.

When I heard about Shannon's almost being hit by the car, I decided that I should teach him and his friends how to cross streets safely. Let me show you how I did that. One day, I went to see

Shannon. .

Shannon: (waving) Hi, Captain. See, I told you I know Captain Kangaroo. Here he comes now.

Marta: Wow, it is Captain Kangaroo!

Mark: You weren't kiddin', Shannon. It really is him.

C.K.: Hello, Shannon, it's nice to see you again. Will you introduce me to your friends?

Shannon: Hi, Captain. Sure. This is Mark (waves hand toward Mark) and this is Marta (pulls her forward).

C.K.: How are you today, Mark? It's nice to meet you, Marta. 
SCRIPT FOR DOT FILM

Title "Don't Dart-Out"
VISUAL

All four are sitting on steps near where children were seen playing earlier.

\section{NARRATION/DIALOGUE}

C.K.: (to Shannon) Can we sit down here and talk for a minute? (Shannon nods assent).

Shannon: I told them that you wanted to talk to us about street safety, Captain.

C.K.: Right, Shannon. Since you were nearly hit by that car last week, I'm sure you're more careful now. But what about you, Marta? Have you ever come close to being hit by a car like Shannon did?

Marta: One day when my dog ran away, yes. The car stopped very close to me. I was scared to death.

C.K.: $\quad$ And what about you, Mark?

Mark: Well, no, not me. But my friend Butch was hit last summer and his leg was broken. He was in the hospital for awhile and he said it really hurt.

C.K.: We11, then, a11 three of you already know how important it is to cross streets safely, even while you're playing.

Medium shot of C.K., then of all four.

Shannon hangs his head a little, looks slightly ashamed.

Shannon:

It's tough to remember to look when your bal1 goes in the street.

Mark: Yeah, or if somebody's chasing you.

Marta: Or when you're chasing a dog.

C.K.: $\quad$ Yes, it is, but today I'd like you to practice with me and we'11 see how well you can remember.. 


\section{VISUAL}

C.K. takes envelope out of pocket holding it in his hand (safety badge inside).

Almost simultaneously said.

Al1 four are shown, children looking very eager.

C.K. removes three badges from envelope, shows them to children. Close-up of badge, which may be metal or fabric.

Camera pulls back and children are looking at C.K., 1 eyeing the badge eagerly. They can be seen (but not heard) to say "How can I get a badge?" "What do we have to do?"

C.K. is shown pointing to ball, bat, and then waving his arm as if to include all games.

Medium shot of all four characters, and C.K. motions to children to watch him. He steps to curb, glances at parked cars, then steps to edge of cars.

C.K. looks left, right, left in an exaggerated manner. Street is clear of traffic.

\section{NARRATION/DIALOGUE}

C.K.: If you can remember to check both ways before you cross, no matter what's going on, I'11 have a prize for you--a safety badge. You'11 have to earn it, though.
Mark:

Shannon:

Marta:

C.K. :

C.K.:
How do we earn it?

This is the safety badge you can earn if you always remember to check both ways when crossing the street.

\section{(Voiceover)}

I explained that to earn the badge they would have to show me that they could cross streets safely when playing tag, baseball, or anything else.

Then I showed the children how to do that.

First, I checked that the two parked cars were not moving. Then, I stopped at the edge of the parked cars. I looked left, then right, then left again to make sure no cars were in sight. Then, I knew it was safe. 
C.K. walks back onto sidewalk where children are waiting and they appear to talk.

C.K. takes progress chart out of an envelope and enters the three names.

Close-up of progress chart, C.K.'s hand writing names, one in each space on left. Close-up of chart's blank rows, then pan to close-up of end of chart when C.K. says "filled."

Shot of C.K. and Mark, who appears to be asking the question. C.K. shakes head "No," and takes token out of his pocket. Close-up of token in C.K.'s hand.

1 Shot of Mark and C.K. again, with C.K. showing Mark the token and pretending to mark a check on the chart.

C.K. and children appear to be engrossed in deciding on who will be first. Each child is raising his and and one is jumping up and down. C.K. singles out Mark, then puts Marta behind him and Shannon last in line. Mark starts forward, checks parked cars, then looks left and right and steps into street, still looking right. Freeze action with Mark's head still turned to right, with C.K. in view.

Return to normal action. C.K. touches Mark's shoulder and points to curb, motions for him to come back to start again. Mark starts again, checks parked cars, then goes forward and stops at edge of parked cars. He looks left-right-left in an exaggerated manner. No
C. K. : After that, I showed the children how I would keep track of how they were doing. I wrote each of their names on a chart, and told them we would get together to practice for a little while whenever we could. Each time we were done practicing for the day, they would get a check mark next to their names. When the entire row was filled, they would get their safety badges.

When Mark asked if I was going to carry the chart with us all the time, I said "No." It was easier to use the safety token. Whenever they crossed the street correctly, I'd give them a token. At the end of the day's practice, I'd collect all the tokens and mark a check on the chart.

By this time the children were ready to start practicing their street crossing. I asked who wanted to go first. Mark went first and we all watched.

Boys and girls, what did Mark forget to do? (Pause) You're right. He forgot to look left again.

I asked Mark to go back and start again, and this time he looked left, right, then left again. (The left-right-left coincides with Mark's head movements.) 
cars are visible either way. He says, "OK, it's safe." (Unheard) C.K. is seen standing at edge of cars with token ready. As soon as Mark finishes, C.K. puts token in his hand, smiles, and says "Right." Shot of Mark receiving token from Captain Kangaroo.

Mark walks back to stand behind Marta.

Bunny Rabbit (B.R.) appears at edge of a parked car. C.K. looks at B.R. B.R. motions toward the street, moves his head slowly from left to right. All three children look delighted; Marta giggles behind her hand. Camera picks up B.R. from rear, sees his head move slowly left-right-left, follows him part way across the street, then shows him on the other side of the street, waving and peeking from behind another car. C.K. claps his hands a little, waves goodbye to him, and prods the children to wave goodbye, too.

Marta begins to walk toward the edge of the parked cars, glancing at cars she passes between, halting at edge of car on her right. Looks left, then right, then left again. Car is seen some distance way, approaching from right. C.K. puts token in her hand immediately after she finishes sequence and mouths, "OK, I could cross."
C.K.: $\quad$ Then it was Marta's turn. But wait a minute.

What are you doing here, Bunny Rabbit?

Oh, I see. You want to try crossing the street, too. We11, can you show the children how to do it safely, as I have?

Al1 right, we'11 let you show them, then you can go back to the Treasure House.

Good for you, Bun. Thanks for showing the boys and girls. You can go back now. Tell Mr. Green Jeans I'Il be there later.

(To audience) Now that Bunny Rabbit is finished we can get back to learning how people cross streets safely, not rabbits. It's your turn now, Marta.

Marta did very well, and got her first safety token. 


\section{VISUAL}

Shannon is shown asking C.K. questions, pointing in one direction and then the other. C.K. smiles, puts up one finger, steps to curb, checks without stopping, steps to edge of cars, looks left-right-left. A car approaches from the left on the second left look, so C.K. tracks it past, then reinitiates left-right-left sequence, as he says in voiceover.

Shannon watches closely, then smiles and nods assent when C.K. returns to curb. He then glances at both parked cars, steps off curb, walks to edge of parked cars, and looks left-right-left slowly. No cars are in view. C.K. has followed him and presses token into tr his hand, smiling. Close shot of token in Shannon's 占 hand, then of Shannon smiling up at C.K.

All four are seen discussing where to go next. Dissolve to new scene where cars are parked only on opposite side of street.

Taking turns, each child steps to edge of curb, looks left, right, left, and receives token. C.K. smiles at each. On last turn (Marta's), a car approaches from left. Marta tracks it past, then mistakenly looks only to the right and begins to step off curb.

Freeze action with Marta's head to right (on word "Whoops").

\section{NARRATION/DIALOGUE}

C.K.: When it was Shannon's turn, he asked what he should do if a car came one way while he was looking another.

I showed Shannon what to do if a car comes while he is looking left, right, and left, I watched the car until it passed, and then started over looking left, right, and left again.

When Shannon took his turn, there were no cars coming so he just looked left, right; left and got his token.

Then, we all decided that tomorrow we would practice on a different kind of street, one where cars were parked only on one side. (Pause) And, there all three children earned another safety token. This time, since there were no parked cars, Shannon, Mark, and Marta had to stop at the curb and look left-right-left.

On Marta's turn, a car came from her left. Let's watch what she does. Whoops! Children, what has Marta forgotten? (Pause) That's right. She forgot to start all over again after the car had passed.

I told them to step off the curb only after they finished looking for cars. If a car was coming, they should start looking all over again after it passed. 
C.K. calls Marta back and explains to her that she must begin again with left-right-left after tracking a passing car. Marta nods and smiles, then approaches curb, looks left, right and tracks a car approaching from right. When the car has passed, she again looks left-right-left, and C.K. gives her a token.

Children are shown giving tokens to C.K., and we see close shot of his hand placing checks beside their names, only three checks for each.

No cars are parked on street. Marta is shown on sidewalk, running toward camera with Shannon chasing tor. She slows down, looks into the street where a $\stackrel{f}{t}$ car approaches from her left. After it passes, she looks at Shannon who is gaining on her, looks leftright-left, then runs across the street because no cars are in view. C.K. meets her on other side, and gives her a safety token.

Close-up of C.K.'s hand holding progress chart and putting checkmarks in blocks beside each child's name (shown to be just three checks from being full).

When C.K.'s voiceover reaches "left-right-left," picture shows close-up of Shannon looking left-rightleft. Bunny Rabbit appears once behind a telephone pole, holding his token and waving wildly, but C.K. points off-camera and Bunny Rabbit disappears.
C.K.: $\quad$ Marta tried again, and this time she watched car go by, then looked, left, right, left, and so earned her safety token.

At the end of our practice time, the children gave me their tokens and we marked their checks on the chart.

For the next week or so we practiced often. Sometimes we crossed streets during our games, and we were always careful and watched for cars. We all agreed that we would stop chasing while we were crossing the street. We enjoyed playing the games while we practiced safe street crossings. Each time they looked left, right, and left (coincides with Marta's head movements) they got a safety token.

We practiced on all sorts of streets. We crossed big streets, sma11 streets, straight ones, and crooked ones, streets with cars parked alongside, and with. no cars parked. And, no matter which streets we crossed, we always crossed safely by looking left, right, and then left again (coincides with Shannon's head movement).

Bunny Rabbit came out to join us again, but we told him he'd just have to go back to the Treasure House because we had some serious practicing to do. 
Shows Marta, then Mark, crossing as volceover describes. When reach left-right-left, shows Mark looking left-right-left, then C.K.'s giving him the token. Then shows all four watching C.K. placing checks beside their names. (Chart is now half-fu11.)

(Dissolve)

New scene of C.K. at same spot on original street, with progress charts in hand. Three kids are walking toward him, smiling. They stop near him. Close-up of filled chart, then of safety badge.

C.K. turns toward children, puts charts in his pocket, and holds out safety badge to Mark with left hand while shaking his right.

C.K. turns to Shannon. Mark steps to C.K.'s left to allow Shannon to come forward. C.K. shakes hands with Shannon as he presents award.
C.K.: When we crossed streets where cars were parked, we always stopped at the edge of the parked cars. Where no cars were parked, we stopped at the curb. But, we always looked left, right, and then left (coincides with Mark's head movements). And, each time the children crossed the street correctly they got a safety token. And, each time we were done practicing they got another check on the progress chart, so the progress chart filled up quick1y,

And that's how I taught the children to cross the street safely. And today I'm here to award safety badges to all three of my students. I'm proud of them. Their charts are totally filled. That means that they've earned the right to wear the Captain Kangaroo safety badge.

Mark, congratulations on earning your safety award. This badge shows everyone that you know how to look left-right-left to cross streets safely. (Shakes his hand.)

Mark: Thanks, Captain. It was fun to learn this way.

C.K.: Congratulations to you, too, Shannon. Here's your safety award. I'm glad to know that you've learned how to play safely near the street.

Shannon: Thank you Captain. That's a neat badge. 
Marta comes forward to receive award and handshake from C.K. Other two children stand with awards in hand 3-4 feet away.

Bunny Rabbit sppears from behind telephone pole, holding tokens, and patting his chest as if to say "Me, too."

Close-up of Bunny Rabbit who nods "yes" vigorously, and wave a handful of tokens.

C.K. takes carrots out of his pocket and hands them to Bunny Rabbit, who holds them tightly, then disappears $\stackrel{1}{1}$ behind pole.

$\omega$ Close-up of C.K., holding badge. Points to camera when he says "You can earn one."

Camera pulls back to show all four characters at curb, waving goodbye.

Children wave goodbye to C.K., then run toward original spot. Mark produces a ball from his pocket, and throws it against wall. Marta and Shannon are standing in original positions. Repeat original scene, but instead of running in front of oncoming car, Shannon is shown to stop, wait for car to pass, look left-right-left, and then proceed into street to get ball. B.R. appears behind parked car, waving goodbye, wearing safety badge. He clutches carrots, looks left-right-left, and nods "yes."
C.K.: And you, too, Marta. You earned your safety award. Congratulations (shakes hands).

Now, since that the last of our awards I want to. - •

Marta: Captain, wait. There's someone else who needs to get something from you.

C.K.: What do you mean, Marta? (He spies Bunny Rabbit.) Oh, I see. Well, Bun, have you practiced your safe street crossing?

C.K.: I can only think of one reward for you, Bunny Rabbit. It's one I'm sure you'll like. Carrots!

C.K.: $\quad$ Remember boys and girls, this safety badge can only be worn by children who've learned to cross streets safely. You can earn one, too. Your teacher will show you how, and we're all glad to know that you'11 soon be learning how to be safe when you're playing outside.

Goodbye now, and play safe. 


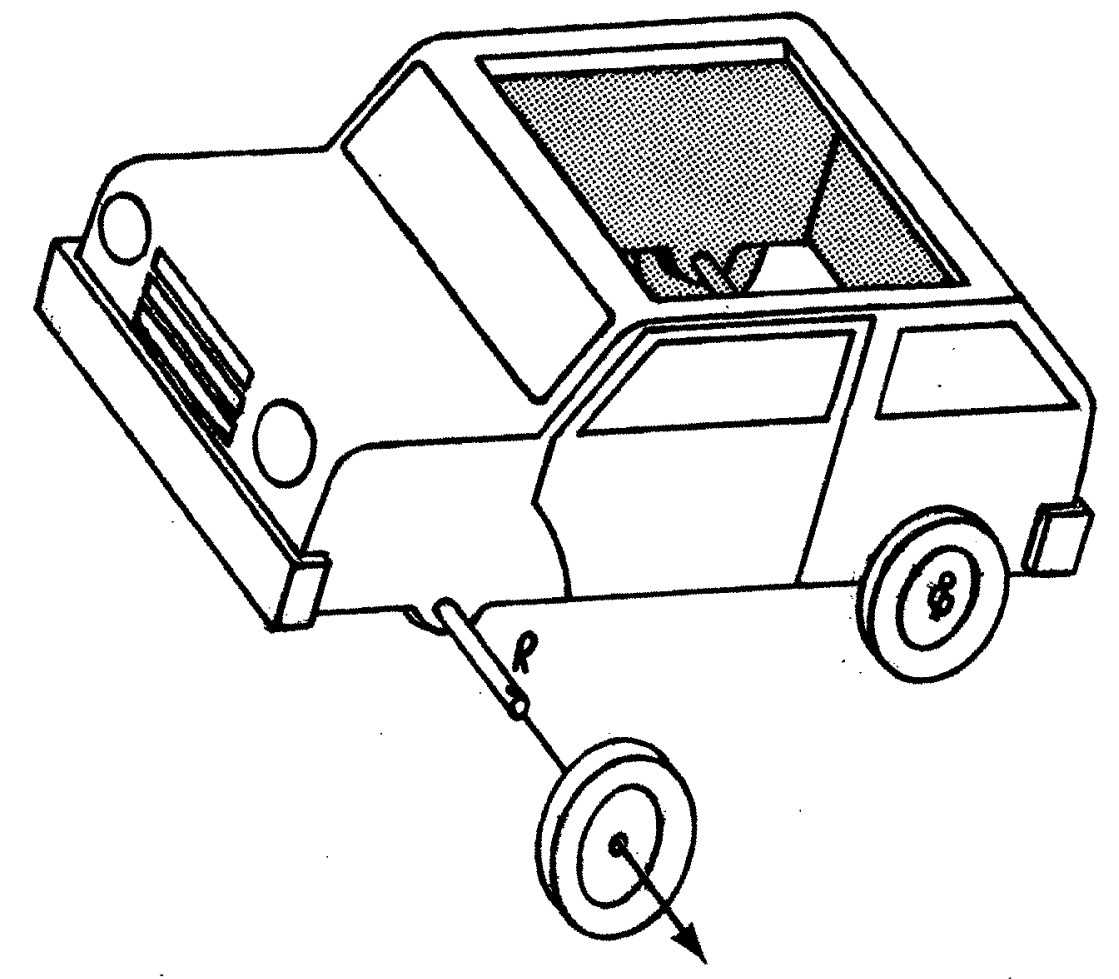

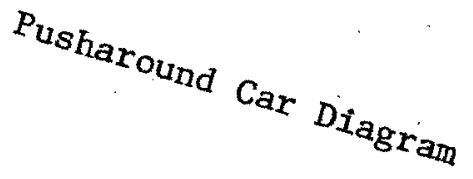




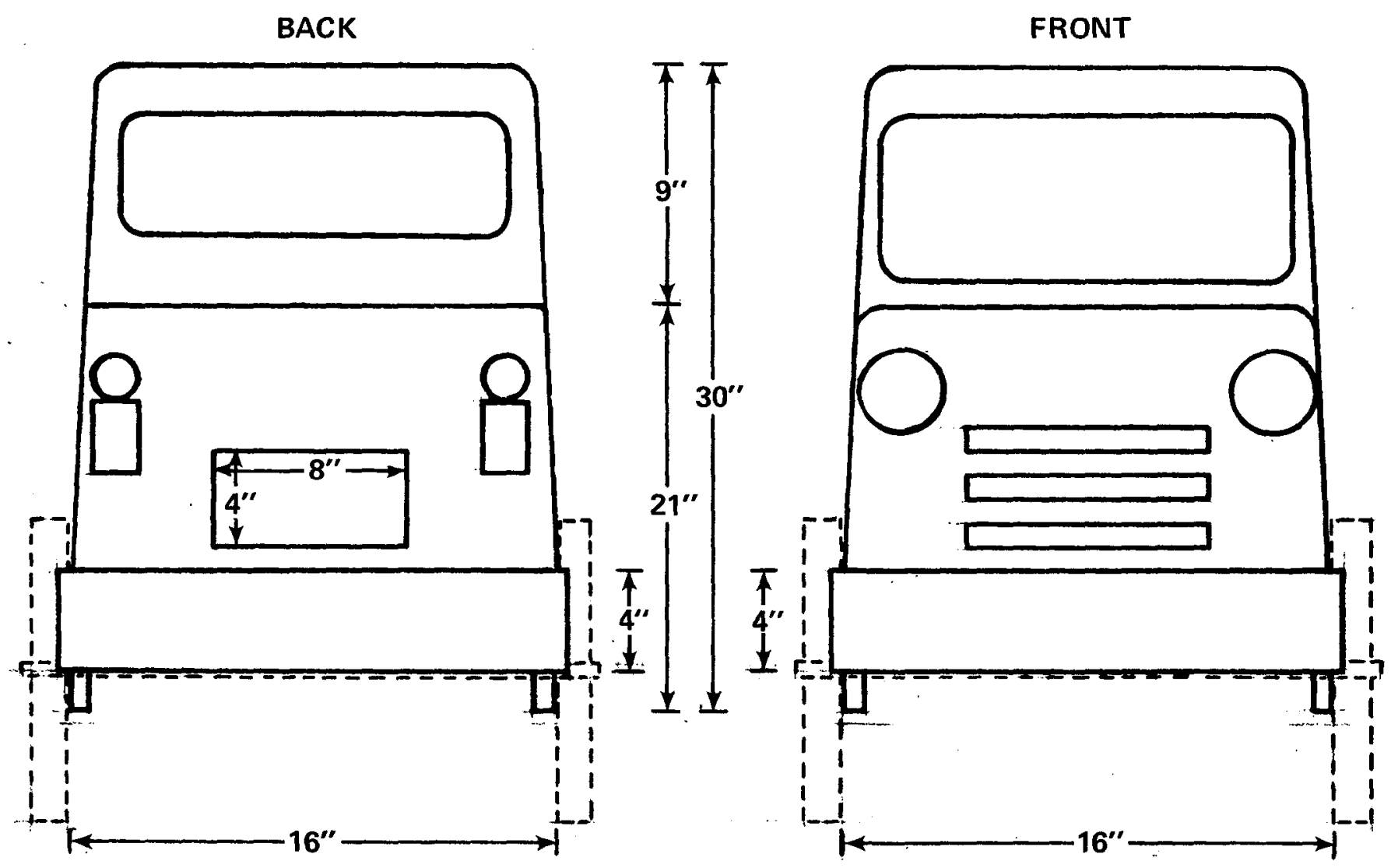


SIDE

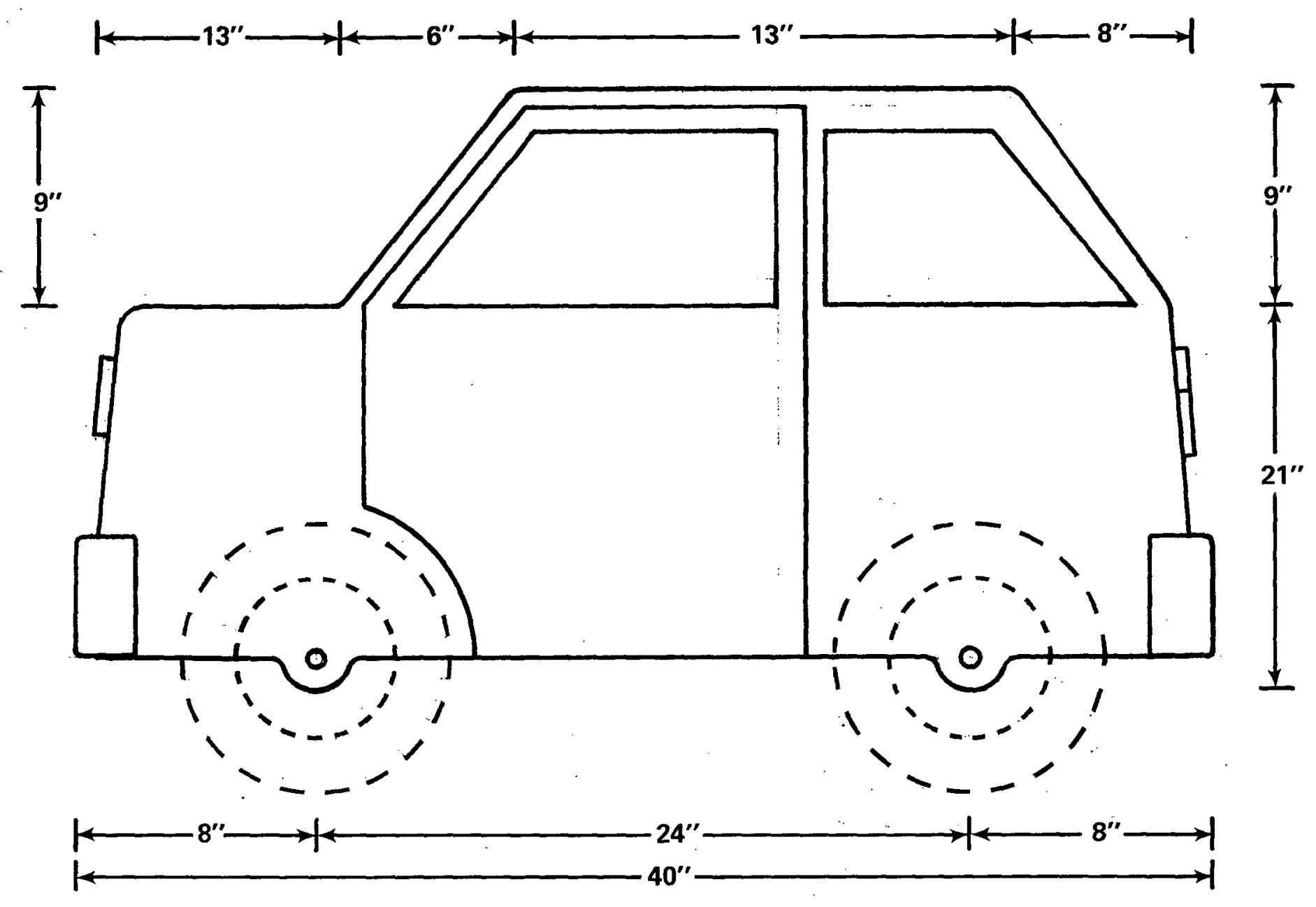

Pusharound Car Diagram 


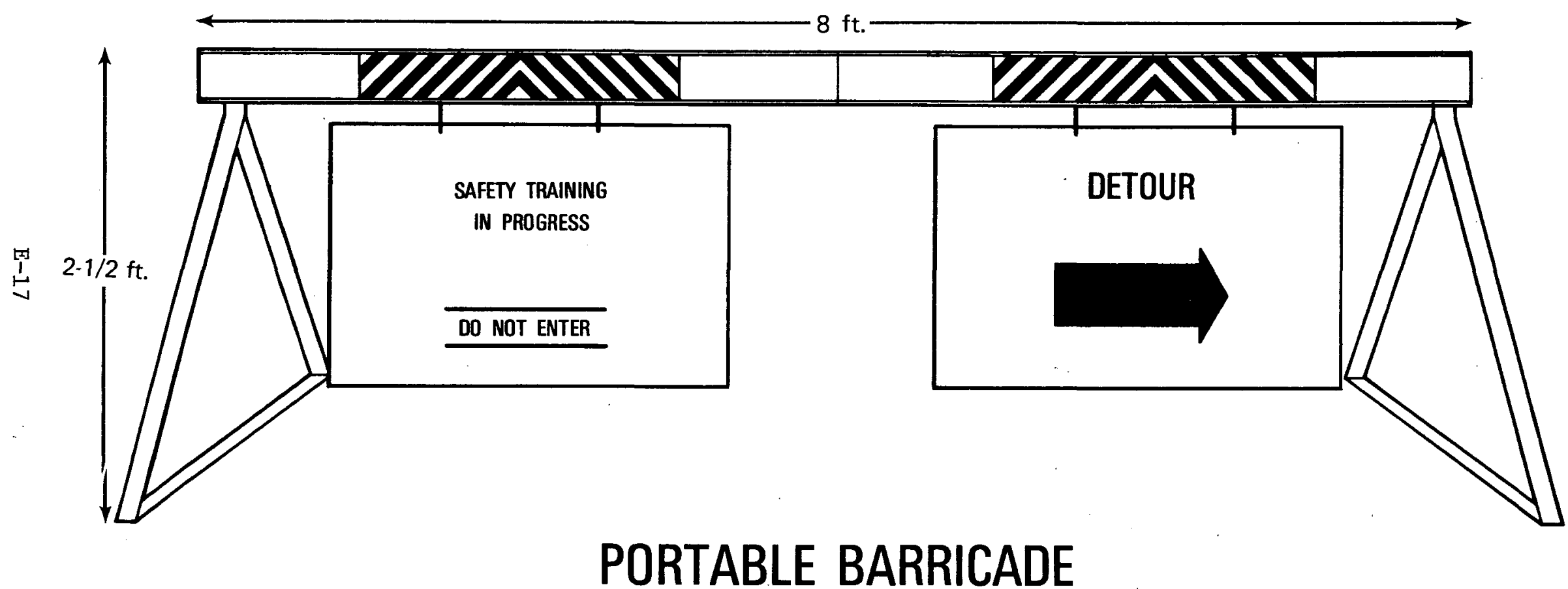




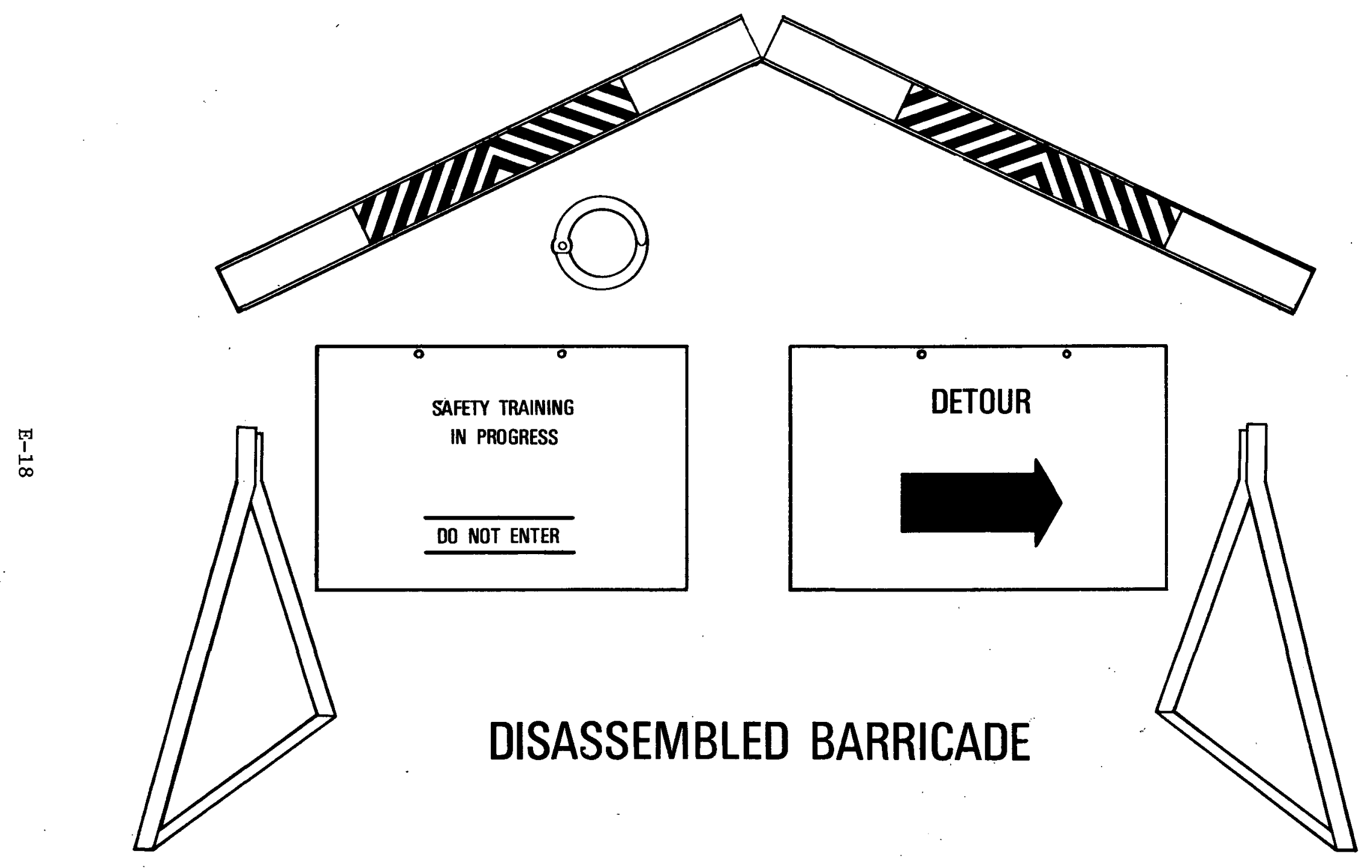




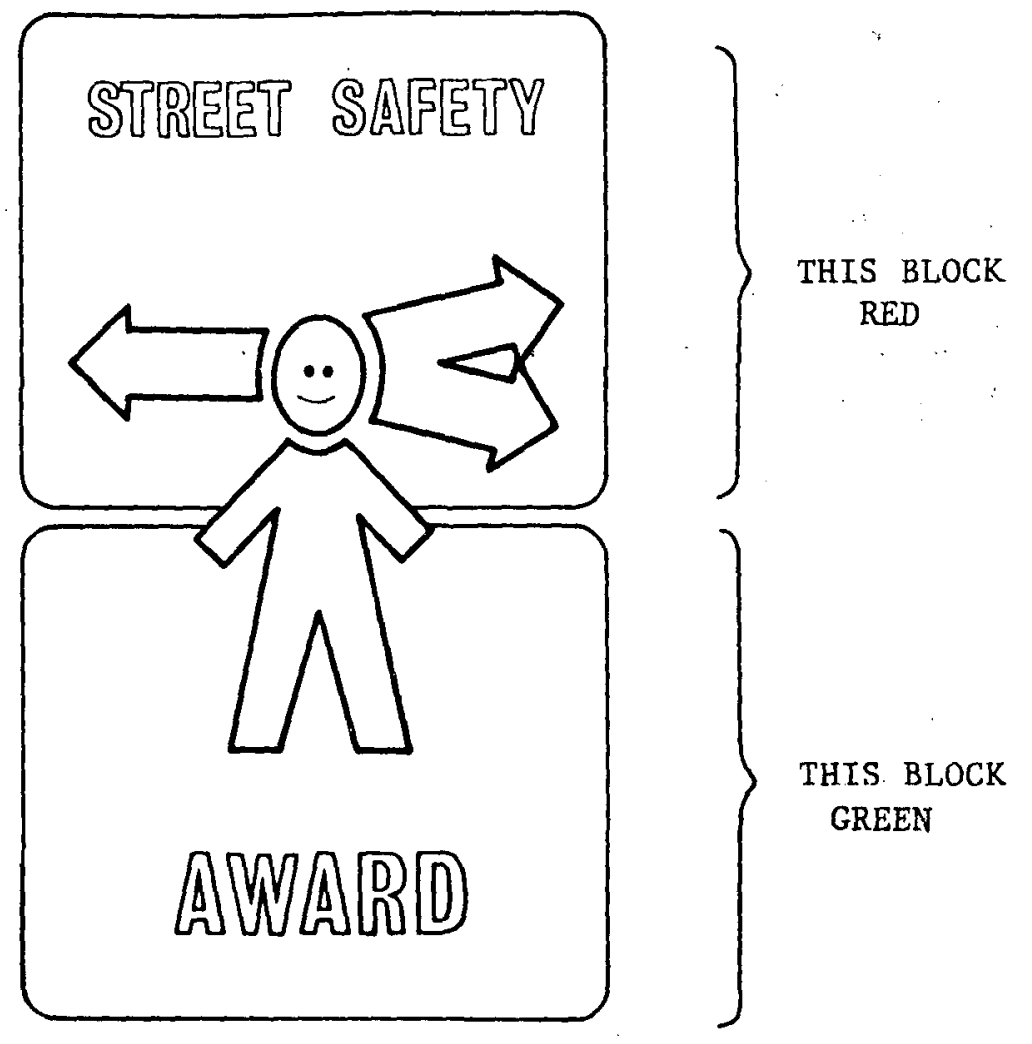

"Street Safety Award" Patch 
APPENDIX F

GAME MATERIALS

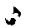

$$
\text { F-1 }
$$


GAME MATERIALS

The game materials are simple items that should be locally available to any school syystem. They are generally found in discount stores. These items include:
1. Masking tape.
2. Game baskets.
3. Ba11s.
4. Game tokens.
5. Game rope.

The masking tape should be sturdy, brightly colored, and at least two inches wide. Game baskets are any type of plastic wastebaskets, approximately 11 inches in diameter and 12-15 inches high. One blue, one pink, and one white wastebasket make up each game set.

The balls can be made of rubber, foam, or plastic. Foam or plastic balls may be better than rubber balls because they bounce less and are more easily recovered during game playing. The balls should be of a convenient size to toss into the baskets (about three inches in diameter). One blue and one red ball make up each game set.

Game tokens are round plastic chips approximately one inch in diameter. Poker chips are appropriate for this purpose. One set (approximately 75 chips) of blue and one set of red chips should be included in each game set.

The game rope is a 80 -foot rope, dyed different colors at 10 -foot intervals with a 10-foot uncolored portion (to extend across the simulated street) beginning 20 feet in from each end.

The method for determining the amounts of these materials required for each school system is detailed in the Coordinator's Guide (Appendix A). 